Rui Lopes Gonçalves

\title{
Aspectos cinéticos da determinação do equilíbrio sólido-líquido por meio de calorimetria exploratória diferencial
}

São Paulo

2021 

Rui Lopes Gonçalves

\title{
Aspectos cinéticos da determinação do equilíbrio sólido-líquido por meio de calorimetria exploratória diferencial
}

\author{
Dissertação apresentada à Escola Politéc- \\ nica da Universidade de São Paulo para \\ obtenção do título de Mestre em Ciências \\ Versão Corrigida \\ Área de Concentração: Engenharia \\ Química \\ Universidade de São Paulo - USP \\ Escola Politécnica \\ Pós-graduação em Engenharia Química \\ Orientador: Pedro de Alcântara Pessôa Filho
}

São Paulo

2021 
Autorizo a reprodução e divulgação total ou parcial deste trabalho, por qualquer meio convencional ou eletrônico, para fins de estudo e pesquisa, desde que citada a fonte.

Este exemplar foi revisado e corrigido em relação à versão original, sob responsabilidade única do autor e com a anuência de seu orientador.

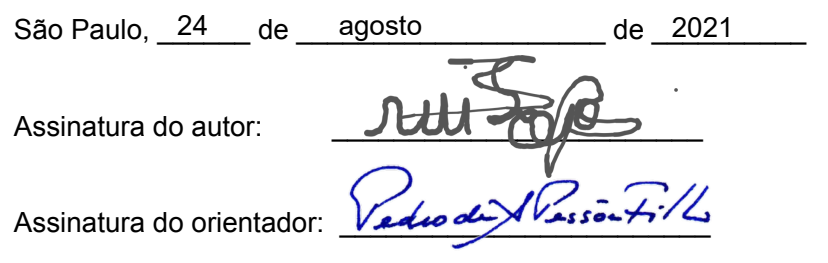

\section{Catalogação-na-publicação}

Gonçalves, Rui

Aspectos cinéticos da determinação do equilíbrio sólido-líquido por meio de calorimetria exploratória diferencial / R. Gonçalves -- versão corr. -- São Paulo, 2021.

$155 \mathrm{p}$.

Dissertação (Mestrado) - Escola Politécnica da Universidade de São Paulo. Departamento de Engenharia Química.

1.Equilibrio Sólido-Líquido 2.Termodinâmica 3.Modelagem 4.Cinética I.Universidade de São Paulo. Escola Politécnica. Departamento de Engenharia Química II.t. 
Este trabalho é dedicado àqueles que nos deixaram devido à pandemia do COVID-19,

que não sejam esquecidos e somente números.

Que a ciência traga a luz para nos guiar através de um período tão escuro. 



\section{Agradecimentos}

Os agradecimentos principais são direcionados a Larissa Castello Branco Almeida Bessa, por fornecer dados experimentais cruciais ao desenvolvimento do projeto e por lhe dar um tema e direção. À Coordenação de Aperfeiçoamento de Pessoal de Nível Superior (CAPES) pela bolsa de amparo à pesquisa destinada ao projeto. O conhecimento científico desenvolvido é de valor incalculável.

Agradecimentos pessoais são direcionados à minha família por todo o apoio e suporte, sem os quais seria impossível a conclusão deste trabalho. À minha mãe Rosa por sempre acreditar em mim. Ao meu pai Ricardo por sempre ser uma inspiração, ao meu irmão Rafael por ser um ponto de referência. Ao meu sobrinho Raul, que trouxe novo ânimo.

À minha namorada Lilian por estar sempre ao meu lado, nos momentos mais difíceis, nas distâncias mais longas, nos momentos mais doces. Sem sua parceria este trabalho não seria possível.

Ao meu orientador Prof. Dr. Pedro de Alcântara Pessôa Filho, por acreditar em mim mais até do que eu mesmo. Por nunca desistir e me apoiar mesmo nos momentos mais complicados.

Aos meus amigos, em especial Henrique, Natan, Ivan, Felipe e Erick, por providenciar o alívio necessário para carregar o fardo de um projeto de mestrado.

À minha amiga Flávia, que já há muito tempo corrige meu português sofrível e que continua do meu lado apesar de todas nossas inúmeras desavenças e desencontros.

Aos meus companheiros de corrida do Fundusp. Grupo que nasceu durante esse mestrado e que espero que continue fazendo história. Corremos juntos, damos voltas e voltas, começando e terminando no mesmo lugar, mas a jornada nos transforma. 

"It is the struggle itself that is most important.

We must strive to be more than we are.

It does not matter that we will never reach our ultimate goal.

The effort yields its own rewards."

Lt. Commander Data 



\section{Resumo}

GONÇALVES, Rui Lopes. Aspectos cinéticos da determinação do equilíbrio sólido-líquido por meio de calorimetria exploratória diferencial. 2021. XX

f. Dissertação (Mestrado em Engenharia Química) - Departamento de Engenharia Química da Escola Politécnica, Universidade de São Paulo, São Paulo, 2021.

O equilíbrio sólido-líquido é uma das áreas mais estudadas pela termodinâmica, possuindo características complexas que o diferenciam de outros tipos de equilíbrio de fases. Para a análise das transições de fases pertinentes, existem diversas abordagens disponíveis. Uma das técnicas mais correntes na atualidade, para a determinação de dados de equilíbrio, é a utilização da calorimetria exploratória diferencial. Entretanto, aspectos cinéticos são inerentes ao uso dessa técnica. Desse modo, a modelagem das limitações cinéticas em equipamentos de calorimetria exploratória diferencial pode ser útil para a correta interpretação dos resultados experimentais, permitindo uma avaliação mais adequada da influência da cinética de transferência de calor na análise dos fenômenos observados. Esse trabalho visa a desenvolver modelos para o funcionamento de equipamento de calorimetria exploratória diferencial que incorporem as relações cinéticas de transferência de calor no equacionamento fenomenológico. Um dos modelos desenvolvidos assume a existência de um gradiente de temperatura na fase líquida. A descrição deste gradiente depende de uma dimensão espacial, assim, é preciso uma modelagem do aspecto geométrico da amostra. O trabalho propõe duas geométricas distintas para amostra, cilíndrica e esférica. O trabalho apresenta o desenvolvimento matemático das relações pertinentes, a programação das equações, e uma análise do comportamento dos modelos aplicados à fusão de ésteres etílicos (laurato, miristato, oleato e palmitato de etila), estudados em diferentes velocidades de aquecimento. Embora a concordância entre os resultados do modelo e dados experimentais seja principalmente qualitativa, observa-se que a consideração de uma geometria esférica para a amostra fornece resultados mais semelhantes ao comportamento experimentalmente observado.

Palavras-chave: equilíbrio sólido-líquido, modelagem, cinética, termodinâmica. 



\section{Abstract}

GONÇALVES, Rui Lopes. Kinetic aspects of solid-liquid equilibrium determination through differential scanning calorimetry 2021. XX f. Dissertação (Mestrado em Engenharia Química) - Departamento de Engenharia Química da Escola Politécnica, Universidade de São Paulo, São Paulo, 2021.

Solid-liquid equilibrium is one of most studied areas in Thermodynamics. It presents complex features that set it apart from other types of phase equilibrium. To study all pertinent phase transitions, different techniques are available. One of the most currently used is the differential scanning calorimetry. However, kinetic aspects are intrinsic to the use of this technique. The modeling of the kinetic hindrances inherent to a differential scanning calorimeter can thus be useful to the correct interpretation of experimental results, allowing a more adequate assessment of the influence of heat transfer kinetics in the analysis of the observed phenomena. This work aims to develop models for differential exploratory calorimeters that incorporate heat transfer kinetic relations. One developed model assumes the existence of a temperature gradient on the liquid phase during fusion. To properly describe this gradient one spatial dimension is required, therefore modelling the geometry of the sample is required. The present work presents two possible geometries, a cylindrical one and a spherical one. This work presents the mathematical development of the pertinent relationships, the programming of the resulting equations, and an analysis of the results applied to the melting of ethyl esters (ethyl laurate, myristate, oleate and palmitate) studied at different heating rates. The agreement between simulated and experimental results is mostly qualitative. However, considering a spherical geometry for the sample generates results more consistent with the experimentally observed behavior.

Keywords: solid-liquid equilibrium, modelling, kinetics, thermodynamics. 



\section{Lista de ilustrações}

Figura 1 - Microscopia de uma amostra de ferro carbono. Áreas escuras se encontram na forma cementita, enquanto as áreas claras na forma ferrita. Imagem retirada de $[26]$. . . . . . . . . . . . 31

Figura 2 - Exemplo de diagrama de fases de um SLE simples. imagem de [27] 32

Figura 3 - Esquema de um aparelho de análise térmica diferencial. Imagem adaptada de $[28] \ldots \ldots \ldots$. . . . . . . . . . . . . . . . . . 34

Figura 4 - Termograma genérico fornecido por um aparelho de análise térmica diferencial. Imagem adaptada de $[28]$. . . . . . . . . 35

Figura 5 - Termograma para mistura oleato de etila - laurato de etila em diferentes composições. Imagem de $[13]$. . . . . . . . . . . . . 36

Figura 6 - Esquema do funcionamento de um aparelho DTA . . . . . . . . 44

Figura 7 - Perfil de temperatura desenvolvido durante a fusão. Imagem de $[24] \ldots \ldots \ldots \ldots \ldots \ldots \ldots$

Figura 8 - Geometria cilíndrica proposta . . . . . . . . . . . 55

Figura 9 - Geometria esférica proposta . . . . . . . . . . . . 55

Figura 10 - Termograma simulado para o modelo de A.P. Gray segundo os dados apresentados nas Tabeleas de 1 a $4 \ldots 7 . \ldots 7$

Figura 11 - Perfil de temperatura da amostra e referencia ao longo do tempo para o modelo de Gray. em azul $T_{s}$, em laranja $T_{r} \ldots$. . . . . 72

Figura 12 - Termograma simulado para o modelo de A.P. Gray, com Abscissa representando o tempo. . . . . . . . . . . . . . . 73

Figura 13 - Termograma simulado para o modelo HTD com geometria cilíndrica aproximada. . . . . . . . . . . . . . . . . . . 74

Figura 14 - Perfil de temperatura ao longo do tempo para amostra e refrencia para o modelo HTD-Cilindro.Em azul $T_{s}$. Em laranja $T_{r} \ldots$. . 75

Figura 15 - Termograma simulado para o modelo HTD com geometria esférica 75

Figura 16 - Perfi do raio de sólido ao longo do tempo simulado com o modelo HTD esférico . . . . . . . . . . . . . . . 76 
Figura 17 - Perfi do volume de sólido ao longo do tempo simulado com o modelo HTD esférico . . . . . . . . . . . . . . . . . 77

Figura 18 - Perfil alocação de calor gasto ao longo do tempo, para amostra simulada com o modelo HTD esférico. Em azul: calor de aquecimento da fase sólida. Em laranja: calor gasto no processo de fusão. Em amarelo: calor gasto no aquecimento da fase líquida. Em roxo: calor gasto com aquecimento do cadinho de referência

Figura 19 - Perfil percentual da alocação de calor gasto ao longo do tempo, para amostra simulada com o modelo HTD esférico.Em azul: calor de aquecimento da fase sólida. Em laranja: calor gasto no processo de fusão. Em amarelo: calor gasto no aquecimento da fase líquida. Em roxo: calor gasto com aquecimento do cadinho de referência . . . . . . . . . . . . . . . 79

Figura 20 - Comparativo direto dos tres modelos para mesmo dados de entrada. Em azul: modelo de Gray. Em laranja: modelo HTD cilíndrico. Em amarelo modelo HTD esférico.

Figura 21 - Análise de sensibilidade da taxa de varredura. Em azul Sr0. Em laranja $S_{r}=1 \frac{K}{\min }$. Em amarelo $S_{r}=10 \frac{K}{\min } \ldots \ldots . . . \quad 81$

Figura 22 - Análise de sensibilidade da taxa de varredura, Abscissa no tempo.Em azul Sr0. Em laranja $S_{r}=1 \frac{K}{\mathrm{~min}}$. Em amarelo $S_{r}=$ $10 \frac{K}{\min } \ldots \ldots \ldots \ldots \ldots \ldots$

Figura 23 - Análise de sensibilidade da resistência a troca térmica da célula de referência.Em azul $R_{0}$. Em laranja $R=20 \frac{K}{W}$ em amarelo $R=150 \frac{K}{W} \ldots \ldots \ldots \ldots \ldots \ldots$. . . . . . . . 83

Figura 24 - Análise de sensibilidade da capacidade térmica da célula de referência.Em azul $C_{r, 0}$. Em laranja $C_{r}=5 E-2 \frac{J}{K}$. Em amarelo $C_{r}=5 E-4 \frac{J}{K} \ldots \ldots \ldots \ldots \ldots \ldots \ldots$

Figura 25 - Análise de sensibilidade do passo do método numérico.Em azul $h_{0}$. Em laranja $h=0,1 s$. Em amarelo $h=0,001 s \ldots$.

Figura 26 - Análise de sensibilidade da porcentagem de faísca. Em azul $f_{0}$. Em laranja $f=0,99$. Em amarelo $f=0,9999 \ldots \ldots$. . . . 86 
Figura 27 - Termograma simulado para o ajuste de dados para laurato de etila.Modelo de Gray Abscissa em $t$. Valores de $\mathrm{R}$ variando entre $60 \frac{K}{W}$ e $220 \frac{K}{W}$ segundo legenda. Em azul claro e linha continua a curva experimental . . . . . . . . . . . . . . . . . 9 91

Figura 28 - Termograma simulado para o ajuste de dados para laurato de etila. Modelo HTD com geometria cilíndrica. Abscissa em $t$. Valores de R variando entre $60 \frac{K}{W}$ e $220 \frac{K}{W}$ segundo legenda. Em azul claro e linha continua a curva experimental . . . . . . . . 91

Figura 29 - Termograma simulado para o ajuste de dados para laurato de etila. Modelo HTD com geometria esférica. Abscissa em $t$. Valores de $\mathrm{R}$ variando entre $60 \frac{K}{W}$ e $220 \frac{K}{W}$ segundo legenda. Em azul claro e linha continua a curva experimental . . . . . . . . . . 92

Figura 30 - Termograma simulado para os 3 modelos com o valor de $R=$ $100 \frac{K}{W}$ para a substancia laurato de etila . . . . . . . . . 94

Figura 31 - Termograma simulado para o ajuste de dados para miristato de etila. Modelo de Gray. Abscissa em $t$. Valores de $\mathrm{R}$ variando entre $140 \frac{K}{W}$ e $300 \frac{K}{W}$ segundo legenda. Em azul claro e linha continua a curva experimental . . . . . . . . . . 96

Figura 32 - Termograma simulado para o ajuste de dados para miristato de etila. Modelo HTD - Cilindro. Abscissa em $t$. Valores de R variando entre $140 \frac{K}{W}$ e $300 \frac{K}{W}$ segundo legenda. Em azul claro e linha continua a curva experimental . . . . . . . . . . . . 96

Figura 33 - Termograma simulado para o ajuste de dados para miristato de etila. Modelo HTD - Esfera Abscissa em $t$. Valores de R variando entre $140 \frac{K}{W}$ e $300 \frac{K}{W}$ segundo legenda. Em azul claro e linha continua a curva experimental . . . . . . . . . . . . 97

Figura 34 - Termograma simulado para os 3 modelos com o valor de $R=$ $140 \frac{K}{W}$ para a substancia miristato de etila . . . . . . . . . 99

Figura 35 - Termograma simulado para o ajuste de dados para oleato de etila. Modelo de Gray. Abscissa em t. Valores de $\mathrm{R}$ variando entre $60 \frac{K}{W}$ e $220 \frac{K}{W}$ segundo legenda. Em azul claro e linha continua a curva experimental . . . . . . . . . . . . . . 101 
Figura 36 - Termograma simulado para o ajuste de dados para oleato de etila. Modelo de HTD - Cilindro. Abscissa em $t$. Valores de R variando entre $60 \frac{K}{W}$ e $220 \frac{K}{W}$ segundo legenda. Em azul claro e linha continua a curva experimental . . . . . . . . . . . . 101

Figura 37 - Termograma simulado para o ajuste de dados para oleato de etila. Modelo de HTD - Esfera. Abscissa em t. Valores de R variando entre $60 \frac{K}{W}$ e $220 \frac{K}{W}$ segundo legenda. Em azul claro e linha continua a curva experimental . . . . . . . . . . . . . 102

Figura 38 - Termograma simulado para os 3 modelos com o valor de $R=$ $140 \frac{K}{W}$ para a substancia oleato de etila . . . . . . . . . . 104

Figura 39 - Termograma simulado para o ajuste de dados para palmitato de etila. Modelo de Gray. Abscissa em $t$. Valores de $\mathrm{R}$ variando entre $60 \frac{K}{W}$ e $220 \frac{K}{W}$ segundo legenda. Em azul claro e linha continua a curva experimental . . . . . . . . . . 106

Figura 40 - Termograma simulado para o ajuste de dados para palmitato de etila. Modelo HTD - Cilindro. Abscissa em $t$. Valores de R variando entre $60 \frac{K}{W}$ e $220 \frac{K}{W}$ segundo legenda. Em azul claro e linha continua a curva experimental . . . . . . . . . . . 106

Figura 41 - Termograma simulado para o ajuste de dados para palmitato de etila. Modelo HTD - Esfera. Abscissa em $t$. Valores de R variando entre $60 \frac{K}{W}$ e $220 \frac{K}{W}$ segundo legenda. Em azul claro e linha continua a curva experimental . . . . . . . . . . . . 107

Figura 42 - Termograma simulado para os 3 modelos com o valor de $R=$ $140 \frac{K}{W}$ para a substancia palmitato de etila . . . . . . . . . 109

Figura 43 - Gráfico gerado como saída do programa de simulação do modelo HTD esférico. Eixos sem legenda, pois este é o resultado gerado. A Abscissa esta em $T_{s}[K]$ e a ordenada em $q[W] \ldots . . .139$

Figura 44 - Tabelas de ajuste de dados para o composto laurato de etila. Modelo de Gray . . . . . . . . . . . . . . . . . . . . . . . . . 142

Figura 45 - Tabelas de ajuste de dados para o composto laurato de etila. Modelo HTD cilindro . . . . . . . . . . . . . . . . . . . . 143

Figura 46 - Tabelas de ajuste de dados para o composto laurato de etila. Modelo HTD esfera . . . . . . . . . . . . . . . . . . 144 
Figura 47 - Tabelas de ajuste de dados para o composto miristato de etila.

Modelo de Gray . . . . . . . . . . . . . . . . . 145

Figura 48 - Tabelas de ajuste de dados para o composto miristato de etila.

Modelo HTD cilindro . . . . . . . . . . . . . . . 146

Figura 49 - Tabelas de ajuste de dados para o composto miristato de etila.

Modelo HTD esfera . . . . . . . . . . . . . . . . . . . 147

Figura 50 - Tabelas de ajuste de dados para o composto oleato de etila.

Modelo de Gray . . . . . . . . . . . . . . . . . . . . . . . . . 148

Figura 51 - Tabelas de ajuste de dados para o composto oleato de etila. Modelo HTD cilindro . . . . . . . . . . . . . . . . . . . . . . . 149

Figura 52 - Tabelas de ajuste de dados para o composto oleato de etila.

Modelo HTD esfera . . . . . . . . . . . . . . . 150

Figura 53 - Tabelas de ajuste de dados para o composto palmitato de etila.

Modelo de Gray . . . . . . . . . . . . . . . . . . . . . . 151

Figura 54 - Tabelas de ajuste de dados para o composto palmitato de etila. Modelo HTD cilindro . . . . . . . . . . . . . . . . . . . . 152

Figura 55 - Tabelas de ajuste de dados para o composto palmitato de etila. Modelo HTD esfera . . . . . . . . . . . . . . . . . . . 153 



\section{Lista de tabelas}

Tabela 1 - Propriedades termodinâmicas da água . . . . . . . . . . . . 70

Tabela 2 - Propriedades da varredura . . . . . . . . . . . . . 70

Tabela 3 - Propriedades da célula de referência . . . . . . . . . . . . . . . 71

Tabela 4 - Propriedades do método numérico . . . . . . . . . . . . . . . 71

Tabela 5 - Area soba curva para cada um dos modelos simulados, e resultado subtraido da area da linha de base . . . . . . . . . . . 80

Tabela 6 - Área sob a curva, em $[\mathrm{J}]$, para análise de sensibilidade da taxa de varredura . . . . . . . . . . . . . . . . 83

Tabela 7 - Área sob a curva, em [J], para análise de sensibilidade da resistência a troca térmica da célula de referência . . . . . . . . . 83

Tabela 8 - Área sob a curva, em [J], para análise de sensibilidade da capacidade térmica da célula de referência. . . . . . . . . . . . . . . 84

Tabela 9 - Área sob a curva,em [J] para análise de sensibilidade do passo do método numérico. . . . . . . . . . . . . . . . . . 85

Tabela 10 - Área sob a curva, em [J], para análise de sensibilidade da porcentagem de faísca. . . . . . . . . . . . . . . 86

Tabela 11 - Fórmula e massa molar dos compostos estudados . . . . . . . . 87

Tabela 12 - Propriedades termodinâmicas do laurato de etila. Dados da literatura . . . . . . . . . . . . . . . . . 89

Tabela 13 - Dados gerais de entrada do programa de simulação para o laurato de etila . . . . . . . . . . . . . . . . . . 990

Tabela 14 - Dados comparativos para o ajuste do parâmetro R para o laurato de etila.Modelo de Gray. A última linha apresenta os parâmetros medidos para os dados experimentais disponíveis . . . . . . . 92

Tabela 15 - Dados comparativos para o ajuste do parâmetro R para o laurato de etila. Modelo de HTD - Cilindro. A última linha apresenta os parâmetros medidos para os dados experimentais disponíveis 
Tabela 16 - Dados comparativos para o ajuste do parâmetro R para o laurato de etila.Modelo HTD - Esfera . A última linha apresenta os parâmetros medidos para os dados experimentais disponíveis . . 93

Tabela 17 - Propriedades termodinâmicas do miristato de etila.Dados da literatura . . . . . . . . . . . . . . . . 95

Tabela 18 - Dados gerais de entrada do programa de simulação para o miristato de etila . . . . . . . . . . . . . . . . 95

Tabela 19 - Dados comparativos para o ajuste do parâmetro R para o miristato de etila. Modelo de Gray. A última linha apresenta os parâmetros medidos para os dados experimentais disponíveis . . 97

Tabela 20 - Dados comparativos para o ajuste do parâmetro R para o miristato de etila. Modelo HTD- Cilindro. A última linha apresenta os parâmetros medidos para os dados experimentais disponíveis

Tabela 21 - Dados comparativos para o ajuste do parâmetro R para o miristato de etila. Modelo HTD - Esfera. A última linha apresenta os parâmetros medidos para os dados experimentais disponíveis

Tabela 22 - Propriedades termodinâmicas do oleato de etila. dados da literatura. . . . . . . . . . . . . . . . . 99

Tabela 23 - Dados gerais de entrada do programa de simulação para o oleato de etila . . . . . . . . . . . . . . . . 100

Tabela 24 - Dados comparativos para o ajuste do parâmetro R para o oleato de etila. Modelo de Gray. A última linha apresenta os parâmetros medidos para os dados experimentais disponíveis . . . . . . . . 102

Tabela 25 - Dados comparativos para o ajuste do parâmetro R para o oleato de etila. Modelo HTD - Cilindro. A última linha apresenta os parâmetros medidos para os dados experimentais disponíveis . . 103

Tabela 26 - Dados comparativos para o ajuste do parâmetro R para o oleato de etila. Modelo HTD - Esfera. A última linha apresenta os parâmetros medidos para os dados experimentais disponíveis . . 103

Tabela 27 - Propriedades termodinâmicas do palmitato de etila. Dados da literatura. . . . . . . . . . . . . . . . . . . . 104

Tabela 28 - Dados gerais de entrada do programa de simulação para o palmitato de etila . . . . . . . . . . . . . . . . . 105 
Tabela 29 - Dados comparativos para o ajuste do parâmetro $\mathrm{R}$ para o palmitato de etila. Modelo de Gray. A última linha apresenta os parâmetros medidos para os dados experimentais disponíveis . . 107

Tabela 30 - Dados comparativos para o ajuste do parâmetro R para o palmitato de etila. Modelo HTD - Cilindro. A última linha apresenta os parâmetros medidos para os dados experimentais disponíveis 108

Tabela 31 - Dados comparativos para o ajuste do parâmetro R para o palmitato de etila. Modelo HTD- Esfera. A última linha apresenta os parâmetros medidos para os dados experimentais disponíveis 108 



\section{Lista de abreviaturas e siglas}

DSC Differential scanning calorimetry

DTA Differential thermal analysis

DTG Differential thermal gravimetry

HTD Heterogeneous temperature distribution

SLE Solid-liquid equilibrium

ESL Equilibrio sólido líquido

VLE Vapor liquid equilibrium 



\section{Lista de símbolos}

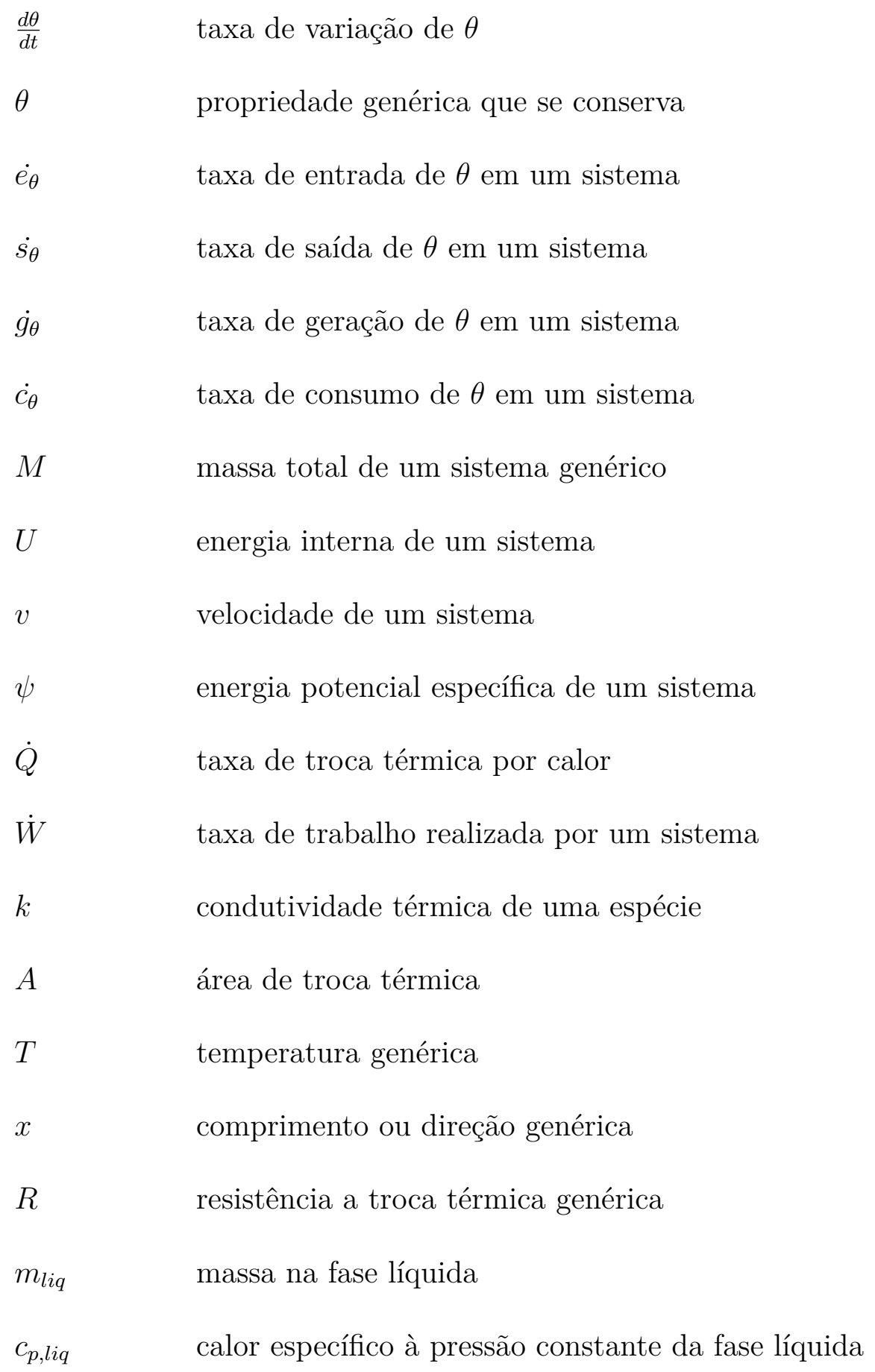




\begin{tabular}{|c|c|}
\hline$T_{l i q}$ & temperatura da fase líquida \\
\hline$\lambda$ & calor específico de fusão \\
\hline$m_{\text {sol }}$ & massa na fase sólida \\
\hline$c_{p, s o l}$ & calor específico à pressão constante da fase sólida \\
\hline$T_{\text {sol }}$ & temperatura da fase sólida \\
\hline$T_{p}$ & temperatura da fonte externa de calor \\
\hline$T_{p}^{0}$ & temperatura da fonte externa de calor no início da varredura \\
\hline$S_{r}$ & scan rate, taxa de varredura \\
\hline$t$ & tempo \\
\hline$C_{r}$ & capacidade térmica da referência \\
\hline$T_{r}$ & temperatura da referência \\
\hline$C_{s}$ & capacidade térmica da amostra \\
\hline$T_{s}$ & temperatura da amostra \\
\hline$\frac{d h}{d t}$ & taxa de calor cedido ou recebido em uma transformação de fase \\
\hline$q_{D S C}$ & sinal do aparelho DSC \\
\hline$T_{\text {fus }}$ & temperatura de fusão \\
\hline$\Delta H_{f u s}$ & variação total de entalpia devido ao processo de fusão \\
\hline$q_{D S C_{\max }}$ & valor de desvio máximo do sinal do aparelho DSC \\
\hline$t_{\text {end }}$ & tempo que marca o final do processo de fusão \\
\hline$R_{s, l}$ & $\begin{array}{l}\text { resistência á troca térmica da camada de líquido da amostra com } \\
\text { geometria cilíndrica }\end{array}$ \\
\hline$\dot{q}_{l}$ & $\begin{array}{l}\text { taxa de troca térmica na camada de líquido da amostra de } \\
\text { geometria cilíndrica }\end{array}$ \\
\hline
\end{tabular}




\begin{tabular}{|c|c|}
\hline$\left(\frac{d U}{d t}\right)_{s}$ & variação da energia interna da amostra \\
\hline$T_{l}$ & temperatura da fase líquida \\
\hline$m$ & massa da fase líquida para a amostra de geometria cilíndrica \\
\hline$c_{p, l}$ & calor específico da fase líquida \\
\hline$m_{l}$ & massa da fase líquida \\
\hline $\bar{T}_{l}$ & temperatura média da fase líquida \\
\hline$C_{w}(m)$ & capacidade térmica da fase líquida para a amostra cilíndrica \\
\hline$\dot{Q}_{s}$ & taxa de troca térmica da amostra \\
\hline$R_{\text {shell }}$ & resistência a troca térmica do cadinho \\
\hline$Z_{s}(m)$ & derivada de $R_{s, l}$ em função da massa, m \\
\hline$r_{s}$ & raio de sólido \\
\hline$A\left(r_{s}\right)$ & área de troca térmica em função de $r_{s}$ \\
\hline$r_{0}$ & raio inicial da amostra de geometria cilíndrica \\
\hline$h_{0}$ & altura inicial da amostra de geometria cilíndrica \\
\hline$m_{0}$ & massa inicial da amostra de geometria cilíndrica \\
\hline$C_{1}, C_{2}$ & $\begin{array}{l}\text { constantes obtidas pelo método dos mínimos quadrados para } \\
\text { ajuste de } r_{s} \text { em função } m\end{array}$ \\
\hline$\rho$ & densidade \\
\hline$r$ & raio original da amostra de geometria esférica \\
\hline$m_{l}$ & massa da fase líquida para a amostra de geometria esférica \\
\hline$T_{1}, T_{2}, r_{1}, r_{2}$ & extremos genéricos de integração \\
\hline$R_{l}$ & $\begin{array}{l}\text { resistência à troca térmica da camada de líquido da amostra de } \\
\text { geometria esférica }\end{array}$ \\
\hline
\end{tabular}


$y_{i+1} \quad$ função genérica $y$ avaliada no ponto $i+1$

$y_{i} \quad$ função genérica $y$ avaliada no ponto i

$f\left(t_{i}, y_{i}\right) \quad$ derivada da função $y$ avaliada no ponto $y_{i}$ e $t_{i}$

$h \quad$ tamanho do passo numérico

$k_{1}, k_{2}, k_{3}, k_{4} \quad$ constantes do método de Runge-Kutta 


\section{Sumário}

INTRODUÇÃO $\ldots \ldots \ldots \ldots \ldots \ldots \ldots \ldots$

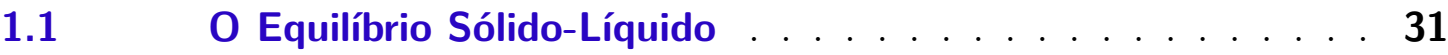

$1.2 \quad$ Análise térmica diferencial $\ldots \ldots \ldots \ldots$

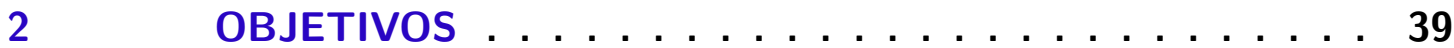

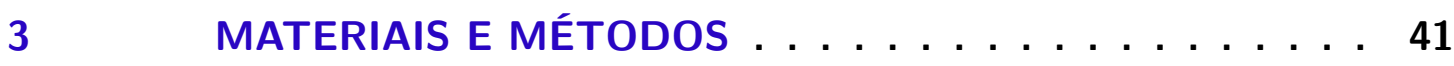

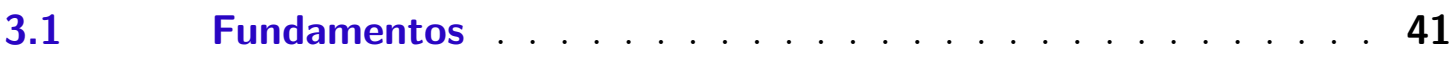

$3.2 \quad \mathrm{O}$ modelo de Gray . . . . . . . . . . . . . . . . . . 44

$3.2 .1 \quad$ Primeira fase $\ldots \ldots \ldots \ldots \ldots \ldots \ldots \ldots$

$3.2 .2 \quad$ Segunda Fase $\ldots \ldots \ldots \ldots \ldots \ldots \ldots$

3.2.3 Terceira fase . . . . . . . . . . . . . . . . . . . . . . . . 49

3.3 Modelo de perfil de temperatura heterogêneo. Geometria cilíndrica aproximada . . . . . . . . . . . . . . . 51

3.4 Modelo de perfil de temperatura heterogêneo.Geometria esférica . . . . . . . . . . . . . . . . . . 58

3.5 Programação, métodos numéricos e simulação . . . . . . . 66

$4 \quad$ RESULTADOS . . . . . . . . . . . . . 69

$4.1 \quad$ Resultados qualitativos $\ldots \ldots \ldots \ldots$

4.1.1 Comparação de modelos . . . . . . . . . . . . . . . . . . 69

4.1.2 Análises de sensibilidade . . . . . . . . . . . . . . . 80

4.2 Resultados quantitativos . . . . . . . . . . . . . . . 87

4.2.1 Ajuste de dados experimentais . . . . . . . . . . 88

4.2.1.1 Laurato de Etila . . . . . . . . . . . . . . . . . 89

4.2.1.2 Miristato de Etila . . . . . . . . . . . . . . . . 94

4.2.1.3 Oleato de Etila . . . . . . . . . . . . . . . . . . . . . . 99

4.2.1.4 Palmitato de Etila . . . . . . . . . . . . . . . . . 104

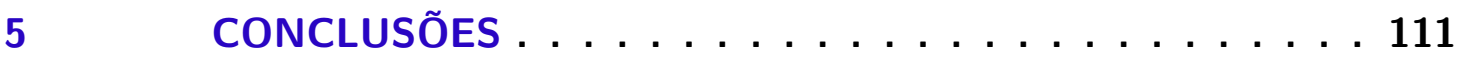


ANEXO A - CÓDIGO MATLAB®

PARA GEOMETRIA ESFÉRICA . . . . . . . . 121

ANEXO B - EXEMPLO DE DADOS DE ENTRADA E SAÍDA DO PROGRAMA DE SIMULAÇÃO PARA GEOMETRIA ESFÉRICA . . . . . . . . . . . 137

ANEXO C - TABELAS COMPLETAS DE AJUSTE DE DADOS ................... 141 


\section{Introdução}

\subsection{O Equilíbrio Sólido-Líquido}

O estudo dos estados de equilíbrio é uma das principais áreas de atuação da termodinâmica. No contexto do equilíbrio de fases, temos que o equilíbrio vaporlíquido (VLE) é muito bem definido, e bem explicado pelos métodos e modelos atuais. Ao tratarmos do equilíbrio sólido-líquido, contudo, temos um panorama menos definido onde os modelos atuais ainda não são tão consolidados devido a diversas peculiaridades da fase sólida, especialmente o fato de que esta muitas vezes não se apresenta de uma única forma, sendo possível a existência de vários estados de equilíbrio estáveis com configurações diferentes da fase sólida. Alguns exemplos são as diferentes fases do ferro-carbono, ferrita e cimentita, que podem ser vistas na Figura 1, a formação de compostos peritéticos na mistura e solidificação de dois compostos orgânicos, como por exemplo o sistema laurato de etila - miristato de etila [1], ou ainda a presença de soluções sólidas, como no caso da mistura difenilacetileno - estilbeno [2].
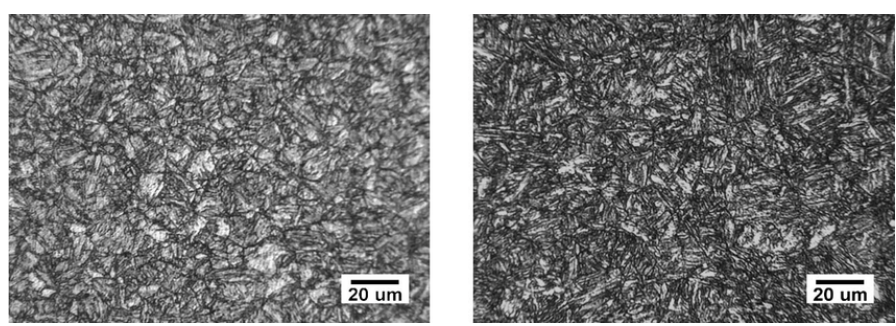

Figura 1 - Microscopia de uma amostra de ferro carbono. Áreas escuras se encontram na forma cementita, enquanto as áreas claras na forma ferrita. Imagem retirada de [26]

Uma ferramenta fundamental no estudo do SLE é o diagrama de fases, que relaciona as variáveis independentes (usualmente temperatura e composição no caso do estado sólido, já que a pressão pouco influencia este estado) ao estado 
de equilíbrio em que a mistura em estudo se encontra. As transições de fases são representadas por linhas sólidas e o estado da matéria é geralmente representado por uma letra que caracterize aquele estado (usualmente S para sólido, L para líquido, e um índice para indicar qual componente). Qualquer ponto que esteja contido entre as linhas da transição de fase se encontrará naquele estado. Um diagrama de fases de um SLE simples, como o visto na Figura 2, conterá apenas a linha solidus, temperatura abaixo da qual não existe nenhuma matéria em fase líquida, e a linha liquidus, representando o conjunto de temperaturas acima do qual não existe nenhum componente na fase sólida. Porém, o equilíbrio sólido líquido apresenta muito mais nuances do que somente uma fase líquida e sólida, que resultam em diagramas de fases que carregam muito mais informações e linhas de transição de interesse.

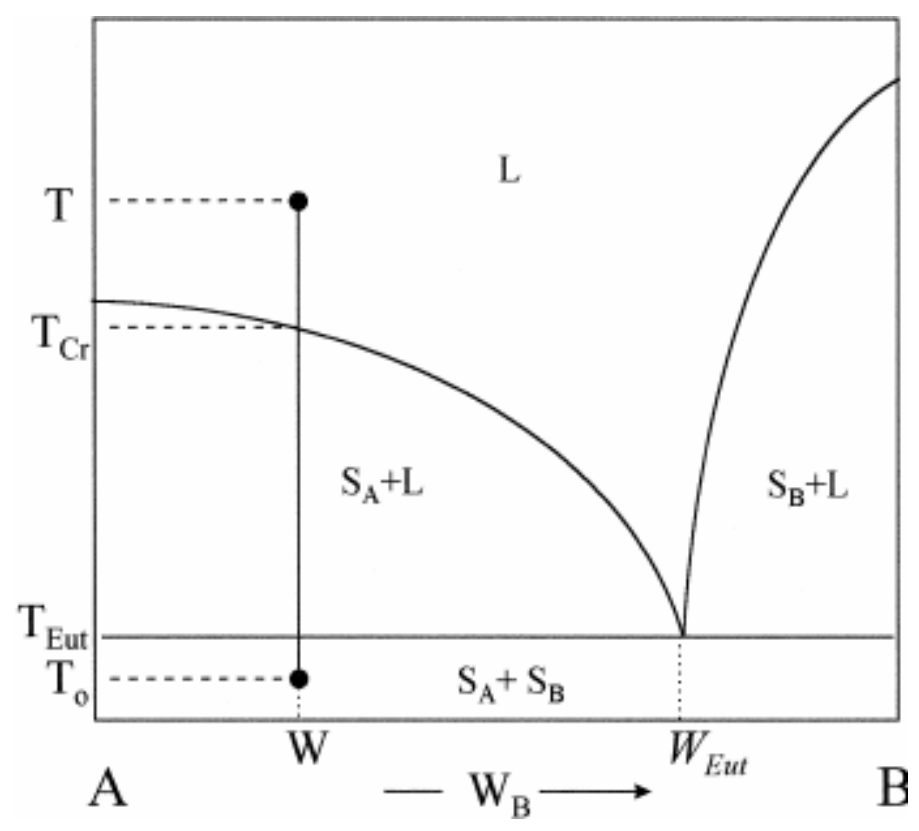

Figura 2 - Exemplo de diagrama de fases de um SLE simples. imagem de [27]

O equilíbrio sólido-líquido pode ser calculado ou observado de diversas formas. Cálculos envolvendo a minimização da energia livre de são apresentados por Rocha \& Guirardello [3] e Slaughter \& Doherty [4]. Métodos experimentais para a construção dos diagramas de fase e obtenção de parâmetros relevantes ao SLE 
são muitos e diversos, entre eles métodos de detecção visual [5], ou os apresentados por McGhie [6] e Matsuoka [7]; contudo esses métodos costumam ser lentos e dependentes da observação.

Uma técnica que se apresenta como alternativa a esses problemas é a de varredura calorimétrica diferencial, ou Differential Scanning Calorimetry (DSC) e seus métodos semelhantes, como análise diferencial de temperatura (DTA) ou a análise termogravimétrica diferencial (DTG). A base desses três métodos é explicada por A.P Gray (1968) e vem sendo utilizada nos últimos anos com muito sucesso na detecção da transição de fases para diversos compostos, sejam eles metais [8-10], polímeros [11,12] ou misturas de compostos orgânicos [1, 13-15].

\subsection{Análise térmica diferencial}

O princípio básico de funcionamento de uma análise térmica diferencial é expor duas células, uma denominada referência, que estará vazia, e uma denominada amostra, que conterá uma pequena quantia da amostra, a uma rotina de aquecimento ou resfriamento programada e registrar as diferenças térmicas,ou seja a diferença entre o calor fornecido as células no caso do DSC e a diferença de temperatura entre as células no DTA, ou a diferença de massa entre as células ao longo da rotina programada no caso de uma análise DTG. Um diagrama apresentando a estrutura de um desses aparelhos pode ser visto na Figura 3. 


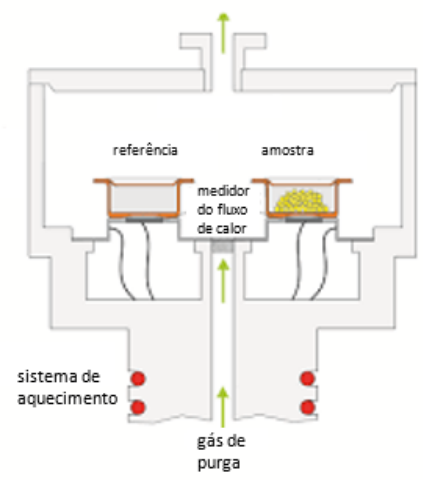

Figura 3 - Esquema de um aparelho de análise térmica diferencial. Imagem adaptada de [28]

A base por trás do funcionamento dessas análises é de que, devido a suas propriedades termodinâmicas intrínsecas, cada substância reagirá a um fluxo de calor de forma diferente. Mais importante, contudo, é que cada transição de fase ou reação que ocorra na amostra deixará uma marca térmica. No caso de uma fusão, a temperatura da amostra supostamente permanece constante, um aparelho DSC tentará sempre manter as duas temperaturas constantes, logo enviará mais calor para amostra, enquanto num aparelho DTA a diferença entre amostra e referência irá se ampliar durante a transição. Esse princípio também é válido para qualquer transição que ocorra uma variação de entalpia da amostra (ex: uma reação química exotérmica).

A forma que os resultados de uma varredura DSC são apresentados é chamada de termograma, um gráfico que relacionará a temperatura que a amostra deverá estar com o fluxo de calor necessário para mantê-lo nessa temperatura. Dessa forma, durante o período onde nenhuma transição ocorre, o resultado típico de um termograma é uma linha base ligeiramente deslocada do zero, devido à diferença entre as capacidades térmicas da amostra e da referência, já durante uma transição o sinal registrado será o de um pico, já que haverá um aumento (transição endotérmica) ou diminuição (transição exotérmica) no calor fornecido. Um exemplo de um termograma simples pode ser visto na Figura 4. Por convenção as transições 
endotérmicas são apresentadas como picos para baixo e as exotérmicas como picos para cima.

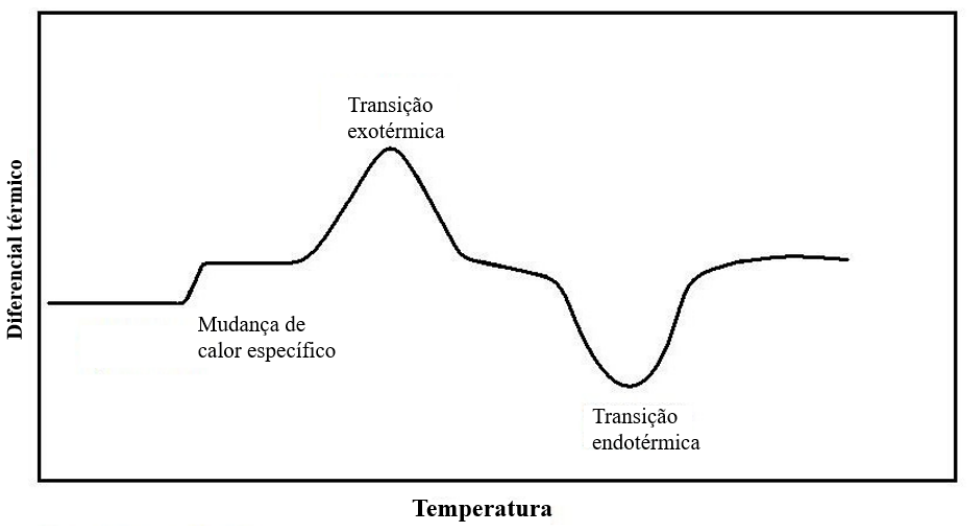

Figura 4 - Termograma genérico fornecido por um aparelho de análise térmica diferencial. Imagem adaptada de [28]

A obtenção de um termograma mesmo para uma transição simples fornece muita informação a respeito de suas propriedades termodinâmicas: a temperatura de fusão é aquela onde a temperatura começa o seu desvio da linha base. Devido a seus princípios de funcionamento, o calor de fusão da amostra pode ser calculado pela área do pico da transição, e o desvio da linha de base pode ser usado para o cálculo do calor específico da amostra entre muitas outras aplicações.

Além dessas medidas para uma transição simples, um termograma contém muitas informações importantes a respeito do equilíbrio sólido-líquido, o termograma de uma mistura que apresenta um ponto eutético simples é apresentado na Figura 5. Ao contrário de um termograma de substância que apresenta somente um pico, pode-se observar que há um pico inicial e um decaimento lento. A temperatura eutética é aquela de primeiro desvio da linha de base e corresponde à linha solidus de um diagrama de fases, enquanto a temperatura da linha liquidus pode ser extrapolada como a de do início do segundo pico. Na figura podemos observar o termograma para diversas composições do par oleato de etila - laurato de etila [13], múltiplas curvas são apresentadas de uma vez com um pequeno deslocamento entre cada curva para tornar a visualização mais clara, contudo todas apresentam 
a mesma linha base.

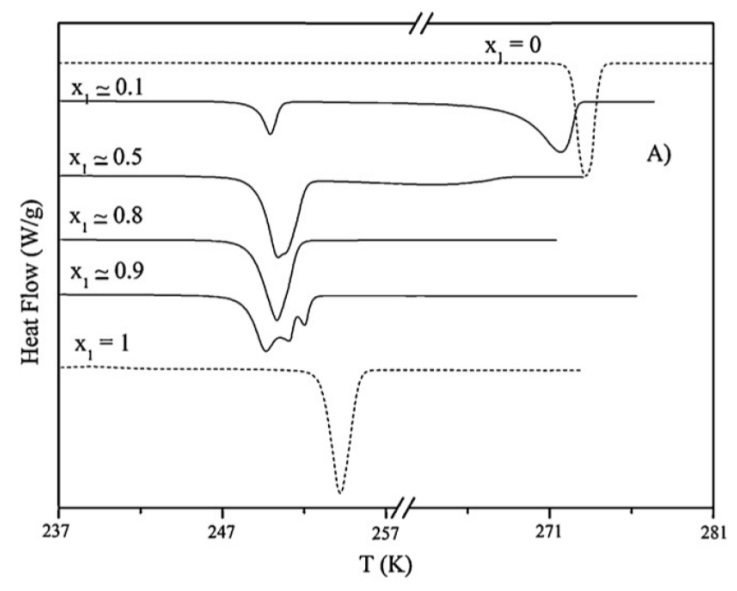

Figura 5 - Termograma para mistura oleato de etila - laurato de etila em diferentes composições. Imagem de [13]

A composição do ponto eutético pode ser determinada observando-se o deslocamento do pico secundário, que representa o derretimento do restante da mistura após a fusão inicial no ponto eutético. Na composição do ponto eutético espera-se apenas um pico na temperatura inicial.

A versatilidade e praticidade do DSC faz o seu uso ser cada vez mais disseminado e com isso diversos estudos acerca de seu funcionamento foram realizados, desde modelagens matemáticas de sua estrutura e funcionamento [3,16], às diversas aplicações e interpretações dos termogramas gerados, como predições de SLEs complexos [17], detecções de impurezas [18], ou métodos para relacionar a forma dos picos com as transições observadas [19].

Uma área de estudo muito importante é a do estudo dos erros instrumentais inerentes da técnica e da modelagem e simulação precisa de uma varredura. A simulação precisa de uma varredura fornece informações importantes a respeito do SLE $[2,20]$. Um dos principais erros que visam ser corrigidos é o lag térmico introduzido pela forma de funcionamento da aparelhagem. A resposta da amostra não é imediata ao calor fornecido, dessa forma deformando os picos que são gerados. Muitas formas de localizar as temperaturas corretas foram propostas, 
como o método proposto pela GEFTA [21] e a consequente alteração a esse método proposto por Sarge [22]. Além desses métodos de correção de temperatura, há diversas propostas de modelagem que visam corrigir a convolução das curvas geradas devido a limitações da aparelhagem [23]. 



\section{Objetivos}

O objetivo do presente trabalho é desenvolver um modelo de simulação matemática para o aparelho de análise térmica diferencial, conhecido usualmente como DSC (diffrential scanning calorimetry). O desenvolvimento do modelo baseiase nos fundamentos da engenharia química, ou seja, as equações fundamentais de balanço de massa e energia para um volume de controle definido em conjunto com as leis de transporte que regem a cinética da transferência de calor. Inicia-se o desenvolvimento do modelo a partir da teoria básica de A.P. Gray [25], que não prevê a mudança de temperatura da amostra durante o processo de fusão. O passo seguinte é a introdução de um gradiente linear de temperatura na fase líquida. Para esta etapa passa a ser necessário a consideração da geometria da amostra. Primeiramente o trabalho desenvolveu-se com uma geometria cilíndrica aproximada, como visto em Bhatnagar [24]. Conclui-se o trabalho com uma análise rigorosa ao assumir uma geometria esférica. 



\section{Materiais e métodos}

\subsection{Fundamentos}

A primeira etapa para a resolução de um problema de engenharia química é a formulação das equações de balanço e definição do volume de controle onde estas serão aplicadas. A equação geral de balanço de uma grandeza qualquer $\theta$ aplicada a um volume de controle será escrita, segundo [30], nos seguintes termos:

$$
\frac{d \theta}{d t}=\dot{e_{\theta}}-\dot{s_{\theta}}+\dot{g_{\theta}}-\dot{c_{\theta}}
$$

Onde:

$\frac{d \theta}{d t}$ : taxa de variação de $\theta$ no volume de controle

$\dot{e_{\theta}}$ : taxa com que $\theta$ entra no sistema através das fronteiras do volume de controle

$\dot{s_{\theta}}$ : taxa com que $\theta$ deixa o sistema através das fronteiras do volume de controle

$\dot{g}_{\theta}$ : taxa de geração de $\theta$ dentro do volume de controle

$\dot{c_{\theta}}$ : taxa de consumo de $\theta$ dentro do volume de controle

Para o problema do aparelho de calorimetria diferencial, definem-se dois volumes de controle: o cadinho de referência, que se encontra vazio, e será referido sempre pelo índice r, e o cadinho que contém a amostra, referido pelo índice s.

Ambos os volumes de controle definidos são fechados para entrada de massa, de forma que podemos escrever a equação de balanço de massa para os dois sistemas como:

$$
\frac{d M}{d t}=0
$$

Ou seja, não há variação da massa total dos sistemas avaliados. 
Para um sistema fechado o balanço de energia é definido por [30] como:

$$
\frac{d U}{d t}+M \frac{d}{d t}\left(\frac{v^{2}}{2}+\psi\right)=\dot{Q}+\dot{W}
$$

Onde:

$\frac{d U}{d t}$ : taxa de variação de energia interna

$M \frac{d}{d t}\left(\frac{v^{2}}{2}+\psi\right)$ : taxa de variação de energia mecânica

$\dot{Q}$ : taxa de troca de calor

$\dot{W}$ : taxa de trabalho realizado pelo sistema

No sistema analisado não há variação da energia mecânica do sistema, já que este se encontra sempre na mesma cota e não velocidade envolvida estando o sistema parado dentro do aparelho DSC.

Não há trabalho de eixo envolvido nem variação de volume do sistema, de forma que o termo de trabalho também é nulo. Dessa forma, simplifica-se a equação de balanço para a seguinte forma:

$$
\frac{d H}{d t}=\dot{Q}
$$

Logo se faz necessária a definição do calor trocado, $\dot{Q}$, e da energia interna do volume de controle.

Os fundamentos da troca de calor são estudados pelas equações de fenômenos de transporte. Ao analisar uma troca térmica verifica-se que o calor pode ser transferido de três formas: via condução, convecção ou radiação.

Para a presente análise será considerada apenas a troca térmica por condução. Considera-se que não há troca por convecção com o ambiente ou no interior da amostra. As trocas por radiação são admitidas como não significativas

A equação que rege a condução é a lei de Fourier, que ao se considerar o fluxo térmico em somente uma direção expressa por [31] como: 


$$
\dot{Q}=-k A \frac{d T}{d x}
$$

Sendo:

$\dot{Q}:$ taxa de calor trocado

$k$ : condutividade térmica da espécie

$A$ : área através da qual flui o calor $T$ : temperatura da espécie

$x$ : dimensão espacial na qual flui o calor

Uma forma simplificada da Lei de Fourier é conhecida como Lei de Resfriamento de Newton.

$$
\dot{Q}=\frac{\Delta T}{R}
$$

Sendo $\mathrm{R}$, a resistência a troca térmica :

$$
R \propto \frac{x}{k A}
$$

Utiliza-se a Lei de resfriamento de Newton quando não se conhece o perfil de temperatura desenvolvido, sabendo somente as temperaturas nos extremos.

Há uma forte semelhança entre a forma da Equação 6 e a Lei de Ohm, que rege a corrente elétrica. Temos uma grandeza que é proporcional a uma diferença de potencial sendo dividida por uma resistência. Esse é outro benefício da forma simplificada da Lei de Fourier, que permite que se trate circuitos térmicos complexos como uma associação de resistências térmicas, análogo ao que é realizado no estudo de circuitos elétricos.

Resta a definição da energia interna. Usualmente temos que $U \propto c_{p} T$ conduto no problema analisado temos uma mudança de fase, onde não há mudança de temperatura, contudo há mudança na energia interna da espécie. Sendo assim, definirá-se o lado esquerdo da Equação 4 como:

$$
\frac{d U}{d t}=m_{l i q} c_{p, l i q} \frac{d T_{l i q}}{d t}-\lambda \frac{d m_{s o l}}{d t}+m_{s o l} c_{p, s o l} \frac{d T_{s o l}}{d t}
$$


Será considerada cada fase em separado, sendo o seu termo só utilizado na equação quando a fase estiver presente. Da mesma forma que o termo de mudança de fase também só será considerado durante o processo de fusão.

\subsection{O modelo de Gray}

O modelo clássico para a descrição de operação de um aparelho de calorimetria diferencial é o modelo apresentado por A. P. Gray [25]. Um esquema visual é apresentado na Figura 6:

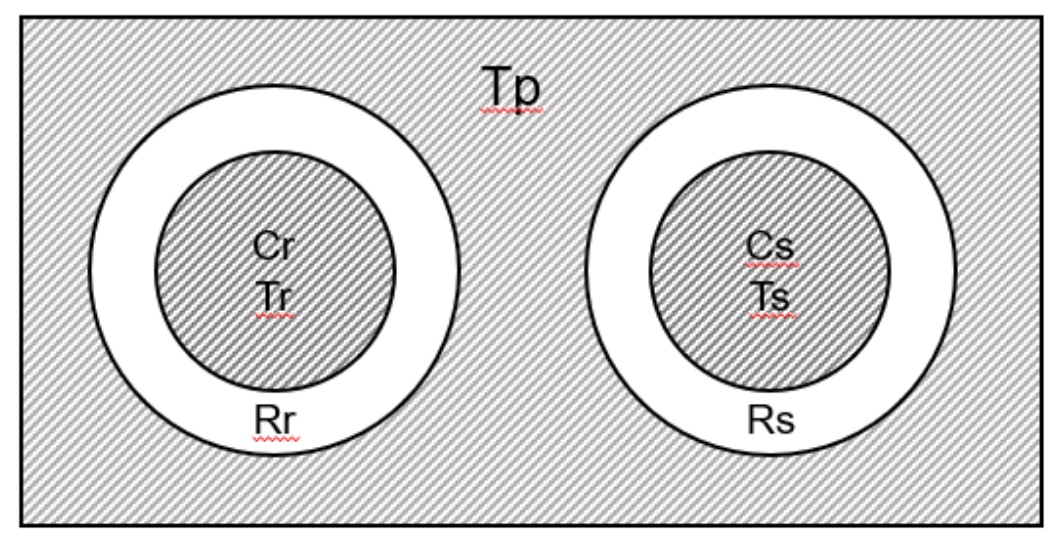

Figura 6 - Esquema do funcionamento de um aparelho DTA

Nele considera-se uma fonte de calor externa $T_{p}$ à qual tanto a amostra como a referência estão expostos. A transferência de calor da fonte externa para essas células é resistida por uma resistência térmica, $R_{s}$ para amostra e $R_{r}$ para referência. Ao considerarmos que ambas as células são iguais, podemos escrever a resistência térmica apenas como $R$. Referência e amostra tem uma capacidade térmica $C_{r}$ e $C_{s}$ respectivamente.

As duas principais técnicas de análise térmica diferencial são a varredura calorimétrica diferencial, ou Differential Scanning Calorimetry (DSC), e a análise térmica diferencial, ou Differential Thermal Analysis (DTA). A diferença entre essas duas técnicas está no que é medido. Em ambas, segundo A.P. gray [25], 
uma programação de temperatura é estabelecida para fonte externa $T_{p}$, essa fonte externa seguirá o seguinte comportamento:

$$
T_{p}=T_{p}^{0}+S_{r} t
$$

Onde $T_{p}^{0}$ é uma temperatura inicial definida e $S_{r}$ é a taxa de varredura também definida pelo usuário. Em um aparelho do tipo DTA o que será medido será a diferença de temperaturas entre as amostras ao serem expostas à rampa de temperatura predefinida, ou seja, não há controle da temperatura das células. Num aparelho DSC é fornecido calor diretamente às células para que estas estejam sempre na temperatura da programação definida, e o sinal do aparelho é justamente a diferença de calor fornecida para cada uma de forma a manter as temperaturas dentro do programado.

A dedução do funcionamento do aparelho se baseará na utilização das equaç oes basicas de alanço e troca térmica. Inicia-se combinado a Equação 6 a Equação 8

$$
\frac{\Delta T}{R}=m_{l i q} c_{p, l i q} \frac{d T_{l i q}}{d t}-\lambda \frac{d m_{\text {sol }}}{d t}+m_{\text {sol }} c_{p, s o l} \frac{d T_{\text {sol }}}{d t}
$$

A análise precisa ser separada para a amostra e para a referencia. No caso da referencia temos somente uma fase e também que $C_{r}$ é o produto de sua massa por seu calor específico. Para o diferencial de temperatura $\Delta T$ tem-se o valor $T_{p}-T_{r}$ resultando em :

$$
\frac{T_{p}-T_{r}}{R}=C_{r} \frac{d T_{r}}{d t}
$$

Ao considerar a amostra combina-se os termos da fase liquida e sólida em um só termo para simplicidade, já que as fases não coexitirão, exceto durante a mudança de fase, contudo nesse periodo não haverá variação de temperatura. Da mesma forma reescreve-se o termo $-\lambda \frac{d m_{s o l}}{d t}$ como uma variação entálpica $-\frac{d h}{d t}$. Obtém-se: 


$$
\frac{T_{p}-T_{s}}{R}=C_{s} \frac{d T_{s}}{d t}-\frac{d h}{d t}
$$

Ao substrair a Equação 12 da Equação 11 e reanrranjarmos os termos obteremos:

$$
\frac{T_{s}-T_{r}}{R}=C_{r} \frac{d T_{r}}{d t}-C_{s} \frac{d T_{s}}{d t}+\frac{d h}{d t}
$$

Para o auxilio da análise da equação uma manipulação nas variáveis é desejável, para que se produzam termos com maior significado físico e que facilitem a resolução de problemas seguintes. Essa manipulação consiste em somar e subtrair o termo $C_{s} \frac{d T_{r}}{d t}$

$$
\frac{T_{s}-T_{r}}{R}=C_{r} \frac{d T_{r}}{d t}-C_{s} \frac{d T_{s}}{d t}+\frac{d h}{d t}+C_{s} \frac{d T_{r}}{d t}-C_{s} \frac{d T_{r}}{d t}
$$

Rearranjo das variáveis resulta em:

$$
\frac{T_{s}-T_{r}}{R}=-\left(C_{s}-C_{r}\right) \frac{d T_{r}}{d t}-C_{s} \frac{d T_{s}-T_{r}}{d t}+\frac{d h}{d t}
$$

Em adição a isso é interessante multiplicar e dividir o termo $\frac{d\left(T_{s}-T_{r}\right)}{d t}$ pelo valor $\mathrm{R}$ e representa-lo da seguinte maneira:

$$
\frac{T_{s}-T_{r}}{R}=-\left(C_{s}-C_{r}\right) \frac{d T_{r}}{d t}-R C_{s} \frac{d \frac{T_{s}-T_{r}}{R}}{d t}+\frac{d h}{d t}
$$

O termo do lado esquerdo da igualdade será justamente o sinal do aparelho DSC, já que é a diferença entre o calor fornecido para a amostra e o calor fornecido para a referência.

$$
q_{D S C}=\frac{T_{s}-T_{r}}{R}
$$

O primeiro termo do lado direito da Equação 16 representa a diferença de energia necessária para aquecer a amostra em relação a referência, ou seja o quanto de energia se faz necessário para aquecer somente a amostra localizada dentro do 
cadinho, dado que tanto referência como amostra contém essa peça e seu calor específico é contabilizado tanto em $C_{s}$ como em $C_{r}$; já o segundo termo do lado direito representa a variação do sinal do DSC ao longo do tempo; o último termo contabiliza a energia devido a qualquer transformação que ocorra no sistema. Por fim representa-se a equação da seguinte forma:

$$
q_{D S C}=-\left(C_{s}-C_{r}\right) \frac{d T_{r}}{d t}-R C_{s} \frac{d(D S C)}{d t}+\frac{d h}{d t}
$$

A equação para o DSC apresenta um fator único de que pode-se obter a entalpia de transição unicamente a partir do sinal gerado pelo aparelho já que o termo $\frac{d h}{d t}$ se encontra livre na equação, ou seja pode ser isolado e associado com os termos restantes.

Para um melhor entendimento do processo de fusão é conveniente dividir o processo em três fases distintas. O primeiro deles sendo o período onde toda a amostra esta no estado sólido, ou seja $T_{s}<T_{\text {fus }}$.

A segunda etapa é o processo de fusão propriamente dito. Esta etapa durará até todo o material sólido ter mudado de fase para o estado líquido. Durante esta etapa a temperatura da amostra $T_{s}$ é admitida como constante e mantém-se no valor $T_{\text {fus }}$

A terceira e última etapa é aquela na qual todo o material da amostra e encontra na fase líquida, ou seja todos os valores $T_{s}>T_{\text {fus }}$

\subsubsection{Primeira fase}

Nessa etapa não há nenhuma mudança de fase, de forma que o termo de variação de entalpia da Equação 18 pode ser considerado nulo. Tanto $T_{s}$ como $T_{r}$ estarão variando conforme a rampa de temperatura programada ou seja, na primeira etapa :

$$
\frac{d T_{s}}{d t}=\frac{d T_{r}}{d t}=S_{r}
$$

Sendo $S_{r}$ a taxa de aquecimento programada. Dessa forma o segundo termo 
do lado direito da Equação 18 também é nulo. Esse fato fica ainda mais claro ao se avaliar a Equação 15. Combinando essas observações com a Equação 19,obtém-se:

$$
q_{D S C}=-\left(C_{s}-C_{r}\right) S_{r}
$$

Assim, o sinal do DSC na primeira etapa é uma reta constante, com valor igual ao inverso da capacidade témica da amostra contida no cadinho somente. Pois:

$$
C_{s}=m_{s o l} c_{p, s o l}+C_{r} \Longrightarrow C_{s}-C_{r}=m_{s o l} c_{p, s o l}
$$

\subsubsection{Segunda Fase}

A segunda fase corresponde ao processo de fusão propriamente dito. Admitese como hipótese que, durante esta etapa, $T_{s}=T_{f u s}$, com $T_{f} u s$ constante. Admite-se também que $T_{r}$ varia linearmente nessa fase, e sua taxa de variação é igual ao scan rate $S_{r}$.

$$
T_{r}(t)=T_{r}^{0}+S_{r} t
$$

A temperatura $T_{r}^{0}$ é um valor conhecido em algum ponto do tempo. Pode-se deduzir seu valor no início da segunda fase com o auxílio da Equação 20 e da Equação 17

$$
\begin{gathered}
\frac{T_{\text {fus }}-T_{r}^{0}}{R}=-\left(C_{s}-C_{r}\right) S_{r} \\
T_{r}^{0}-T_{\text {fus }}=R S_{r}\left(C_{s}-C_{r}\right) \Longrightarrow T_{r}^{0}=T_{f u s}+R S_{r}\left(C_{s}-C_{r}\right)
\end{gathered}
$$

Obtém-e o sinal do DSC ao combinar a Equação 17 ao resultado da Equação 24 junto a Equação 22

$$
q_{D S C}=\frac{T_{f u s}-T_{f u s}-R S_{r}\left(C_{s}-C_{r}\right)-S_{r} t}{R}
$$

Ou seja: 


$$
q_{D S C}=-S_{r}\left(C_{s}-C_{r}+\frac{1}{R} t\right)
$$

Ou seja, espera-se um perfil linear decrescente partindo-se da linha de base, o que é esperado já que o sinal do termograma é contínuo.

É importante notar a presença do termo entálpico durante a segunda fase. Ele determinará a duração desta fase do processo. Com a Equação 26 caraterizando o sinal do DSC a sua derivada no tempo será :

$$
\frac{d\left(q_{D S C}\right)}{d t}=-\frac{S_{r}}{R}
$$

Resultado que aplicado em conjunto com a Equação 26 a Equação 18 fornece:

$$
-S_{r}\left(C_{s}-C_{r}+\frac{1}{R} t\right)=-S r\left(C_{s}-C_{r}\right)-R C_{s} \frac{-S_{r}}{R}+\frac{d h}{d t} \Longrightarrow \frac{-S_{r}}{R} t=S_{r} C_{s}+\frac{d h}{d t}
$$

Resultando:

$$
\frac{d h}{d t}=-S_{r}\left(C_{s}+\frac{1}{R} t\right)
$$

O processo de fusão estará completo quando a integral do termo do lado esquerdo ao longo do tempo for igual ao $\Delta H_{\text {fus }}$ do material analisado. O valor para o tempo que corresponderá a este resultado é:

$$
t_{\text {end }}=R C_{s}\left(\sqrt{1-\frac{2 \Delta H_{f u s}}{R C_{s}^{2} S_{r}}}-1\right)
$$

Dessa forma o máximo desvio do sinal do termograma será:

$$
q_{D S C_{\max }}=S_{r}\left(C_{s}-C_{r}\right)+\frac{S_{r}}{R} t_{\text {end }}
$$

\subsubsection{Terceira fase}

Muito tempo após o término do processo de fusão ambos os cadinhos voltarão a variar de temperatura da mesma forma, e iguais a taxa de varredura , porém isso não verdade logo após o fim do processo. 
Nessa fase novamente não há o termo de variação entalpica devido a transformações. Os outros dois termos da Equação 18 contudo se fazem presentes

$$
q_{D S C}=-S_{r}\left(C_{s}-C_{r}\right)-R C_{s} \frac{d(D S C)}{d t}
$$

Esse resultado é uma equação diferencial com variáveis separáveis, sua resolução se da da seguinte forma:

$$
\begin{gathered}
q_{D S C}+S_{r}\left(C_{s}-C_{r}\right)=-R C_{s} \frac{d(D S C)}{d t} \\
\frac{d\left(q_{D S C}\right)}{d t}=\frac{q_{D S C}+S_{r}\left(C_{s}-C_{r}\right)}{-R C_{s}} \\
\int \frac{d\left(q_{D S C}\right)}{q_{D S C}+S_{r}\left(C_{s}-C_{r}\right)}=\int \frac{d t}{-R C_{s}} \\
\ln \left(q_{D S C}+S_{r}\left[C_{s}-C_{r}\right]\right)=-\frac{t}{R C_{s}}+C \\
q_{D S C}+S_{r}\left(C_{s}-C_{r}\right)=e^{-\frac{t}{R C_{s}}} * C
\end{gathered}
$$

Para $t=0, q_{D S C}=q_{D S C_{\max }}$. Logo:

$$
C=q_{D S C_{\max }}+\operatorname{Sr}\left(C_{s}-C_{r}\right)
$$

Resultando:

$$
q_{D S C}=q_{D S C_{\max }} e^{-\frac{t}{R C_{s}}}+S r\left(C_{s}-C_{r}\right)\left(e^{-\frac{t}{R C_{s}}}-1\right)
$$

Este resultado esta de acordo com o esperado já que para um tempo infinito o sinal do DSC volta a linha base e no seu inicio ele parte do ponto de desvio máximo do sinal. 


\subsection{Modelo de perfil de temperatura heterogêneo. Geometria cilíndrica aproximada}

Uma das hipóteses assumidas no modelo de Gray é de que durante a segunda fase toda a amostra permanece a temperatura de fusão $T_{f} u s$, dado que a amostra tem um volume pequeno ela não é sem cabimento, porém é uma que pode ser facilmente relaxada. Assumindo que haverá uma parcela sólida que se diminuíra, e que no líquido formado haverá um perfil de temperaturas linear como mostrada na Figura 7 pode-se escrever novos balanços de energia que modelarão como a fusão irá proceder e como esse perfil de temperatura se desenvolverá ao longo do tempo.

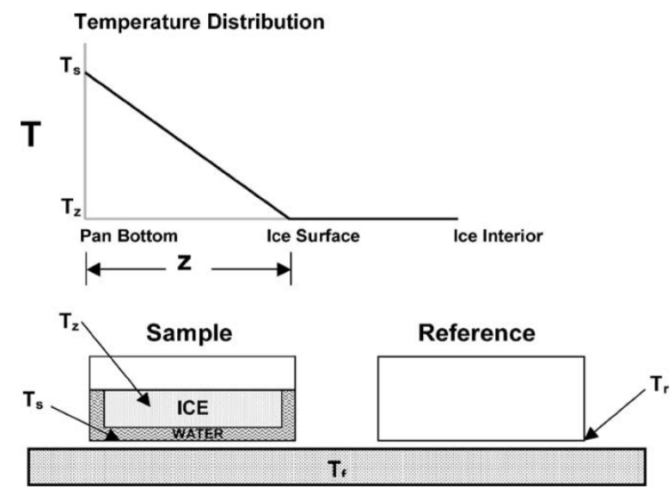

Figura 7 - Perfil de temperatura desenvolvido durante a fusão. Imagem de [24]

Do perfil linear desenvolvido vem a abreviação do nome deste modelo, utilizada neste trabalho, HTD, que vem de Heterogeneous Temperature Distribution

Através dessa camada de liquido será transferido calor, que será resistido pela camada de líquido que ira se desenvolver, e concomitantemente se aquecer. Esse transporte de calor pode ser descrito da seguinte forma:

$$
\dot{Q}_{l}=\frac{T_{s}-T_{f u s}}{R_{s, l}}
$$

Essa formulação assume que a amostra no estado sólido permanecerá com ua temperatura constantemente na temperatura de fusão, $T_{f u s}$, enquanto que o 
recipiente que contém a amostra, cuja temperatura é $T_{s}$, e o seu conteúdo na fase líquida terão sua temperatura aumentada pela fonte externa de calor. O calor passa a ser modelado pela Lei de Resfriamento de Newton tendo como temperaturas referentes do gradiente de temperatura os valores nos dois extremos da camada de liquido formada, ou seja a temperatura na parede do cadinho e a fronteira com a fase sólida.

Na Equação 40 os termos $T_{s}$ e $R_{l}$, referente a resistência a troca térmica da camada de líquido serão variáveis ao longo do tempo. O primeiro pois a temperatura irá aumentar devido a fonte de calor externa, e o segundo devido a o aumento da camada de líquido.

Ao assumir tais hipóteses sobre o processo de fusão da amostra o balanço de energia da célula de amostra toma a seguinte forma :

$$
\left(\frac{d U}{d t}\right)_{s}=\lambda \frac{d m_{l}}{d t}+m_{l} c_{p, l} \frac{d T_{l}}{d t}+C_{r} \frac{d T_{s}}{d t}
$$

Em que $\lambda$ é calor latente de fusão por unidade de massa, $m_{l}$ é a massa de líquido já fusionada, $c_{p}^{l}$ é o calor específico do líquido, $T_{l}$ é a temperatura do líquido. Ou seja, o primeiro termo do lado direito da equação representa o calor gasto para fusão da amostra, o segundo termo o aquecimento da camada de líquido desenvolvida e o último termo o aquecimento do cadinho que contém a amostra.

Ao se assumir que o perfil de temperaturas desenvolvido na camada de líquido é linear, com um extremo a temperatura $T_{s}$, variando no tempo, e outro a temperatura $T_{f u s}$, constante, é possível descrever a temperatura média do líquido, $\bar{T}_{l}$ como uma função de $T_{s}(t)$, o que permite melhor a modelagem do sistema, já que o objetivo da modelagem é simular a temperatura $T_{s}$. Essa manipulação é equivalente em termos de troca térmica, sendo a energia gasta a mesma.

$$
\bar{T}_{l}=\frac{T_{s}(t)+T_{\text {fus }}}{2}
$$

O valor da derivada temporal de $T_{l}$ passa a ser escrito, então, como: 


$$
\frac{d T_{l}}{d t}=\frac{1}{2} \frac{d T_{s}}{d t}
$$

Dado que a variação do temperatura da camada líquida será metade da registrada por $T_{s}$ define-se a função $C_{w}(m)$, capacidade térmica da camada de líquido desenvolvida, como:

$$
C_{w}(m)=\frac{c_{p, l} m_{l}}{2}
$$

Combinando a Equação 44 e Equação 43, reescreve-se o balanço de energia, Equação 41:

$$
\left(\frac{d U}{d t}\right)_{s}=\lambda \frac{d m_{l}}{d t}+C_{w}\left(m_{l}\right) \frac{d T_{s}}{d t}+C_{r} \frac{d T_{s}}{d t}
$$

Ao assumir o gradiente de temperatura na amostra perde-se a facilidade de determinar o fim da fusão apenas pela soma total do calor fornecido a amostra, já que como descrito pela Equação 45 parte dele passa ser gasto no aquecimento do restante da amostra. Dessa forma adiciona-se mais uma variável dependente ao sistema, a massa $m$, total da amostra,logo é necessária uma forma de descreve-la em função da variável independente $t$, de parâmetros do sistema e da outra variável dependente $T_{s}$.

A resolução deste problema vem do conhecimento de outra condição de contorno. A taxa de transferência de calor do cadinho para o líquido na parede do cadinho tem de ser igual a taxa de calor que chega a esse ponto vindo da fonte externa. Para se estabelecer essa igualdade primeiramente deve-se escrever essa taxa de transporte no cadinho, que será

$$
\dot{Q}_{s}=\frac{T_{p}-T_{s}}{R_{\text {shell }}}
$$

O primeiro passo para obtenção da variavel independete desejada é igualar a Equação 40 a Equação 46 


$$
\frac{T_{s}-T f u s}{R_{s, l}}=\frac{T_{p}-T_{s}}{R_{\text {shell }}}
$$

Rearranja-se os termos:

$$
\begin{gathered}
T_{s}-T_{\text {fus }}=\frac{R_{s, l}}{R_{\text {shell }}}\left(T_{p}-T_{s}\right) \\
T_{s}\left(1+\frac{R_{s, l}}{R_{\text {shell }}}\right)=T_{\text {fus }}+T_{p} \frac{R_{s, l}}{R_{\text {shell }}}
\end{gathered}
$$

Aplica-se a derivada temporal na igualdade:

$$
\frac{d\left(T_{s}\left(1+\frac{R_{s, l}}{R_{\text {shell }}}\right)\right)}{d t}=\frac{d T_{\text {fus }}}{d t}+\frac{d\left(T_{p} \frac{R_{s, l}}{R_{\text {shell }}}\right)}{d t}
$$

Para a simplificação da equação é importante ressaltar que $T_{f u s}$ e $R_{\text {shell }}$ são invariantes no tempo,logo suas derivadas são nulas. Aplicando a regra do produto das derivadas a expressão assume a seguinte forma

$$
T_{s} \frac{1}{R_{\text {shell }}} \frac{d R_{s, l}}{d t}+\left(1+\frac{R_{s, l}}{R_{\text {shell }}}\right) \frac{d T_{s}}{d t}=T_{p} \frac{1}{R_{s, l}} \frac{d R_{s, l}}{d t}+\frac{R_{s, l}}{R_{\text {shell }}} \frac{d T_{p}}{d t}
$$

Sendo $\frac{d T_{p}}{d t}$ a definição da taxa de varredura $S_{r}$ e agrupando-se os termos com fatores comuns, resulta em

$$
\left(1+\frac{R_{s, l}}{R}\right) \frac{d T_{s}}{d t}=\left(\frac{T_{p}-T_{s}}{R}\right) \frac{d R_{s, l}}{d t}+\frac{R_{s, l}}{R} S_{r}
$$

$R_{s, l}$ é função da massa $m$, logo pode-se aplicar a regra da cadeia a sua derivada com o tempo:

$$
\frac{d R_{s, l}}{d t}=\frac{d R_{s, l}}{d m} \frac{d m}{d t}=Z_{s}(m) \frac{d m}{d t}
$$

Sendo $Z_{s}(m)$ uma forma mais compacta de expressar a derivada de $R_{s, l} \mathrm{em}$ função da massa de material já derretida.

A Equação 7 indica que a resistência a troca térmica é proporcional a uma dimensão característica e inversamente proporcional a área de troca e a 
condutividade térmica do meio. O conhecimento dessa dimensão caracteristica passa a ser necessário para a resolução do problema de troca de calor.

Esse fato introduz a necessidade de uma modelagem da geometria da amostra analisada. O presente trabalhou optou por duas geometrias possíveis: uma cilíndrica e um hemisfério. Como apresentados na Figura 8 e Figura 9

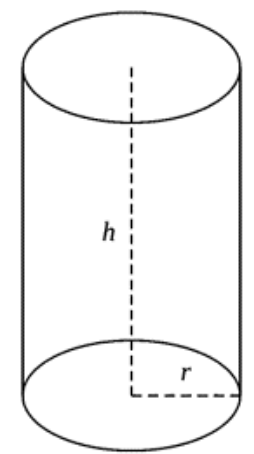

Figura 8 - Geometria cilíndrica proposta

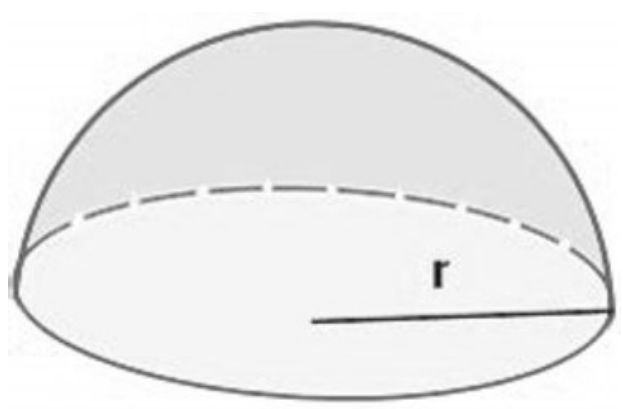

Figura 9 - Geometria esférica proposta

Ao se resolver rigorosamente a Lei de Fourier para uma placa plana para um cilindro e para uma esfera obtém-se diferentes dimensões características e áreas para a Equação 7

O modelo cilíndrico apresentado depende de dois parâmetros, a altura $h$ do cilindro, e seu raio $r$. A presença de duas dimensões diferentes é um problema já que cada uma delas variará há uma taxa diferente no tempo, sendo que uma delas se esgotará antes da outra. Outro problema da modelagem cilíndrica é o fato de que a resolução da Equação 7 para a face curva do cilindro e para a face plana levam resoluções diferentes.

O presente trabalho apresenta uma simplificação importante de forma a contornar esses problemas. Modela-se uma das dimensões do cilindro em função da outra e a resolução da Lei de Fourier é feita sem levar em conta a curvatura

No caso do hemisfério apenas a dimensão do raio $r$ é suficiente para modelagem do volume. A troca térmica é modelada como ocorrendo somente na face curva, não ocorrendo na face plana do hemisfério.

Inicialmente este cilindro tem dimensões: raio inicial $r 0$; altura inicial $h 0 . \mathrm{A}$ 
área de troca térmica em função de $r_{s}$ será aproximada por :

$$
A\left(r_{s}\right)=\pi r_{0}^{2}\left(1-\frac{r_{s}}{r_{0}}\right)^{2}+2 \pi r_{0} h_{0}\left(1-\frac{r_{s}}{r_{0}}\right)\left(1-\frac{r_{s}}{h_{0}}\right)
$$

Porém a variável independente utilizada no sistema de equações é $m$, não $r_{s}$, logo é necessária uma maneira de relacionar essas duas grandezas. Ao se assumir que a densidade da fase sólida e da fase líquida são iguais escreve-se a seguinte relação:

$$
1-\left(1-\frac{r_{s}}{r_{0}}\right)^{2}\left(1-\frac{r_{s}}{h_{0}}\right)-\frac{m}{m_{0}}=0
$$

Onde $m_{0}$ é a massa inicial de sólido. Para cada valor de $m$ variando de 0 até $m_{0}$ há um valor de $r_{s}$ correspondente. Para o programa de simulação desenvolvido nesse trabalho decidiu-se por ajustar um polinômio de segundo grau através do método dos mínimos quadrados para obter essa relação inversa, cuja forma é:

$$
r_{s}(m)=C_{1} m+C_{2} m^{2}
$$

Define-se então a resistência a troca térmica da camada de líquido como sendo:

$$
R_{s, l}(m)=\frac{r_{s}(m)}{k A\left(r_{s}(m)\right)}
$$

A derivada de $R_{s, l}$ com relação a massa, $Z_{s}(m)$, será então

$$
Z_{s}(m)=\left(2 C_{1} m+C_{2}\right) k A\left(r_{s}(m)\right)-6 \pi r_{s}(m)-\frac{[2 \pi(h 0+r 0)]\left(2 C_{1} m+C_{2}\right) r_{s}(m)}{k A\left(r_{s}(m)\right)^{2}}
$$

Dessa forma todas as relações estão sendo dadas em função de $T_{s}, m, t$, ou parâmetros conhecidos do sistema.

Combinando o resultado da Equação 53 a Equação 52 e rearranjado-se alguns dos termos:

$$
\left(\frac{T_{p}-T_{s}}{R}\right) \frac{d m}{d t} Z_{s}(m)=\left(1+\frac{R_{s, l}(m)}{R}\right) \frac{d T_{s}}{d t}-\frac{R_{s, l}(m)}{R} S_{r}
$$


Isolando-se o termo $\frac{d m}{d t}$ :

$$
\frac{d m}{d t}=\frac{R+R_{s, l}(m)}{\left(T_{p}-T_{s}\right) Z_{s}(m)} \frac{d T_{s}}{d t}-\frac{R_{s, l}(m)}{\left(T_{p}-T_{s}\right) Z_{s}(m)} S_{r}
$$

Ao combinar o resultado da Equação 60 com o balanço de energia (Equação 45) e a Equação 40 explicitar $\frac{d T_{s}}{d t}$ obtém-se a segunda relação procurada :

$$
\begin{gathered}
\frac{T_{p}-T s}{R_{\text {shell }}}=\lambda\left(\frac{R+R_{s, l}(m)}{\left(T_{p}-T_{s}\right) Z_{s}(m)} \frac{d T_{s}}{d t}-\frac{R_{s, l}(m)}{\left(T_{p}-T_{s}\right) Z_{s}(m)} S_{r}\right)+\left(C_{w}(m)+C_{r}\right) \frac{d T_{s}}{d t} \\
\left(\lambda\left(\frac{R+R_{s, l}(m)}{\left(T_{p}-T_{s}\right) Z_{s}(m)}\right)+C_{w}(m)+C_{r}\right) \frac{d T_{s}}{d t}=\frac{T_{p}-T s}{R_{s h e l l}}+\frac{R_{s, l}(m)}{\left(T_{p}-T_{s}\right) Z_{s}(m)} S_{r} \lambda \\
\frac{d T_{s}}{d t}=\frac{S_{r} \lambda \frac{R_{s, l}(m)}{\left(T_{p}-T_{s}\right) Z_{s}(m)}+\frac{T_{p}-T s}{R_{s h e l l}}}{\lambda\left(\frac{R+R_{s, l}(m)}{\left(T_{p}-T_{s}\right) Z_{s}(m)}\right)+C_{w}(m)+C_{r}}
\end{gathered}
$$

O termo $T_{p}$ representa a temperatura externa aplicada que irá aquecer tanto a referência como a amostra, seu comportamento com o tempo é descrito pela Equação 9

Para o modelo de gradiente térmico o tempo final da fusão se dá quando a massa de material derretido se iguala a massa inicial.

Para o cálculo do sinal do DSC resolve-se o perfil de temperatura da amostra, $T_{s}$, e o da referência, $T_{r}$, ao longo do tempo e calcula-se o calor necessário para o aquecimento de cada amostra, para o caso da amostra esse cálculo é feito pela Equação 45 , já para referencia ele assuume a mesma forma que no modelo de Gray, ou seja a Equação 11.

Para o modelo de gradiente térmico a primeira e terceira fases são modeladas da mesma forma que o modelo de Gray. 


\subsection{Modelo de perfil de temperatura heterogêneo.Geometria esférica}

Para a dedução do modelo esférico parte-se do balanço de energia da amostra a partir do momento em que se inicia a fusão . Ou seja a Equação 41

Sendo o termo da esquerda a quantidade de calor fornecida a amostra. Os dois primeiros termos do lado direito da equação se referem a energia gasta para a mudança de fase e o aquecimento da camada de líquido desenvolvida durante o processo, respetivamente. $\lambda$ é o calor latente de fusão, $m_{l}$ a massa de líquido, $c_{p, l}$ o calor específico e $T_{l}$ a temperatura da camada de líquido. $\mathrm{O}$ último termo diz respeito ao aquecimento do cadinho que contém a amostram sendo $C_{r}$ sua capacidade térmica. $T_{s}$ é a temperatura lida pelo aparelho DSC.

Para a resolução do modelo deve-se assegurar que este esteja em função das duas variáveis independentes $r_{s}$, raio da massa da amostra ainda na fase sólida, e $T_{s}$.

Iniciando-se pelo lado direito da equação, a massa de líquido pode ser escrita com base na geometria da amostra, que assume-se como apenas um hemisfério de uma esfera. O raio de líquido será a diferença entre o raio interno do cadinho, $r$, e o raio de sólido $r_{s}$, que variará com o tempo.

$$
m_{l}=\rho \frac{2 \pi}{3}\left(r^{3}-r_{s}^{3}\right)
$$

A variação da massa de líquido ao longo do tempo nada mais será que a derivada no tempo da massa de líquido

$$
\frac{d m_{l}}{d t}=\frac{d\left(\rho \frac{2 \pi}{3}\left(r^{3}-r_{s}^{3}\right)\right)}{d t}
$$

Os termos constantes podem ser tirados da derivada

$$
\frac{d m_{l}}{d t}=\frac{-2 \rho \pi}{3} 3 r_{s}^{2} \frac{d r_{s}}{d t}
$$

E a fração pode ser simplificada obtendo-se: 


$$
\frac{d m_{l}}{d t}=-2 \rho \pi r_{s}^{2} \frac{d r_{s}}{d t}
$$

Assumindo-se um perfil linear de temperatura na camada de líquido que se desenvolve e que a temperatura da amostra sólida permanece constante e igual a temperatura de fusão $T_{\text {fus }}$ pode-se escrever a temperatura do líquido, $T_{l}$, como função da temperatura da amostra $T_{s}$

$$
T_{l}=\frac{T_{s}+T_{f u s}}{2}
$$

Cuja derivada no tempo será:

$$
\frac{d T_{l}}{d t}=\frac{\left(\frac{T_{s}+T_{f u s}}{2}\right)}{d t}
$$

Assumindo-se que a derivada da temperatura de fusão ao longo do tempo é nula e explicitando-se os termos constantes da derivada obtém-se:

$$
\frac{d T_{l}}{d t}=\frac{1}{2} \frac{d T_{s}}{d t}
$$

Dessa forma é possível rescrever a Equação 41 com os novos termos deduzidos acima.

$$
\frac{d U}{d t}=-2 \lambda \rho \pi r_{s}^{2} \frac{d r_{s}}{d t}+c p_{l} \rho \frac{2 \pi}{3}\left(r^{3}-r_{s}^{3}\right) \frac{1}{2} \frac{d T_{s}}{d t}+C r \frac{d T_{s}}{d t}
$$

Agrupando-se os termos comuns e simplificando-se os termos das frações resulta em:

$$
\frac{d U}{d t}=-2 \lambda \rho \pi r_{s}^{2} \frac{d r_{s}}{d t}+\left[\frac{c p_{l} \rho \pi}{3}\left(r^{3}-r_{s}^{3}\right)+C r\right] \frac{d T_{s}}{d t}
$$

Para a taxa de troca térmica parte-se da Lei de Fourier para uma esfera com troca apenas na direção radial :

$$
\dot{Q}=-k A \frac{d T}{d r}
$$


Assume-se que a parte superior do hemisfério, ou seja a parte onde não a curvatura, não participa da troca de calor, de forma que a área superficial para troca de calor pode ser escrita em função do raio

$$
\dot{Q}=-k 2 \pi r^{2} \frac{d T}{d r}
$$

Para resolução da lei de Fourier isolam-se os termos independentes:

$$
\dot{Q}-\frac{1}{r^{2}} d r=k 2 \pi d T
$$

E integra-se o resultado, entre os limites genéricos $\left(T_{1}, r_{1}\right)$ e $\left(T_{2}, r_{2}\right)$

$$
\dot{Q} \int_{r_{1}}^{r_{2}}-\frac{1}{r^{2}}=k 2 \pi \int_{T_{1}}^{T_{2}} d T
$$

A integral resulta em :

$$
\dot{Q}\left(\frac{1}{r_{1}}-\frac{1}{r_{2}}\right)=k 2 \pi\left(T_{2}-T_{1}\right)
$$

Isola-se o termo de calor $\dot{Q}$ :

$$
\dot{Q}=\frac{k 2 \pi\left(T_{2}-T_{1}\right)}{\frac{1}{r_{1}}-\frac{1}{r_{2}}}
$$

O termo do denominador pode ser reescrito como :

$$
\dot{Q}=\frac{k 2 \pi\left(T_{2}-T_{1}\right)}{\frac{r_{2}-r_{1}}{r_{1} r_{2}}}
$$

De forma que toda a fração pode ser reescrita como:

$$
\dot{Q}=\frac{k 2 \pi r_{1} r_{2}\left(T_{2}-T_{1}\right)}{r_{2}-r_{1}}
$$

Outra forma possível de tratar a troca de calor é a analogia da resistência térmica, onde o calor é função da diferença de potencia $T_{2}-T_{1}$ dividida por um 
resistência térmica. Pode-se deduzir que essa resistencia térmica para o caso de um hemisfério é igual a :

$$
R=\frac{r_{2}-r_{1}}{k 2 \pi r_{1} r_{2}}
$$

Ao se utilizar dessa analogia para escrever a taxa de troca de calor para amostra, obtém-se:

$$
\dot{Q}=\frac{T_{p}-T_{f u s}}{R_{\text {shell }}+R_{l}}
$$

Observa-se que seguindo a lógica do circuito elétrico há uma associação de resistências em serie. O termo $R_{\text {shell }}$ é a resistência térmica do cadinho que contém a amostra, enquanto o termo $R_{l}$ representa a resistência térmica da camada de líquido que se desenvolve durante a fusão.

Essa pode ser escrita como função do raio de sólido:

$$
R_{l}=\frac{r-r_{s}}{2 \pi k r r_{s}}
$$

De forma que o termo do lado direito da Equação 82 da equção (1) é reescrito da seguinte forma:

$$
\dot{Q}=\frac{T_{p}-T_{\text {fus }}}{R_{\text {shell }}+\frac{r-r_{s}}{2 \pi k r r_{s}}}
$$

Ao se simplificar as frações obtém-se o termo:

$$
\dot{Q}=\frac{\left(T_{p}-T_{\text {fus }}\right) 2 \pi k r r_{s}}{r-r_{s}+2 \pi k r r_{s} R_{\text {shell }}}
$$

Sendo a assim a Equação 72 pode ser escrita como função das variáveis independentes da presente forma:

$$
\frac{\left(T_{p}-T_{f u s}\right) 2 \pi k r r_{s}}{r-r_{s}+2 \pi k r r_{s} R_{\text {shell }}}=-2 \lambda \rho \pi r_{s}^{2} \frac{d r_{s}}{d t}+\left[\frac{c p_{l} \rho \pi}{3}\left(r^{3}-r_{s}^{3}\right)+C r\right] \frac{d T_{s}}{d t}
$$


Para a resolução completa do problema é necessário obter outra equação independente, pois o problema corrente esta descrito em função de duas variáveis independentes.

O fluxo de calor na fronteira interna do cadinho é igual tanto na parede metálica quanto na camada de líquido. Esse valores podem ser escritos na forma da analogia da resistência térmica e igualadas como segue:

$$
\frac{T_{p}-T_{s}}{R_{\text {shell }}}=\frac{T_{s}-T_{f u s}}{R_{l}}
$$

A seguinte manipulação das variáveis é conveniente para a resolução do problema:

$$
T_{p}-T_{s}=R_{\text {shell }}\left(\frac{T_{s}-T_{\text {fus }}}{R_{l}}\right)
$$

Aplica-se a derivada no tempo

$$
\frac{d T_{p}}{d t}-\frac{d T_{s}}{d t}=R_{\text {shell }}\left(\frac{d\left(\frac{T_{s}}{R_{l}}\right)}{d t}-T_{\text {fus }} \frac{d\left(\frac{1}{R_{l}}\right)}{d t}\right)
$$

A Equação 86 esta escrita em função das derivadas no tempo das variáveis independentes de forma que é útil que a segunda equação independente também esteja nesse formato. Logo deve-se aplicar a derivada no tempo em todos os termos. Resultando no termo acima. A análise termo a termo dessa derivada no tempo fornece:

$$
\frac{d T_{p}}{d t}=S r
$$

A derivada no tempo da temperatura da fornalha nada mais é do que a taxa de varredura $S r$

A manipulação do termo $\frac{d\left(\frac{T_{s}}{R_{l}}\right)}{d t}$ é um pouco mais complexa. O primeiro passo consiste em aplicara a regra do quociente da derivada 


$$
d\left(\frac{T_{s}}{R_{l}}\right)=T_{s} d\left(\frac{1}{R_{l}}\right)-\frac{1}{R_{l}} d\left(T_{s}\right)
$$

É conveniente retornar a Equação 89 e rearranjar os termos

$$
S r-\frac{d T_{s}}{d t}=R_{\text {shell }}\left[T_{s} \frac{d\left(\frac{1}{R_{l}}\right)}{d t}+\frac{1}{R_{l}} \frac{d T_{s}}{d t}-T_{\text {fus }} \frac{d\left(\frac{1}{R_{l}}\right)}{d t}\right]
$$

Explicitando-se os fatores comuns

$$
S r=R_{\text {shell }}\left[\left(T_{s}-T_{\text {fus }}\right) \frac{d\left(\frac{1}{R_{l}}\right)}{d t}+\left(\frac{1}{R_{l}}+\frac{1}{R_{\text {shell }}}\right) \frac{d T_{s}}{d t}\right]
$$

E simplificando-se as frações

$$
S r=R_{\text {shell }}\left(T_{s}-T_{\text {fus }}\right) \frac{d\left(\frac{1}{R_{l}}\right)}{d t}+\frac{R_{\text {shell }}+R_{l}}{R_{l}} \frac{d T_{s}}{d t}
$$

Resta a manipulação do termo referente a resistência térmica da camada de líquido, que pode ser escrito em função do raio da fase sólida, a variável independente desejada

$$
\frac{1}{R_{l}}=2 \pi k r \frac{r_{s}}{r-r_{s}}
$$

De forma que a derivada no tempo deste termo pode ser escrita da seguinte forma, explicitando-se os termos que são invariáveis

$$
d\left(\frac{1}{R_{l}}\right)=2 \pi k r d\left(\frac{r_{s}}{r-r_{s}}\right)
$$

Aplica-se novamente a regra do quociente

$$
d\left(\frac{1}{R_{l}}\right)=2 \pi k r\left(r_{s} d\left(\frac{1}{r-r_{s}}\right)+\frac{1}{r-r_{s}} d r_{s}\right)
$$

Escreve-se o termo $d\left(\frac{1}{r-r_{s}}\right)$ em função de $d r_{s}$ 


$$
d\left(\frac{1}{R_{l}}\right)=2 \pi k r\left(\frac{r_{s}}{\left(r-r_{s}\right)^{2}} d r_{s}+\frac{1}{r-r_{s}} d r_{s}\right)
$$

Simplifica-se a fração para um denominador comum

$$
d\left(\frac{1}{R_{l}}\right)=2 \pi k r\left(\frac{r_{s}+r-r_{s}}{\left(r-r_{s}\right)^{2}} d r_{s}\right)
$$

Resultando em :

$$
d\left(\frac{1}{R_{l}}\right)=\frac{2 \pi k r^{2}}{\left(r-r_{s}\right)^{2}} d r_{s}
$$

Resta reescrever o termo $\frac{R_{\text {shell }}+R_{l}}{R_{l}}$ em função das variáveis independentes

$$
\frac{R_{\text {shell }}+R_{l}}{R_{l}}=\frac{\frac{r-r_{s}}{2 \pi k r r_{s}}+R_{\text {shell }}}{\frac{r-r_{s}}{2 \pi k r r_{s}}}=\frac{r-r_{s}+2 \pi k r r_{s} R_{\text {shell }}}{r-r_{s}}
$$

Substitui-se os valores obtidos na Equação 94:

$$
S r=\frac{R_{\text {shell }}\left(T_{s}-T_{\text {fus }}\right) 2 \pi k r^{2}}{\left(r-r_{s}\right)^{2}} \frac{d r_{s}}{d t}+\frac{r-r_{s}+2 \pi k r r_{s} R_{\text {shell }}}{r-r_{s}} \frac{d T_{s}}{d t}
$$

Separa-se as variáveis independentes

$$
\frac{r-r_{s}+2 \pi k r r_{s} R_{\text {shell }}}{r-r_{s}} \frac{d T_{s}}{d t}=S r-\frac{R_{\text {shell }}\left(T_{s}-T_{\text {fus }}\right) 2 \pi k r^{2}}{\left(r-r_{s}\right)^{2}} \frac{d r_{s}}{d t}
$$

Explicita-se o valor $\frac{d T_{s}}{d t}$

$$
\frac{d T_{s}}{d t}=\frac{S r-\frac{R_{\text {shell }}\left(T_{s}-T_{\text {fus }}\right) 2 \pi k r^{2}}{\left(r-r_{s}\right)^{2}} \frac{d r_{s}}{d t}}{\frac{r-r_{s}+2 \pi k r r_{s} R_{\text {shell }}}{r-r_{s}}}
$$

Finalmente reescreve-se os termos sob um denominador comum 


$$
\frac{d T_{s}}{d t}=\frac{\operatorname{Sr}\left(r-r_{s}\right)^{2}-R_{\text {shell }}\left(T_{s}-T_{\text {fus }}\right) 2 \pi k r^{2} \frac{d r_{s}}{d t}}{\left(r-r_{s}\right)\left(r-r_{s}+2 \pi k r r_{s} R_{\text {shell }}\right)}
$$

A formulação da Equação 105 pode ser substituída na Equação 86

$$
\begin{aligned}
\frac{\left(T_{p}-T_{\text {fus }}\right) 2 \pi k r r_{s}}{r-r_{s}+2 \pi k r r_{s} R_{\text {shell }}}= & \\
& -2 \lambda \rho \pi r_{s}^{2} \frac{d r_{s}}{d t} \\
& +\left[\frac{c p_{l} \rho \pi}{3}\left(r^{3}-r_{s}^{3}\right)+C r\right] \frac{S r\left(r-r_{s}\right)^{2}-R_{\text {shell }}\left(T_{s}-T_{\text {fus }}\right) 2 \pi k r^{2} \frac{d r_{s}}{d t}}{\left(r-r_{s}\right)\left(r-r_{s}+2 \pi k r r_{s} R_{\text {shell }}\right)}
\end{aligned}
$$

A próxima etapa consiste em separar os fatores comuns:

$$
\begin{aligned}
\frac{\left(T_{p}-T_{\text {fus }}\right) 2 \pi k r r_{s}}{r-r_{s}+2 \pi k r r_{s} R_{\text {shell }}}= & \\
& -2 \pi \frac{d r s}{d t}\left[\lambda \rho r_{s}^{2}+\frac{R_{\text {shell }}\left(T_{s}-T_{\text {fus }}\right) k r^{2}\left(\frac{c p_{l} \rho \pi}{3}\left(r^{3}-r_{s}^{3}\right)+C r\right)}{\left(r-r_{s}\right)\left(r-r_{s}+2 \pi k r r_{s} R_{\text {shell }}\right)}\right] \\
& +\left[\frac{c p_{l} \rho \pi}{3}\left(r^{3}-r_{s}^{3}\right)+C r\right] \frac{S r\left(r-r_{s}\right)^{2}}{\left(r-r_{s}\right)\left(r-r_{s}+2 \pi k r r_{s} R_{\text {shell }}\right)}
\end{aligned}
$$

Separa-se a váriavel independente

$$
\begin{gathered}
\frac{\left(r-r_{s}\right)\left(r-r_{s}+2 \pi k r r_{s} R_{\text {shell }}\right) \lambda \rho r_{s}^{2}+R_{\text {shell }}\left(T_{s}-T_{\text {fus }}\right) k r^{2}\left(\frac{c p_{l} \rho \pi}{3}\left(r^{3}-r_{s}^{3}\right)+C r\right)}{\left(r-r_{s}\right)\left(r-r_{s}+2 \pi k r r_{s} R_{\text {shell }}\right)} 2 \pi \frac{d r_{s}}{d t} \\
=\frac{\left(\frac{c p_{l} \rho \pi}{3}\left(r^{3}-r_{s}^{3}\right)+C r\right) S r\left(r-r_{s}\right)^{2}-\left(r-r_{s}\right)\left(T_{p}-T_{f u s}\right) 2 \pi k r r_{s}}{\left(r-r_{s}\right)\left(r-r_{s}+2 \pi k r r_{s} R_{\text {shell }}\right)}
\end{gathered}
$$

Finalmente pode-se isolar o termo $\frac{d r_{s}}{d t}$ e simplificar-se os denominadores 


$$
\begin{aligned}
\frac{d r_{s}}{d t}= & \\
& \frac{\left(\frac{c p_{l} \rho \pi}{3}\left(r^{3}-r_{s}^{3}\right)+C r\right) \operatorname{Sr}\left(r-r_{s}\right)^{2}-\left(r-r_{s}\right)\left(T_{p}-T_{f u s}\right) 2 \pi k r r_{s}}{2 \pi\left[\left(r-r_{s}\right)\left(r-r_{s}+2 \pi k r r_{s} R_{\text {shell }}\right) \lambda \rho r_{s}^{2}+R_{\text {shell }}\left(T_{s}-T_{\text {fus }}\right) k r^{2}\left(\frac{c p_{l} \rho \pi}{3}\left(r^{3}-r_{s}^{3}\right)+C r\right)\right]}
\end{aligned}
$$

O conjunto composto pela Equação 105 e a Equação 109 ao ser resolvido simultaneamente por métodos numéricos permitem a simulação completa do processo que ocorre no DSC

\subsection{Programação, métodos numéricos e simulação}

O desenvolvimento do modelo acima, seja em sua forma mais simples ou sua forma mais complexa resulta em um conjunto de equações diferencias ordinárias, como a maior parte dos problemas de engenharia.

Há um grande arcabouço de técnicas para resoluções de EDOs como as obtidas pelo presente trabalho. Uma das técnicas mais comuns de resolução de problemas desse tipo é a aplicação de métodos numéricos para obtenção da função objetiva. Ao invés de se obter uma função objetivo rigorosa através da integração da equação diferencial constrói-se a função objetivo multiplicando a equação diferencial por um intervalo de tempo suficientemente pequeno e somando-se ao resultado anterior. Esse é o principio do método de euler, que é descrito por [32] como:

$$
y_{i+1}=y_{i}+f\left(t_{i}, y_{i}\right) * h
$$

Onde:

$y_{i+1}$ : valor da função no próximo passo

$y_{i}$ : valor da função no passo atual

$f\left(t_{i}, y_{i}\right)$ : derivada da função $y_{i}$ avaliada no ponto $\left(t_{i}, y_{i}\right)$

$h$ : tamanho do passo 
O método de Euler é uma primeira aproximação simples, e para um caso simples como o modelo de Grey ele pode ser suficiente. Contudo o conjunto de EDOs gerado apresenta uma complexidade maior e para obter-se resultados com maior precisão o método numérico utilizado foi o de Runge-Kutta de quarta ordem, que é descrito por [32] da seguinte forma:

$$
y_{i+1}=y_{i}+\frac{1}{6}\left(k_{1}+2 k_{2}+2 k_{3}+k_{4}\right) * h
$$

onde:

$$
\begin{aligned}
& k_{1}=f\left(t_{i}, y_{i}\right) \\
& k_{2}=f\left(t_{i}+\frac{1}{2} h, y_{i}+\frac{1}{2} k_{1} h\right) \\
& k_{3}=f\left(t_{i}+\frac{1}{2} h, y_{i}+\frac{1}{2} k_{2} h\right) \\
& k_{4}=f\left(t_{i}+h, y_{i}+k_{3} h\right)
\end{aligned}
$$

Dessa forma o método de Runge-Kutta de quarta ordem não baseia sua próxima previsão somente com base no ponto atual mas sim com 4 previsões sendo estas tratadas cada uma com um peso diferente. Por utilizar 4 pontos para prever o próximo valor o método é conhecido como de quarta ordem.

Para implementar a rotina de solução do sistema de equações diferenciais foi utilizada a plataforma MATLAB®. Desenvolveu-se um script aplicando o método acima demonstrado aplicado nas duas equações diferenciais desenvolvidas acima , resolvendo ambas em conjunto a cada passo.

O script desenvolvido recebe como dados de entrada: a densidade da amostra , sua massa ou características geométricas; seus dados termodinâmicos relevantes, ou seja calor específico da fase líquida e sólida, calor de fusão e temperatura de fusão e condutividade térmica ; os dados a respeito da varredura térmica: ponto inicial e final e taxa de varredura; dados referentes a célula de referencia, sua resistência a troca térmica e sua capacidade térmica; e finalmente dados específicos da simulação numérica, sendo esses o tamanho de passo e para o caso do script da geometria esférica um dado adicional, pois a Equação 109 apresentara um 0 no denominador caso o valor atual do raio seja igual ao raio de sólido o que ocorre no primeiro passo. Essa variável adicional retira uma pequena fração do raio inicial da 
fusão, sendo esse parâmetro ajustável pelo.

Os dados de saída fornecidos pelo script são um termograma, gerado automaticamente, resultante da simulação realizada além de todos os pontos de temperatura e calor calculados para referencia e amostra. Para a versão de geometria esférica também são gerados vetores com os valores de todas as variações de raio e temperatura calculados em cada passo, além de dados separados para cada tipo de calor calculado, ou seja o calor gasto no aquecimento da fase líquida, sólida, da referencia e do calor gasto na fusão. Esse script se encontra em ( $<$ https://bit.ly/3pwxCp5> ) e no Anexo A, sendo seu uso autorizado a qualquer parte interessada. Um exemplo de dados de entrada e saída esperados do programa podem ser vistos no Anexo B 


\section{Resultados}

O objetivo principal deste trabalho é a elaboração de uma rotina de cálculos capaz de simular a partir dos dados das espécies envolvidas e especificas de um aparelho DSC o termograma esperado para aquela varredura.

Desenvolveu-se três diferentes rotinas, cada uma delas baseada em um dos modelos expostos na seção acima. O primeiro modelo desenvolvido foi o com base na teoria de A.P. Gray, e consiste no modelo mais simples. A seguir foi desenvolvido o modelo de geometria cilíndrica. Finalmente foi implementado a rotina de cálculo para geometria esférica que aplica com mais rigor os fundamentos do transporte de calor.

Tem-se como principal objetivo equiparar as curvas simuladas a curvas reais obtidas em laboratório, fazendo o ajuste necessário dos parâmetros específicos de um aparelho. Contudo como primeira etapa do desenvolvimento do trabalho realizou-se experimentos simulados com base em uma substancia da qual se tem pleno conhecimento das propriedades termodinâmicas de forma a conhecer quais variáveis influenciam a forma do termograma obtido e para se verificar a validade dos modelos desenvolvido.

\subsection{Resultados qualitativos}

\subsubsection{Comparação de modelos}

Para a comparação dos modelos desenvolvidos um experimento simulado foi realizado. Esse experimento consistiu no processo de fusão de uma massa de água. Essa substância foi escolhida pela facilidade no acesso dos dados termodinâmicos relevantes e pelo fato do trabalho de Bhatnagar [24] tratar de uma mistura aquosa, logo a forma dos termogramas obtidos seria um indicativo de que o método aplicado estava correto

Os dados termodinâmicos para este experimento simulado foram: 
Tabela 1 - Propriedades termodinâmicas da água

\begin{tabular}{|c|c|c|c|c|c|c|}
\hline $\begin{array}{c}m \\
{[k g]}\end{array}$ & $\begin{array}{c}\rho \\
{\left[\frac{\mathrm{kg}}{m^{3}}\right]}\end{array}$ & $\begin{array}{c}c_{p, s} \\
{\left[\frac{J}{k g K}\right]}\end{array}$ & $\begin{array}{c}c_{p, l} \\
{\left[\frac{J}{k g K}\right]}\end{array}$ & $\begin{array}{c}\lambda \\
{\left[\frac{J}{k g}\right]}\end{array}$ & $\begin{array}{c}k \\
{\left[\frac{W}{m K}\right]}\end{array}$ & $\begin{array}{c}T_{\text {fus }} \\
{[K]}\end{array}$ \\
\hline $1,0 * 10^{-5}$ & 1000 & 2054 & 4188 & 333550 & 0,6065 & 273,15 \\
\hline
\end{tabular}

A rotina de varredura foi definida por:

Tabela 2 - Propriedades da varredura

\begin{tabular}{|c|c|c|}
\hline $\begin{array}{c}T_{\text {inicio }} \\
{[K]}\end{array}$ & $\begin{array}{c}T_{\text {final }} \\
{[K]}\end{array}$ & $\begin{array}{c}S_{r} \\
{\left[\frac{K}{\min }\right]}\end{array}$ \\
\hline 270 & 290 & 5 \\
\hline
\end{tabular}


A célula de referência teve seus parâmetros admitidos, arbitrariamente, como:

Tabela 3 - Propriedades da célula de referência

\begin{tabular}{|c|c|}
\hline $\begin{array}{c}R_{\text {shell }} \\
{\left[\frac{K}{W}\right]}\end{array}$ & $\begin{array}{c}C_{r} \\
{\left[\frac{J}{K}\right]}\end{array}$ \\
\hline 100 & 0,005 \\
\hline
\end{tabular}

Por fim os parâmetros do método numérico foram estabelecidos em :

Tabela 4 - Propriedades do método numérico

\begin{tabular}{|c|c|}
\hline$h$ & $f$ \\
\hline 0,01 & 0,999 \\
\hline
\end{tabular}

Primeiramente o modelo mais simples, o de Gray, foi avaliado. O resultado do termo grama pode ser vista na Figura 10.

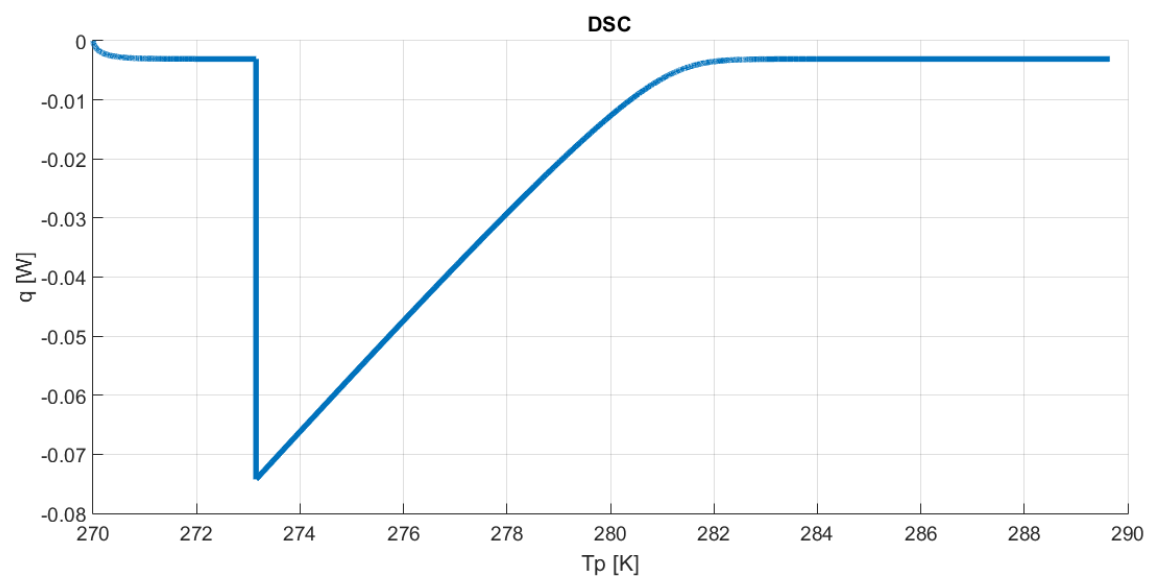

Figura 10 - Termograma simulado para o modelo de A.P. Gray segundo os dados apresentados nas Tabeleas de 1 a 4

O comportamento do termograma simulado é o que se espera. Nos períodos sem processo de fusão observa-se uma reta que corresponde a capacidade térmica da 
amostra. No ponto de fusão há um forte pico em $T_{\text {fus }}$ com um retorno exponencial a linha de base.

O perfil de temperaturas durante o tempo percorrido, Figura 11, mostra mais claramente como todo o processo de fusão ocorre a temperatura constante.

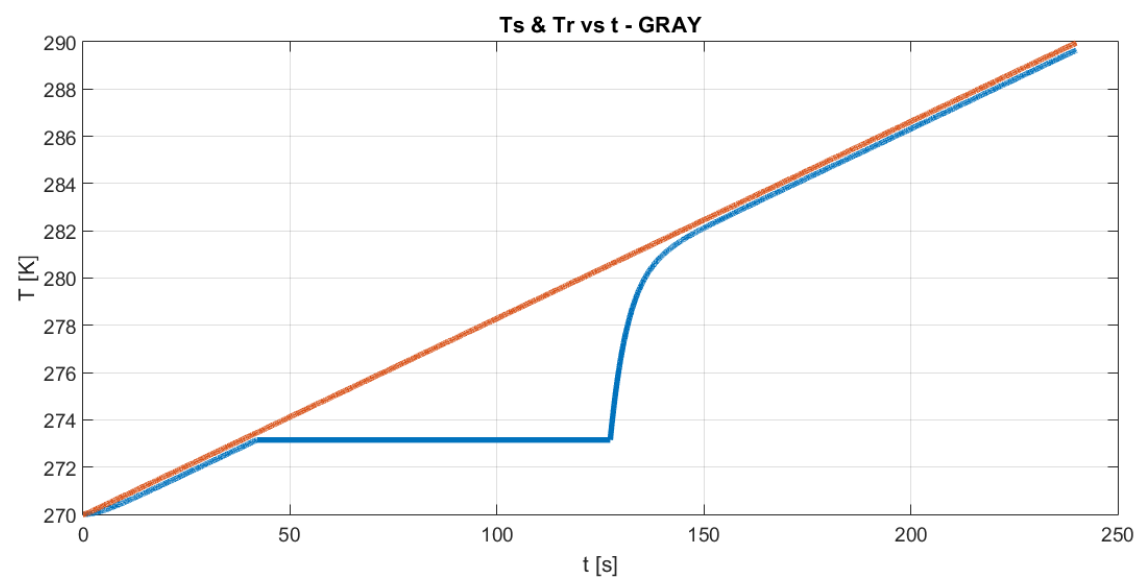

Figura 11 - Perfil de temperatura da amostra e referencia ao longo do tempo para o modelo de Gray. em azul $T_{s}$, em laranja $T_{r}$

Os três comportamentos descritos pelas equações Equação 20, Equação 26 e Equação 39 é observado quando a Abscissa do gráfico é a variável independente $t$, o tempo de varredura, e não $T_{s}$ a temperatura da célula de amostra m como usualmente é apresentado o termograma

Na Figura 12 é possível ver claramente a primeira fase com comportamento constante, segunda de comportamento linear decrescente e a terceira de retomada exponencial e eventual característica constante igualando-se a primeira fase. 


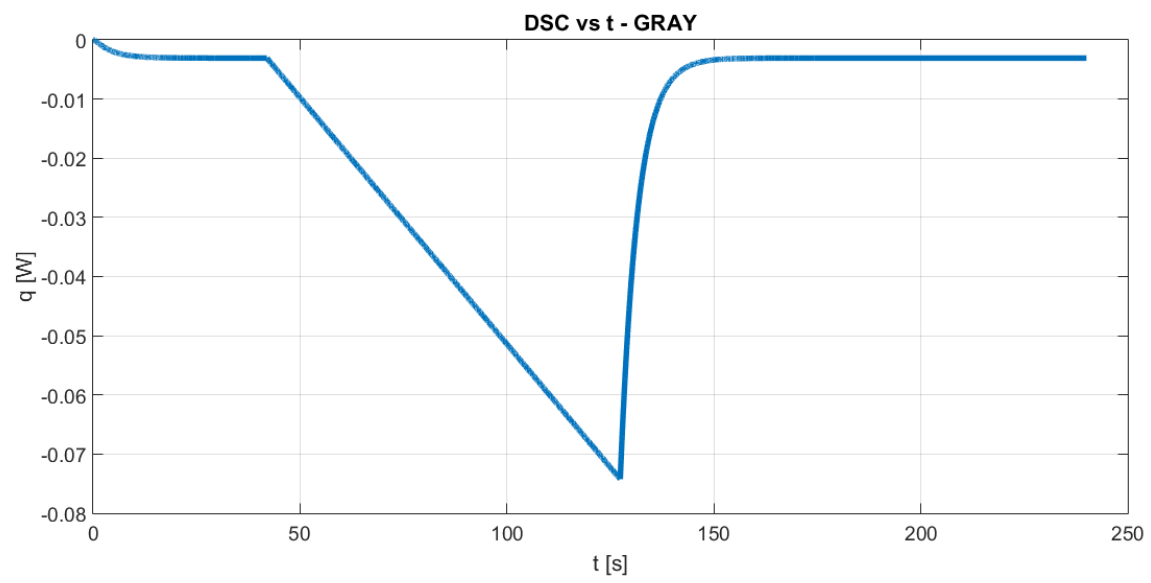

Figura 12 - Termograma simulado para o modelo de A.P. Gray, com Abscissa representando o tempo.

É importante a observação de que para a rotina de cálculo implementada para o modelo de Gray, por se tratar do modelo mais simples, não foi implementada uma forma de diferenciara as capacidades térmicas da fase líquida e sólida. O comportamento seria o mesmo demonstrado porém ele não seguiria as equações determinadas que partem dessa hipótese.

Como este modelo foi montado visando a ampliação do conhecimento do funcionamento do aparelho e como base para modelos futuros, não para o ajuste de parâmetros, essa é uma deficiência aceitável do programa.

O modelo de gradiente de temperatura heterogêneo (HTD) aplicado a geometria cilíndrica aproximada já exige uma maior quantidade de informações a serem fornecidas para a execução dos cálculos, ao mesmo tempo que possibilita o ajuste dos parâmetros próprios do aparelho, ou seja a resistência a troca térmica da célula de referencia $R_{\text {shell }}$ e a capacidade térmica desta mesma célula $C_{r}$

A simulação com os dados apresentados entre a Tabela 1 e Tabela 4 fornecem a Figura 13 


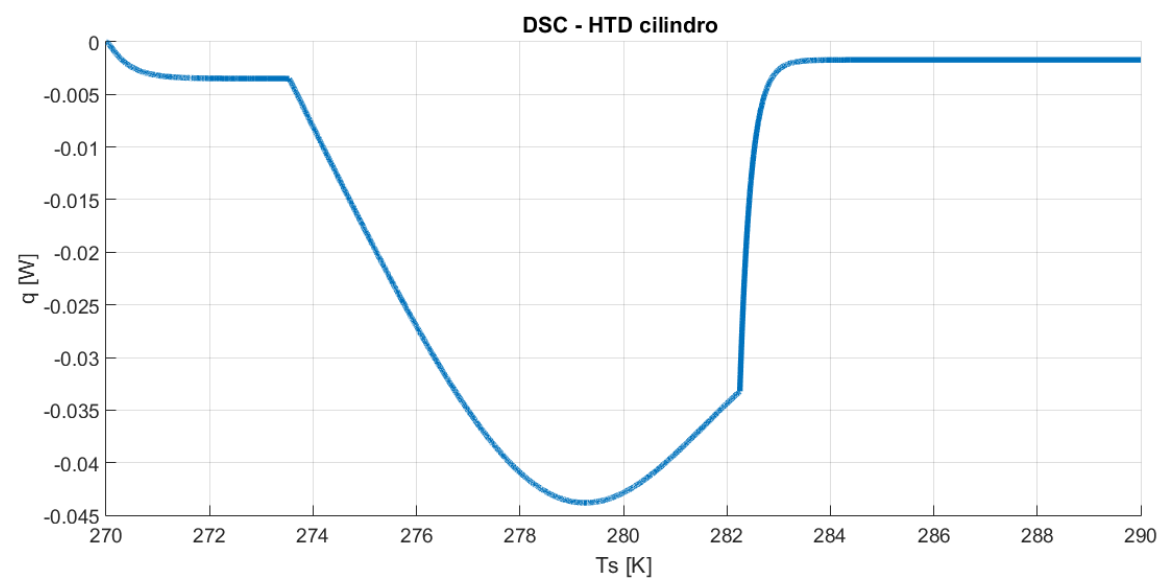

Figura 13 - Termograma simulado para o modelo HTD com geometria cilíndrica aproximada.

Observa-se que próximo ao fim do processo de fusão, no retorno a linha de base há uma mudança brusca no comportamento do sinal. Essa variação brusca se da pela presença de duas dimensões características neste modelo. Um raio , $r$, e uma altura, $h$. O cilindro considerado pela simulação é um objeto tridimensional, cujo volume depende do produto da área gerada pelo raio $r$ multiplicada pela altura $h$. Durante o processo de simulação da fusão ambas essas dimensões estão diminuindo a taxas diferentes, o que leva eventualmente uma delas a se esgotar primeiro, gerando um objeto de duas dimensões, que por definição não apresenta massa.

Para o cálculo de simulação processo de fusão esta encerrado neste ponto, e observa-se um retorno exponencial idêntico ao do modelo ideal de Gray. Esta é uma segunda limitação deste modelo, além da troca de calor que foi aproximada não seguindo as leis de troca térmica rigorosamente, e um dos motivos que motivaram o desenvolvimento do modelo esférico.

Além disso, as variáveis independentes calculadas a cada etapa de cálculo da resolução do sistema de equações diferencias ordinárias são a massa de sólido , $m$, e a temperatura da amostra $T_{s}$, as dimensões do objeto nunca são diretamente calculadas sendo apenas aproximadas por uma correlação matemática aproximada, descrita pela Equação 56, outra limitação que não permite geração adicional de 
conhecimento acerca do processo de fusão

Contudo pode-se verificar que a premissa de um gradiente de temperatura na fase líquida é atingida. Isso fica mais claro ao se observar o perfil de temperaturas ao longo do tempo na Figura 14

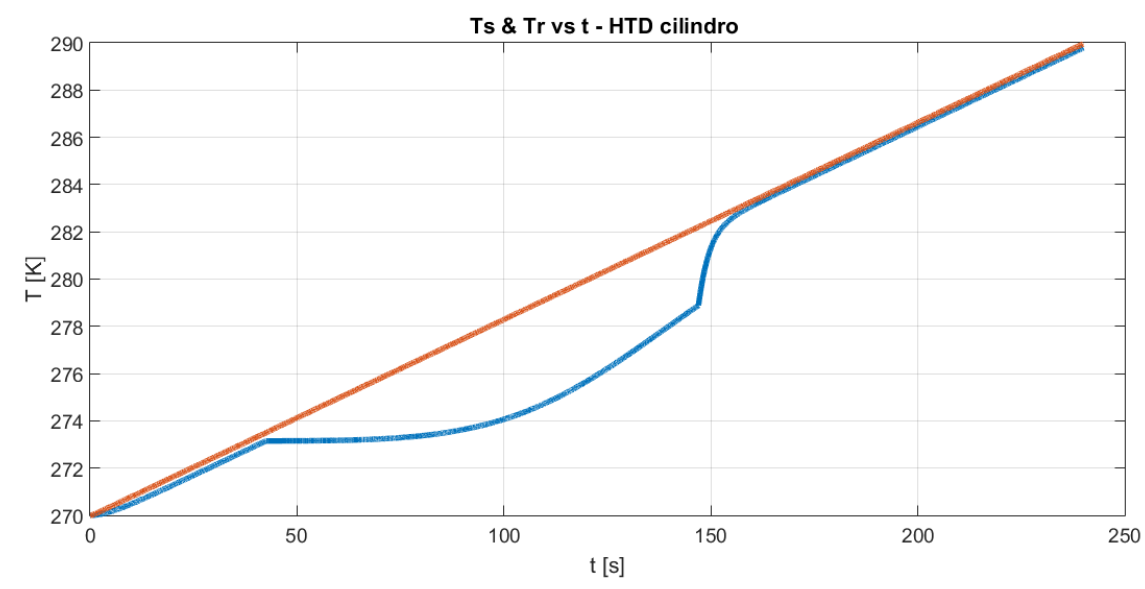

Figura 14 - Perfil de temperatura ao longo do tempo para amostra e refrencia para o modelo HTD-Cilindro.Em azul $T_{s}$. Em laranja $T_{r}$

Por fim os resultados do modelo mais completo, HTD com geometria esférica seguindo as leis de troca térmica rigorosamente mostram grande similaridade com as curvas usuais de um termograma gerado por um DSC, como mostra a Figura 15

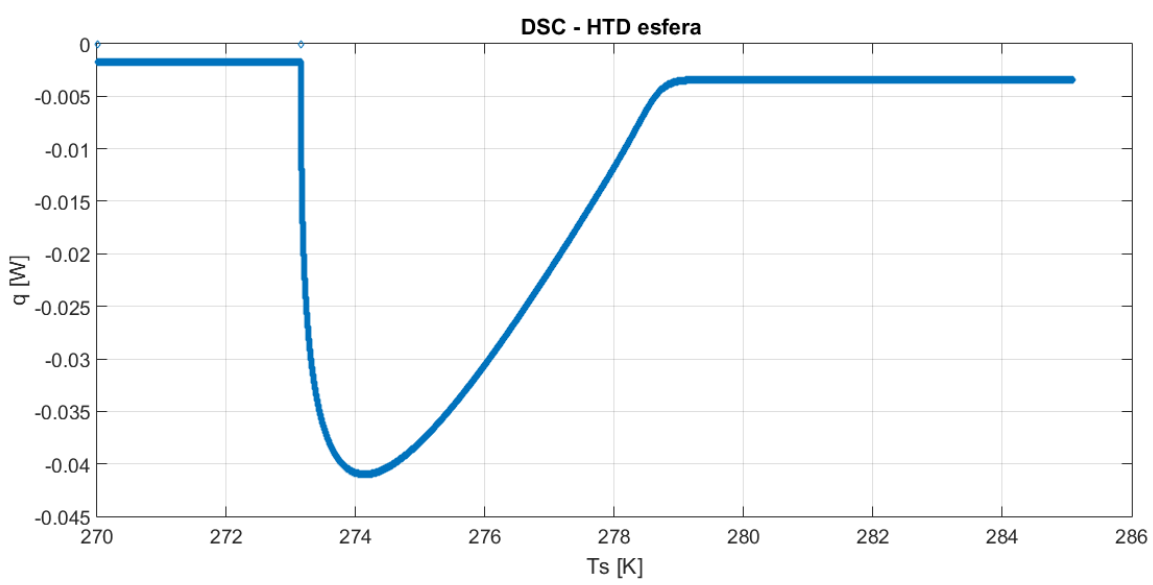

Figura 15 - Termograma simulado para o modelo HTD com geometria esférica 
Não se observa a descontinuidade na curvatura do sinal gerado, sendo o pico gerado contínuo.

Um dos maiores benefícios deste modelo é ele ser calculado em função direta da temperatura e raio como pode ser visto pela Equação 109 e Equação 105.

Esse fato permite que ao se simular o processo de fusão seja possível gerar também um perfil do raio da amostra em fase sólida ao longo do tempo. A Figura 16 mostra a relação do raio de sólido com o raio inicial ao longo do tempo.

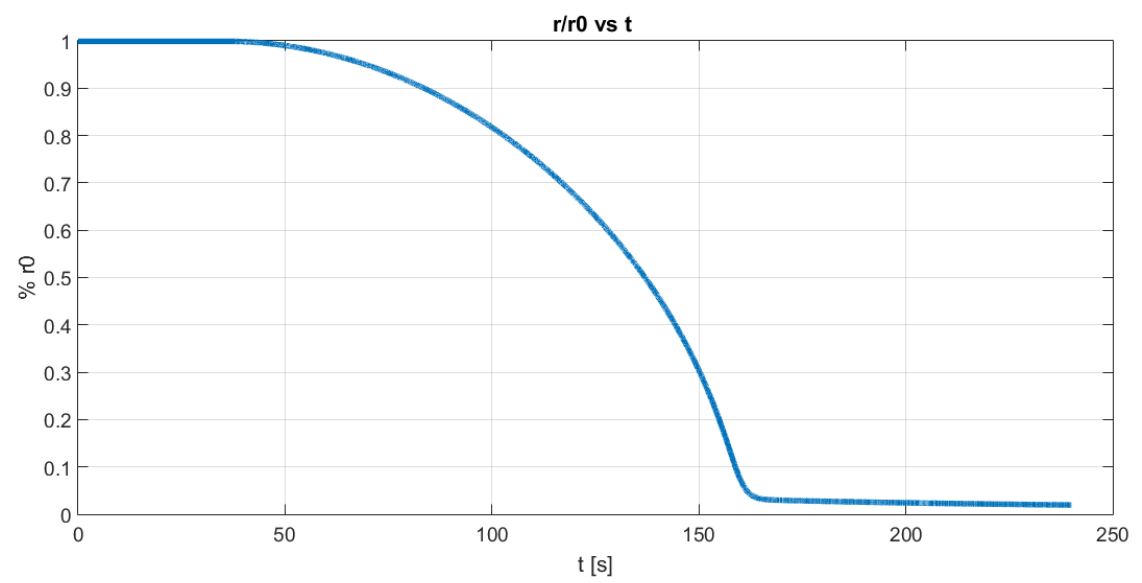

Figura 16 - Perfi do raio de sólido ao longo do tempo simulado com o modelo HTD esférico

Observa-se que o raio não chega a zero nem ao final da varredura, o que se da por se tratarem de dimensões mínimas. o Valor se aproxima o suficiente de 0, podendo-se considerar não haver mais massa sólida no meio. Pode-se verificar essa hipótese ao avaliar o volume de sólido e não seu raio. Essa avaliação pode ser verificada na Figura 17 


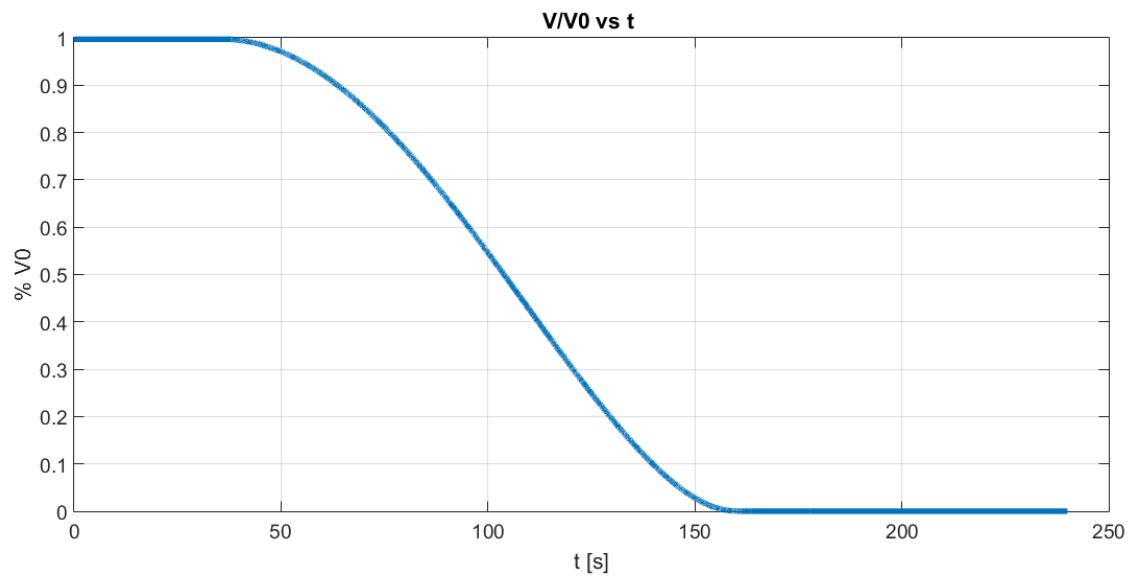

Figura 17 - Perfi do volume de sólido ao longo do tempo simulado com o modelo HTD esférico

Ao se considerar o volume, que é função do cubo do raio, a aproximação a zero se da com muito mais velocidade

Outro benefício de tratar diretamente com as variáveis $r_{s}$ e $T_{s}$ é poder gerar um perfil separado do calor gasto, ou seja, acompanhar ao longo do tempo a Equação 41 termo a termo. Resultado que pode ser observado na Figura 18 


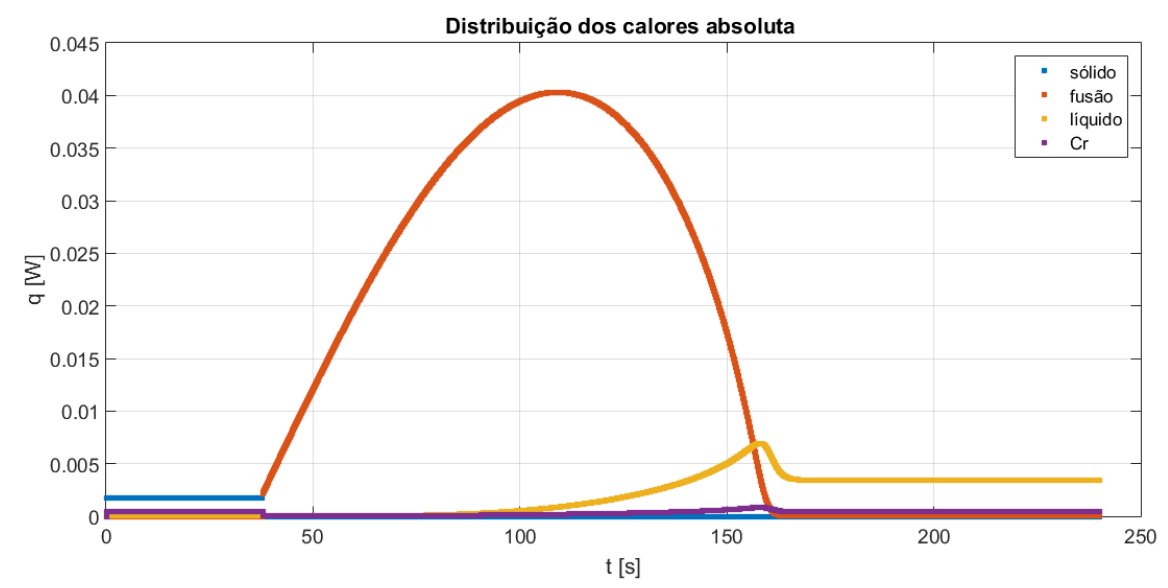

Figura 18 - Perfil alocação de calor gasto ao longo do tempo, para amostra simulada com o modelo HTD esférico. Em azul: calor de aquecimento da fase sólida. Em laranja: calor gasto no processo de fusão. Em amarelo: calor gasto no aquecimento da fase líquida. Em roxo: calor gasto com aquecimento do cadinho de referência

A hipótese de que a maior parte do calor que gera o pico é gasta no processo de fusão pode ser observada neste gráfico ou melhor vista na Figura 19 onde a alocação de calor é disposta como percentagem do calor total. Verifica-se que o modelo desenvolvido esta de acordo com esta hipótese que é utilizada na maior parte dos experimentos que utilizam o DSC para realizar suas investigações e análises 


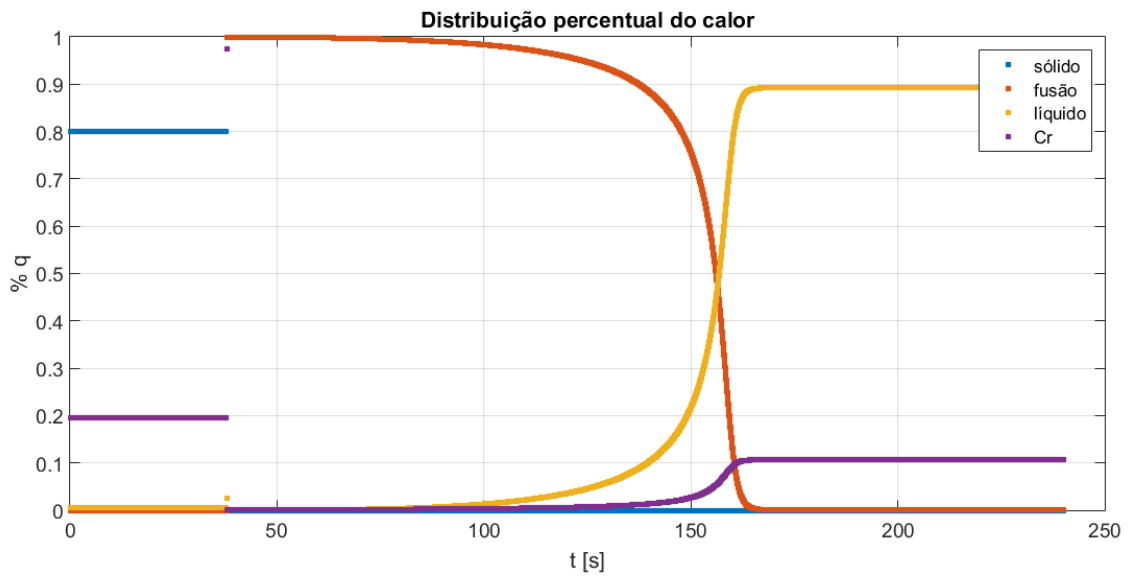

Figura 19 - Perfil percentual da alocação de calor gasto ao longo do tempo, para amostra simulada com o modelo HTD esférico.Em azul: calor de aquecimento da fase sólida. Em laranja: calor gasto no processo de fusão. Em amarelo: calor gasto no aquecimento da fase líquida. Em roxo: calor gasto com aquecimento do cadinho de referência

Por fim pode-se comparar os três modelos concomitantemente, gerando assim a Figura 20

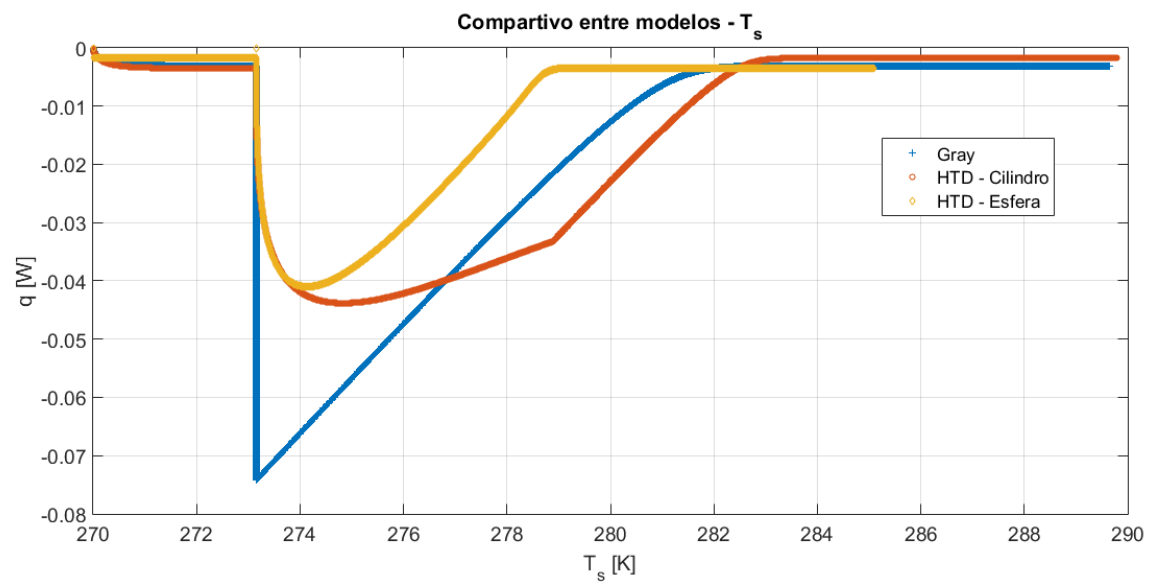

Figura 20 - Comparativo direto dos tres modelos para mesmo dados de entrada. Em azul: modelo de Gray. Em laranja: modelo HTD cilíndrico. Em amarelo modelo HTD esférico. 
Observa-se que todos os termogramas gerados tem comportamento muito similar. Os modelos com gradiente de temperatura não apresentam um máximo de sinal tão elevado quanto o previsto pelo modelo ideal, mas todos preveem um processo de fusão com duração similar, sendo o retorno a linha de base dos três modelos muito próxima.

Um último comparativo que pode-se realizar entre os modelos é a área do termograma, que esta diretamente relacionada a entalpia da transição, a tabela 5 apresenta os resultados obtidos ao se integrar numericamente todos os três termogramas além da área obtida ao se descontar a área gerada pela linha de base.

Tabela 5 - Area soba curva para cada um dos modelos simulados, e resultado subtraido da area da linha de base

\begin{tabular}{|c|c|c|}
\hline Modelo & área da curva[J] & área descontada[J] \\
\hline Gray & $-4,06$ & $-3,32$ \\
\hline Ciindro & $-3,73$ & $-3,00$ \\
\hline Esfera & $-3,82$ & $-3,08$ \\
\hline
\end{tabular}

Os resultados descontados da linha de base se aproximam muito do valor calculado do $\Delta H_{\text {fus }}$ deste processo que é $\lambda * m=-3,35 J$. A pequena discrepância no modelo do gradiente se da pela linha de base que foi considerada como sendo a do líquido, e como neste modelo há consideração dos diferentes valores de $C_{p}$ para fase líquida e sólida a linha de base esta super estimando o calor gasto apenas com o aquecimento da amostra

\subsubsection{Análises de sensibilidade}

Para o ajuste aos dados experimentais fez-se necessário conhecer quais parâmetros influíam mais na forma da curva obtida e de que forma essa influencia se traduzia nos resultados obtidos.

Das variáveis que servem de entrada para o programa aquelas presentes na Tabela 1 são dados termodinâmicos da substancia (exceto a massa $m$, porém esse não será um parêmetro analisado) e não podem ser alterados. 
Da Tabela 2 os limites de varredura e scan rate também são impostos pelo experimento em mãos. Conduto como o scan rate aparece na formulação das equações que são resolvidas e mais de uma taxa de varredura será estudada para a mesma substancia decidiu-se ser interessante verificar seu efeito.

Da Tabela 3 as duas variáveis ali presentes são o alvo do ajuste e saber o seu efeito na curva é primordial.

Sobre a Tabela 4, os parâmetros lá presentes são estudados no sentido da estabilidade da solução, sendo o objetivo encontrar um ponto onde eles não tenham influencia sobre o resultado final já que são variáveis externas ao problema e pertencentes ao método de solução utilizado.

Os resultados para a análise de sensibilidade a taxa de varredura se encontram na Figura 21 e na Figura 22

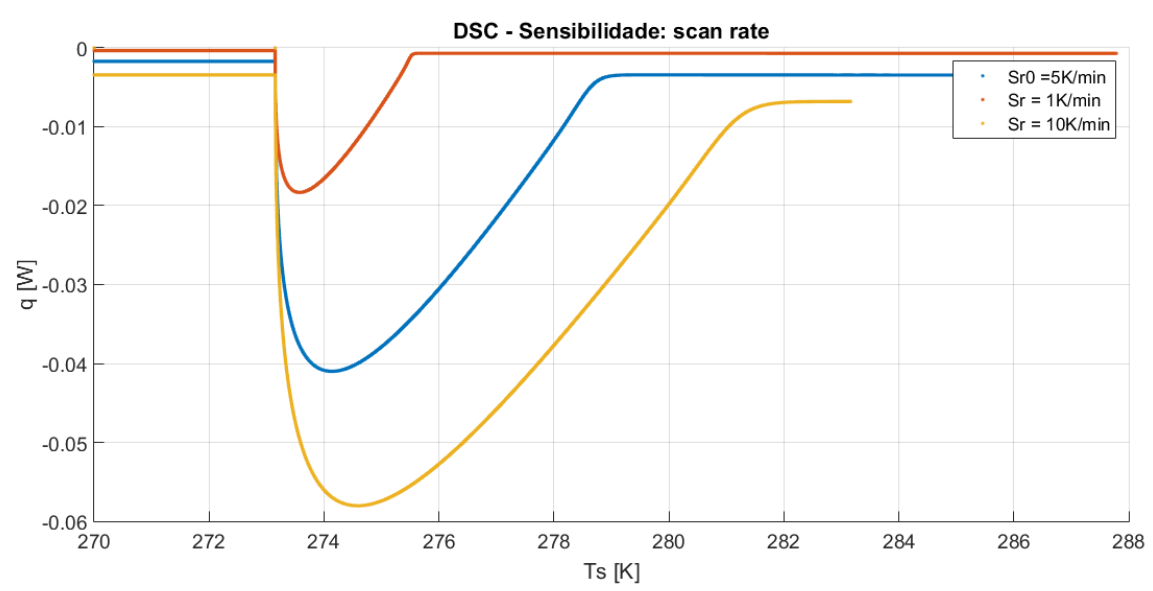

Figura 21 - Análise de sensibilidade da taxa de varredura. Em azul Sr0. Em laranja $S_{r}=1 \frac{K}{\min }$. Em amarelo $S_{r}=10 \frac{K}{\min }$ 


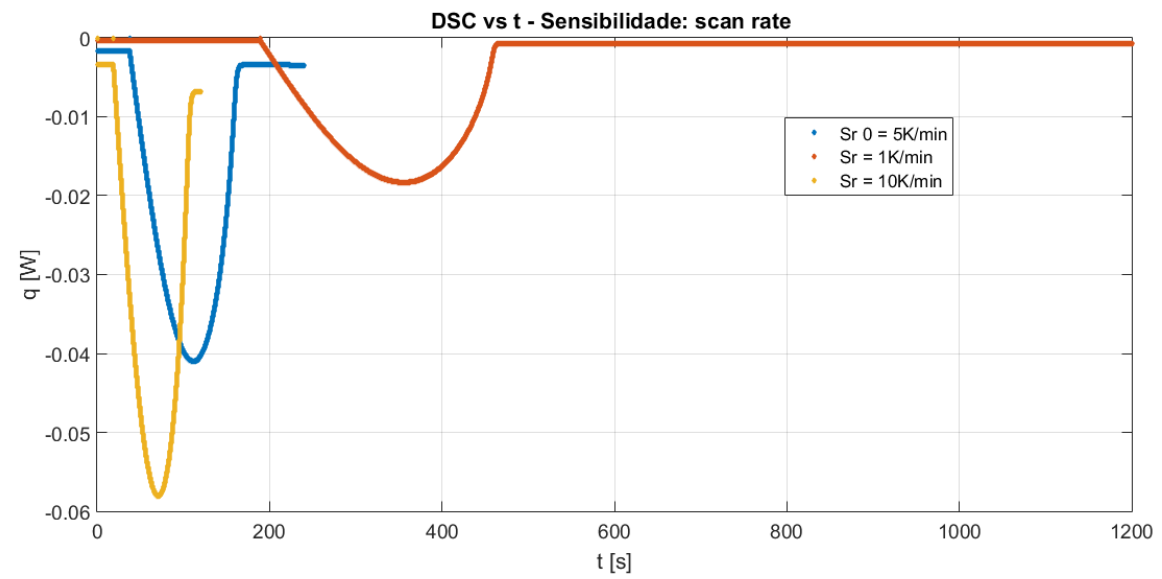

Figura 22 - Análise de sensibilidade da taxa de varredura, Abscissa no tempo.Em azul $S r 0$. Em laranja $S_{r}=1 \frac{K}{\mathrm{~min}}$. Em amarelo $S_{r}=10 \frac{K}{\mathrm{~min}}$

Ao se analisar diferentes taxas de varredura utilizando-se dos eixos normais para o termograma tem-se a impressão de que o sinal fica dilatado no tempo e de que a fusão toma mais tempo nas taxas de varredura maior, e principalmente que a taxa tem uma forte influencia sobre a área da curva, de alguma forma aumentando o calor gasto no processo.

Contudo é importante ressaltar que a área sob a curva que indica o calor gasto na fusão não é a do termograma usual mas sim ao se avaliar o processo no tempo. Uma análise dimensional das variáveis mostra o motivo por trás dessa seleção. A integral de $q[W]$ em $T_{s}[K]$ não gera uma unidade de energia enquanto que $q[W]$ em $t[s] \operatorname{sim}$.

Na Figura 22 nota-se que o aumento da taxa de varredura resulta em um pico de sinal mais intenso e menor duração do processo como todo.

A mera comparação visual das curvas não é suficiente, logo foi calculada a área sob as curvas para quantificar os efeitos ao alterar as variáveis alvo. Os resultados referentes a mudança em $S_{r}$ pode ser visto na Tabela 6 
Tabela 6 - Área sob a curva , em $[\mathrm{J}]$, para análise de sensibilidade da taxa de varredura

\begin{tabular}{|c|c|c|}
\hline$S r_{0}$ & $0,2 * S r_{0}$ & $10 * S r_{0}$ \\
\hline-3.82 & -3.97 & $-3,71$ \\
\hline
\end{tabular}

Observa-se um leve desvio na área total sob a curva, porém este pode ser justificado pela maior permanência dentro dos períodos onde não ocorre fusão para as taxas mais baixas. O desvio não é considerável sendo as áreas virtualmente iguais.

Os efeitos da variação de $R_{\text {shell }}$ podem ser observados na Figura 23 e na Tabela 7

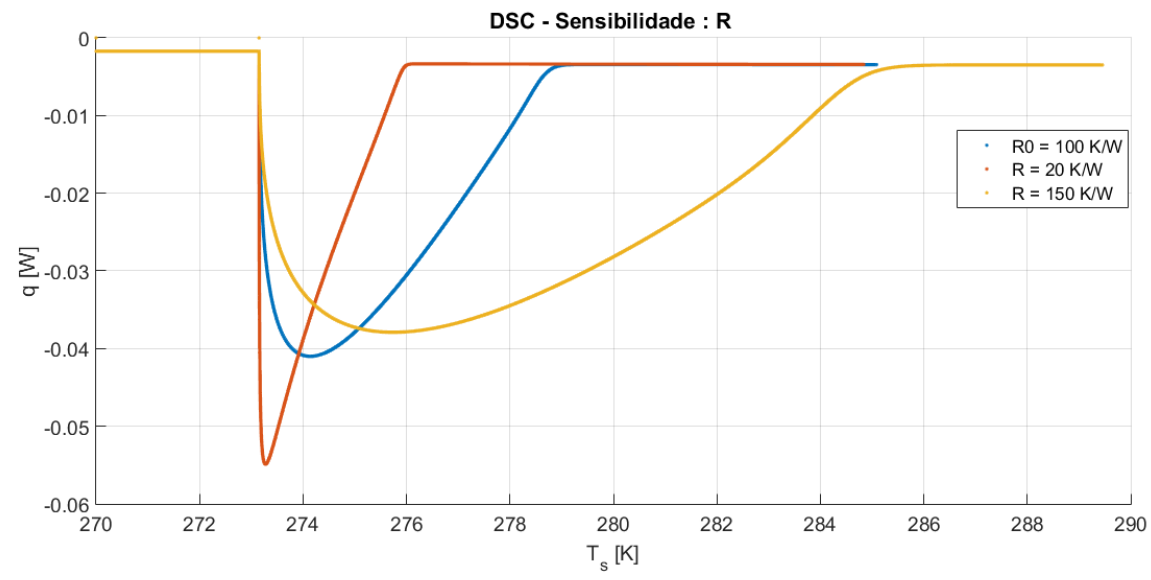

Figura 23 - Análise de sensibilidade da resistência a troca térmica da célula de referência.Em azul $R_{0}$. Em laranja $R=20 \frac{K}{W}$ em amarelo $R=150 \frac{K}{W}$

Tabela 7 - Área sob a curva, em [J], para análise de sensibilidade da resistência a troca térmica da célula de referência

\begin{tabular}{|c|c|c|}
\hline$R_{0}$ & $0,2 * R_{0}$ & $1,5 * R_{0}$ \\
\hline-3.82 & -3.83 & $-3,98$ \\
\hline
\end{tabular}


O efeito da variação da resistência a troca térmica da referência não é tão previsível quanto o de outras variáveis analisadas, no caso da água percebe-se a possível existência de um mínimo local.

Ademais valores muito elevados de $R_{\text {shell }}$ produzem resultados instáveis na simulação, ou que requerem muito mais tempo do que seria razoável para o término do processo de fusão.

A conclusão dessa análise inicial de sensibilidade é a de que essa variável tem de ser tratada caso a caso para cada problema de ajuste apresentado.

A variação da capacidade térmica da referência gerou os resultados apresentados pela Figura 24 e Tabela 8

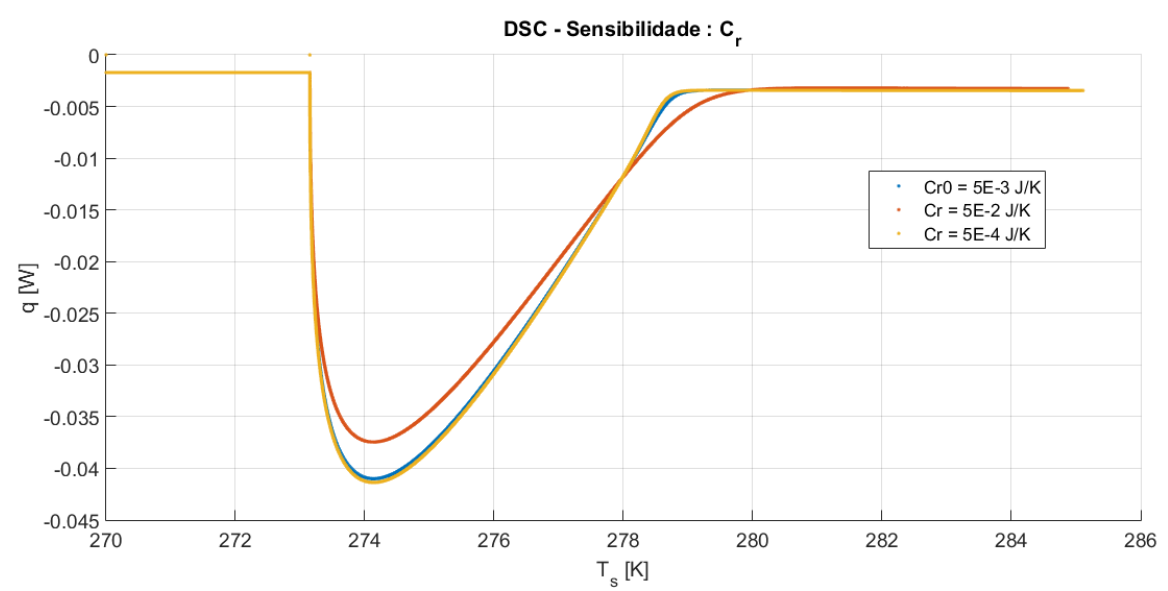

Figura 24 - Análise de sensibilidade da capacidade térmica da célula de referência.Em azul $C_{r, 0}$. Em laranja $C_{r}=5 E-2 \frac{J}{K}$. Em amarelo $C_{r}=5 E-4 \frac{J}{K}$.

Tabela 8 - Área sob a curva, em [J], para análise de sensibilidade da capacidade térmica da célula de referência.

\begin{tabular}{|c|c|c|}
\hline$C_{r}$ & $10 * C_{r}$ & $0,1 * C_{r}$ \\
\hline-3.82 & -3.56 & $-3,84$ \\
\hline
\end{tabular}

A capacidade térmica da referência idealmente não deve influenciar nos resultados obtidos. Dos resultados obtidos apreende-se que é necessária uma grande 
mudança nos valores de $C_{r}$ para influenciar significativamente os valores da área sob a curva, e essa influencia só se nota no sentido do aumento dessa variável.

O calorímetro ideal não tem influencia sob a amostra contida, logo os valores de $C_{r}$ devem ser baixos em relação a $C_{s}$. Nessa faixa observa-se uma influencia negligenciável desta variável sob a o termograma

Por fim restam as análises de estabilidade do método numérico. O objetivo é encontrar um equilíbrio entre valores que geram resultados que não alteram a forma e área da curva ao mesmo tempo em que não exigem mais tempo de computação. Ou seja o mínimo valor para o qual a mudança no termograma é desprezível

Par o o tamanho de passo obteve-se os seguintes dados, apresentados na Figura 25 e Tabela 9

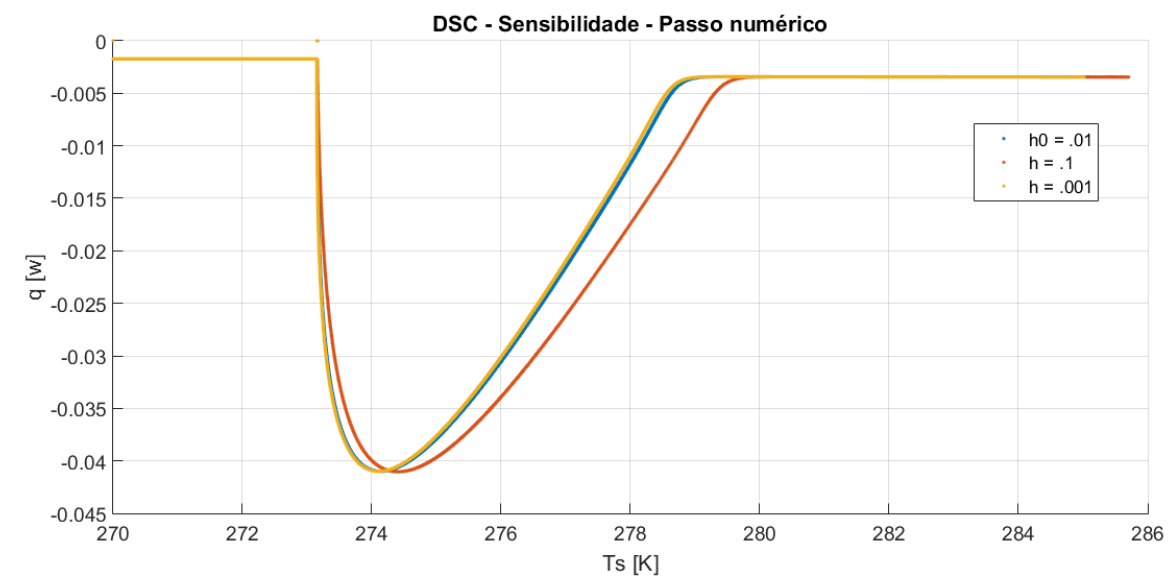

Figura 25 - Análise de sensibilidade do passo do método numérico.Em azul $h_{0}$. Em laranja $h=0,1 \mathrm{~s}$. Em amarelo $h=0,001 \mathrm{~s}$

Tabela 9 - Área sob a curva,em [J] para análise de sensibilidade do passo do método numérico.

\begin{tabular}{|c|c|c|}
\hline$h+0$ & $10 * h_{0}$ & $0,1 * h_{0}$ \\
\hline-3.821 & -3.835 & $-3,818$ \\
\hline
\end{tabular}

No que se refere a área sob a curva observa-se um desvio muito pequeno ao 
Tabela 10 - Área sob a curva, em [J], para análise de sensibilidade da porcentagem de faísca.

\begin{tabular}{|c|c|c|}
\hline$f=0,999$ & $f=0,99$ & $f=0,9999$ \\
\hline-3.82 & -3.74 & $-3,83$ \\
\hline
\end{tabular}

alterar-se o tamanho de passo. Nesse caso a análise visual da curva é relevante pois revela que a partir de um tamanho de passo de 0,01 a curva gerado é praticamente a mesma. Dessa forma este foi o tamanho de passo adotado.

A variável $f$, percentagem de faísca surge da necessidade de iniciar a força o processo d efusão e diminuição do raio de matéria sólida, pois a derivada do raio de sólido depende da da diferença entre o raio atual e o raio inicial de sólido. Quando estes dois valores são iguais essa derivada tem valor 0 e o sistema permanece em equilíbrio. è necessário a introdução de uma pequena perturbação para se iniciar o processo. Um valor demasiado grande ignora parte do calor que deve ser fornecido, um valor muito pequeno torna a rotina de cálculo instável. O objetivo da análise novamente se faz encontrar um valor que gere curvas estáveis e que não comprometa a qualidade dos dados gerados. O resultado desta análise é observado na Figura 26 e Tabela 10

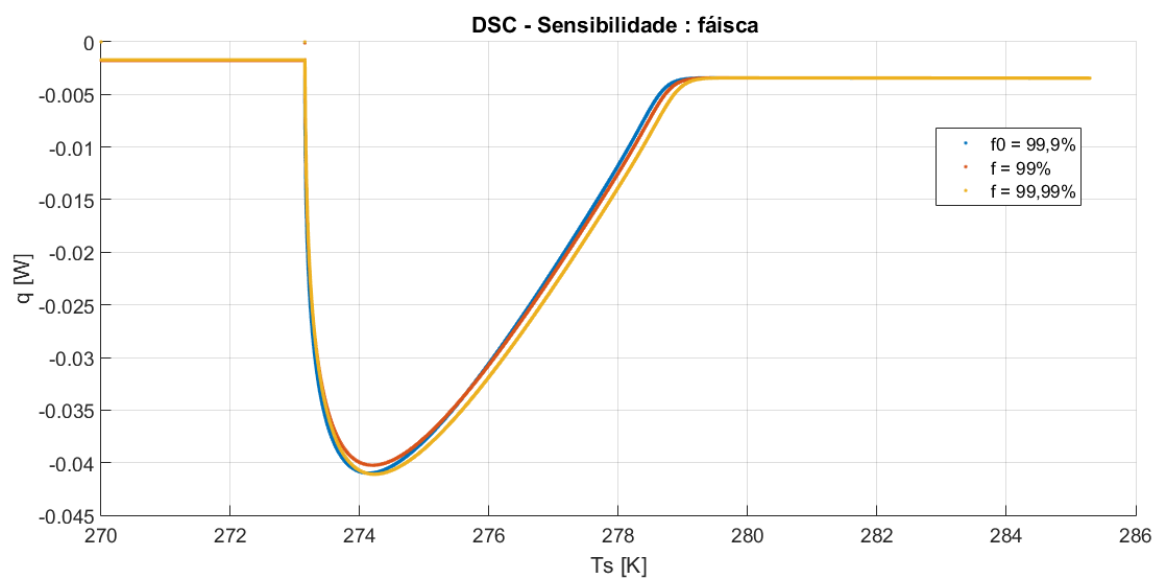

Figura 26 - Análise de sensibilidade da porcentagem de faísca. Em azul $f_{0}$. Em laranja $f=0,99$. Em amarelo $f=0,9999$ 
Observa-se que a partir de valores de 99,9\% os valores e forma da curva convergem. De forma que este passou a ser o valor adotado em todos os cálculos posteriores.

\subsection{Resultados quantitativos}

O principal objetivo desta seção é a validação do modelo de simulação desenvolvido ao se ajustar as curvas simuladas a curvas experimentais obtidas em laboratório

As curvas experimentais pertencem todas a ésteres etílicos de ácidos graxos pesados. Sendo um total de 4 diferentes substancias: laurato de etila, miristato de etila ,oleato de etila palmitato de etila. As formulas e massas molares dos compostos são apresentadas na Tabela 11

Tabela 11 - Fórmula e massa molar dos compostos estudados

\begin{tabular}{|l|c|c|}
\hline Composto & Fórmula & MM $\left[\frac{\mathrm{kg}}{\mathrm{kmol}}\right]$ \\
\hline Laurato de etila & $\mathrm{C}_{14} \mathrm{H}_{28} \mathrm{O}_{2}$ & 228 \\
\hline Miristato de etila & $\mathrm{C}_{16} \mathrm{H}_{32} \mathrm{O}_{2}$ & 256 \\
\hline Oleato de etila & $\mathrm{C}_{20} \mathrm{H}_{28} \mathrm{O}_{2}$ & 310 \\
\hline Palmitato de etila & $\mathrm{C}_{18} \mathrm{H}_{36} \mathrm{O}_{2}$ & 284 \\
\hline
\end{tabular}

Com exceção do oleato de etila que apresenta uma instauração no meio de sua cadeia carbônica os demais compostos são de cadeia saturada, apresentando uma longa cauda apolar e um pequeno grupo etila junto a carboxila.

Para o processo de simulação de cada espécie procurou-se os dados termodinâmicos relevantes de cada substancia. Em relação as propriedades de varredura, ou seja temperaturas inicias e finais, além da taxa de varredura, essas variáveis eram conhecidas, e foram utilizadas em cada caso específico como fornecidas para cada experimento.

O ajuste da curva mostrou-se principalmente da resistência a troca térmica $R_{\text {shell }}$. A capacidade térmica da referência, $C_{r}$, seria um outro parâmetro possível 
de ser ajustado, porém ele mostrou não ter tanto impacto. Dessa forma para toas as análises feitas ele foi estabelecido como um valor que fosse menor do que $10 \%$ do valor de $C_{s}$

Os dados de massa, $m$, foram retirados dos dados experimentais. A densidade,$\rho$, e temperatura de fusão,$T_{\text {fus }}$ na plataforma NIST. A condutividade térmica ,$k$, foi aproximada em $0,15 \frac{\mathrm{W}}{\mathrm{mK}}$ seguindo recomendação de [33] para condutividade de ésteres de ácidos graxos. O calor de fusão , $\lambda$, foi obtido de [29]. Os dados de calor específico foram aproximados com base nos dados experimentais.

Os dados experimentais foram todos levantados por Larissa Castello Branco Bessa(informação pessoal) ${ }^{1}$, que gentilmente os cedeu para realização deste trabalho. Estes dados forma utilizados na composição de [29]. Os dados consistem em dados do aparelho DSC para as quatro substancias, em taxas de varredura variando de $0,5 \frac{K}{\min }$ a $2,5 \frac{K}{\min }$ em incrementos de $0,5 \frac{K}{\min } .1$.

O processo de ajuste é apresentado a seguir, com os resultados consolidados sendo apresentados posteriormente.

\subsubsection{Ajuste de dados experimentais}

Observou-se na seção que o parâmetro livre mais relevante para o ajuste das curvas é a resistência a troca térmica do cadinho que contém a amostra. Dessa forma foram construídas curvas para um intervalo de valores dessa variável.

É importante notar que ao se reduzir arbitrariamente o valor de $R$ a curva se aproxima cada vez mais do modelo de Gray, dessa forma decidiu-se um valor mínimo para essa variável.

Como não se encontrou valores para essa propriedade na literatura, o valor foi estimado usando se a Equação 81, que segue válida neste caso, com os dados termodinâmicos para metais usualmente usados na fabricação de tais componentes.

Dessa forma decidiu-se que o valor mínimo de $\mathrm{R}$ a ser adotado seria de $60 \frac{K}{W}$. Como um valor máximo foi escolhido o valor de $300 \frac{W}{K} .5$ simulações são

$1{ }^{1}$ Pessoa Filho, P. de A. Informações da Larissa Destinatário: Rui Lopes Gonçalves. [São Paulo], 2 de maio. 2019. 1 mensagem eletrônica 
apresentadas realizadas com um intervalo de $40 \frac{K}{W}$ entre cada ponto. O conjunto escolhido é aquele que se aproximou mais do resultado consolidado.

Para o ajuste obteve-se três medidas diferentes com as quais é possível fazer uma avaliação que vai além da visual, dessa forma gerando alguma forma de quantificação do ajuste. Essas grandezas são: A área da curva gerada, em $J$; o valor mínimo atingido pelo pico, em $W$ e a largura do pico gerado, definido nesse caso por sua duração em $s$.

Os ajustes foram realizados em todo o conjunto de curvas disponível, prezando pelo melhor ajuste na família de curvas com diferentes taxas de varredura. No intuito da clareza e de se evitar a repetição desnecessária somente serão expostos os gráficos na taxa de $1,5 \frac{K}{\min }$ contudo todas as taxas de varredura são consideradas, esse fato pode ser verificado nas tabelas que apresentam os dados consolidados após o ajuste nas seções seguintes.

As tabelas completas de ajuste de dados podem ser consultadas no Anexo C

\subsubsection{Laurato de Etila}

A Tabela 12 apresenta os dados termodinâmicos levantados para a substância laurato de etila

Tabela 12 - Propriedades termodinâmicas do laurato de etila. Dados da literatura

\begin{tabular}{|c|c|c|c|c|c|c|}
\hline $\begin{array}{c}m \\
{[k g]}\end{array}$ & $\begin{array}{c}\rho \\
{\left[\frac{\mathrm{kg}}{\mathrm{m}^{3}}\right]}\end{array}$ & $\begin{array}{c}c_{p, s} \\
{\left[\frac{\mathrm{J}}{\mathrm{kgK}}\right]}\end{array}$ & $\begin{array}{c}c_{p, l} \\
{\left[\frac{J}{\mathrm{kgK}}\right]}\end{array}$ & $\begin{array}{c}\lambda \\
{\left[\frac{J}{\mathrm{~kg}}\right]}\end{array}$ & $\begin{array}{c}k \\
{\left[\frac{W}{m K}\right]}\end{array}$ & $\begin{array}{c}T_{\text {fus }} \\
{[K]}\end{array}$ \\
\hline $3,5 * 10^{-6}$ & 858 & 2056 & 2056 & 167578 & 0,15 & 271 \\
\hline
\end{tabular}

Os dados fornecidos para a rotina de simulação são apresentados na Tabela 13 
Tabela 13 - Dados gerais de entrada do programa de simulação para o laurato de etila

\begin{tabular}{|c|c|c|}
\hline$\rho$ & {$\left[\frac{\mathrm{kg}}{\mathrm{m}^{3}}\right]$} & 858 \\
\hline$m$ & {$\left[\frac{\mathrm{kg}}{}\right]$} & $3,5 \times 10^{-6}$ \\
\hline$k$ & {$\left[\frac{\mathrm{W}}{\mathrm{mK}}\right]$} & 0,15 \\
\hline$c_{p, s}$ & {$\left[\frac{\mathrm{J}}{\mathrm{kgK}}\right]$} & 2056 \\
\hline$c_{p, l}$ & {$\left[\frac{\mathrm{J}}{\mathrm{kgK}}\right]$} & 2056 \\
\hline$\lambda$ & {$\left[\frac{\mathrm{J}}{\mathrm{kg}}\right]$} & 167578 \\
\hline$T_{\text {fus }}$ & {$\left[\frac{K}{2}\right]$} & 271 \\
\hline$C_{r}$ & {$\left[\frac{\mathrm{J}}{K}\right]$} & $7 \times 10^{-4}$ \\
\hline$T_{\text {inicial }}$ & {$[K]$} & 268 \\
\hline$T_{\text {final }}$ & {$[K]$} & 277 \\
\hline$S_{r}$ & {$\left[\frac{\mathrm{K}}{\mathrm{min}}\right]$} & 1,5 \\
\hline$h$ & {$[\mathrm{~s}]$} & 0,01 \\
\hline$f$ & {$\left[\frac{\mathrm{kg}}{\mathrm{kg}}\right]$} & 0,999 \\
\hline
\end{tabular}

O resultado dessas simulações pode ser visto na sequencia da Figura 27, Figura 28 e Figura 29 


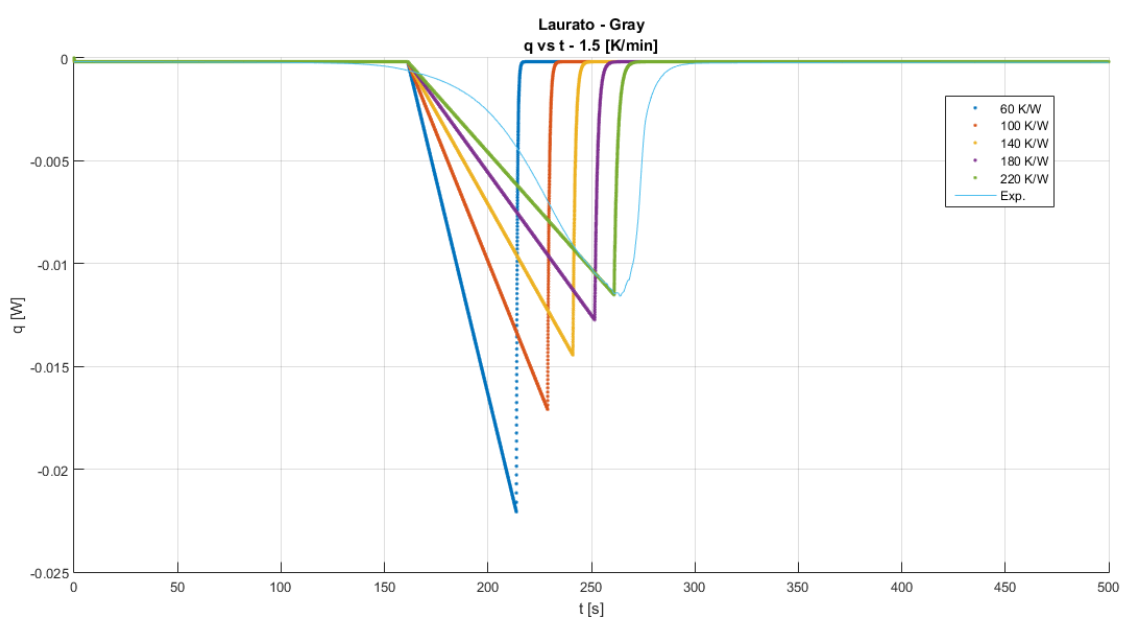

Figura 27 - Termograma simulado para o ajuste de dados para laurato de etila.Modelo de Gray Abscissa em $t$. Valores de $\mathrm{R}$ variando entre $60 \frac{K}{W}$ e $220 \frac{K}{W}$ segundo legenda. Em azul claro e linha continua a curva experimental

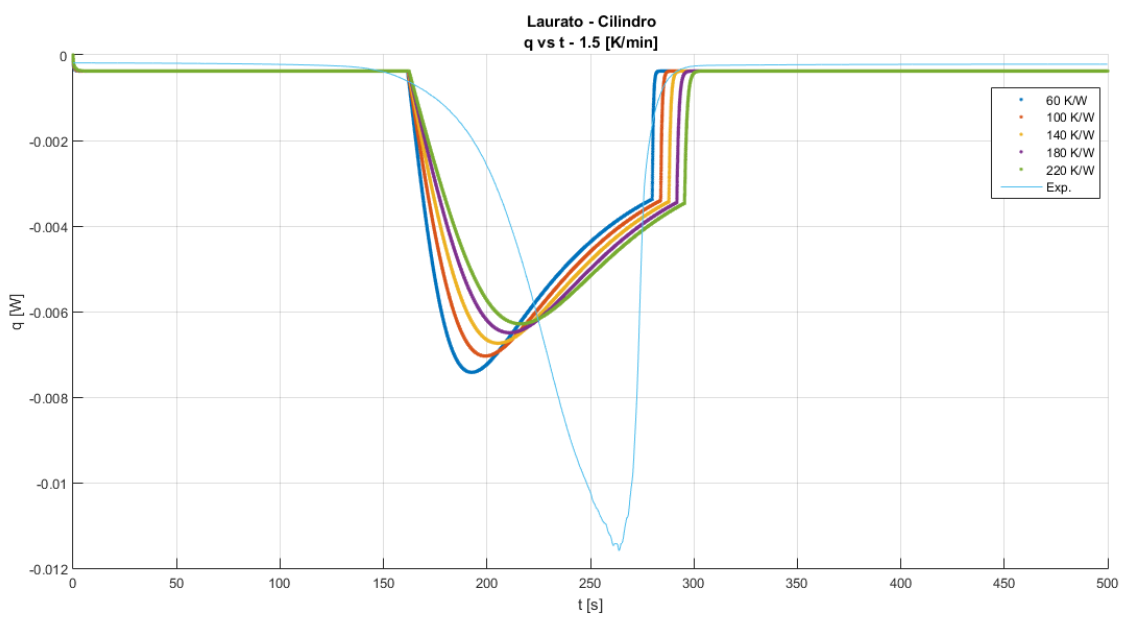

Figura 28 - Termograma simulado para o ajuste de dados para laurato de etila. Modelo HTD com geometria cilíndrica. Abscissa em $t$. Valores de R variando entre $60 \frac{K}{W}$ e $220 \frac{K}{W}$ segundo legenda. Em azul claro e linha continua a curva experimental 


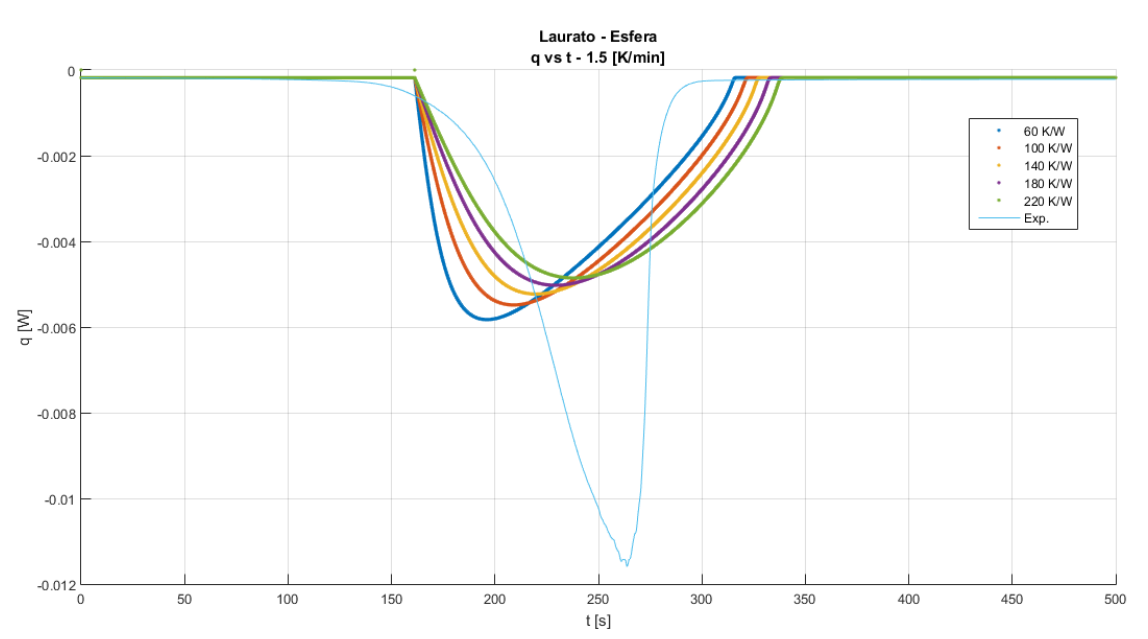

Figura 29 - Termograma simulado para o ajuste de dados para laurato de etila. Modelo HTD com geometria esférica. Abscissa em $t$. Valores de R variando entre $60 \frac{K}{W}$ e $220 \frac{K}{W}$ segundo legenda. Em azul claro e linha continua a curva experimental

As tabelas Tabela 14, Tabela 15 e Tabela 16 mostram os valores calculados para as três variáveis de ajuste, ou seja a área sobre a curva, A, em $J$, o valor do pico, $p_{\text {max }}$ em $W$ e o largura do pico, $l$ em $s$, para os modelos de Gray, HTD-Cilíndrico e HTD esférico respetivamente.

Tabela 14 - Dados comparativos para o ajuste do parâmetro R para o laurato de etila.Modelo de Gray. A última linha apresenta os parâmetros medidos para os dados experimentais disponíveis

\begin{tabular}{|c|c|c|c|}
\hline $\mathrm{R}\left[\frac{K}{W}\right]$ & $\mathrm{A}[J]$ & $p_{\max }[W]$ & $l[s]$ \\
\hline 60 & $-0,6750$ & $-0,0221$ & 52,54 \\
\hline 100 & $-0,6748$ & $-0,0171$ & 67,64 \\
\hline 140 & $-0,6748$ & $-0,0144$ & 79,86 \\
\hline 180 & $-0,6748$ & $-0,0127$ & 90,39 \\
\hline 220 & $-0,6747$ & $-0,0115$ & 99,76 \\
\hline exp. & $-0,7341$ & $-0,0116$ & 137,00 \\
\hline
\end{tabular}


Tabela 15 - Dados comparativos para o ajuste do parâmetro R para o laurato de etila. Modelo de HTD - Cilindro. A última linha apresenta os parâmetros medidos para os dados experimentais disponíveis

\begin{tabular}{|c|c|c|c|}
\hline $\mathrm{R}\left[\frac{K}{W}\right]$ & $\mathrm{A}[J]$ & $p_{\max }[W]$ & $l[s]$ \\
\hline 60 & $-0,7591$ & $-0,0074$ & 118,22 \\
\hline 100 & $-0,7588$ & $-0,0067$ & 125,96 \\
\hline 140 & $-0,7586$ & $-0,0063$ & 133,20 \\
\hline 180 & $-0,7584$ & $-0,0059$ & 140,02 \\
\hline 220 & $-0,7582$ & $-0,0057$ & 146,48 \\
\hline exp. & $-0,7341$ & $-0,0116$ & 137,00 \\
\hline
\end{tabular}

Tabela 16 - Dados comparativos para o ajuste do parâmetro R para o laurato de etila.Modelo HTD - Esfera . A última linha apresenta os parâmetros medidos para os dados experimentais disponíveis

\begin{tabular}{|c|c|c|c|}
\hline $\mathrm{R}\left[\frac{K}{W}\right]$ & $\mathrm{A}[J]$ & $p_{\max }[W]$ & $l[s]$ \\
\hline 60 & $-0,6509$ & $-0,0058$ & 155,17 \\
\hline 100 & $-0,6500$ & $-0,0055$ & 160,98 \\
\hline 140 & $-0,6493$ & $-0,0052$ & 166,60 \\
\hline 180 & $-0,6486$ & $-0,0050$ & 172,06 \\
\hline 220 & $-0,6481$ & $-0,0049$ & 177,37 \\
\hline exp. & $-0,7341$ & $-0,0116$ & 137,00 \\
\hline
\end{tabular}

Para o modelo de Gray observa-se uma maior concordância entre os dados ajustados e os valores experimentas em valores mais altos de $\mathrm{R}$, sendo o valor máximo quase igualado para $220 \frac{K}{W}$. Contudo o melhor ajuste para a área do pico encontra-se com tendência oposta, ou seja um melhor ajuste para os menores valores de $\mathrm{R}$.

O ajuste para o modelo mostra uma tendência inversa, em que há melhor concordância do valor de máximo e duração do pico em valores menores de $\mathrm{R}$ e um melhor ajuste das áreas nos valores maiores.

O modelo esférico não apresenta boa concordância dos dados experimentais, e apresenta tendência monotônica de melhor ajuste para valores menores da resistência 
térmica.

O ajuste de dados tem como objetivo inferir qual o valor da resistência térmica presente no experimento realizado. Nenhum dos três modelos apresentou uma aderência em que possa se concluir com certeza absoluta um valor para tal grandeza. O valor que parece mostrar o melhor compromisso entre os modelos analisados em relação ao 3 parâmetros é o de $\mathrm{R}=100 \frac{K}{W}$. A Figura 30 apresenta os 3 modelos com este valor de $\mathrm{R}$ comparados aos dados experimentais.

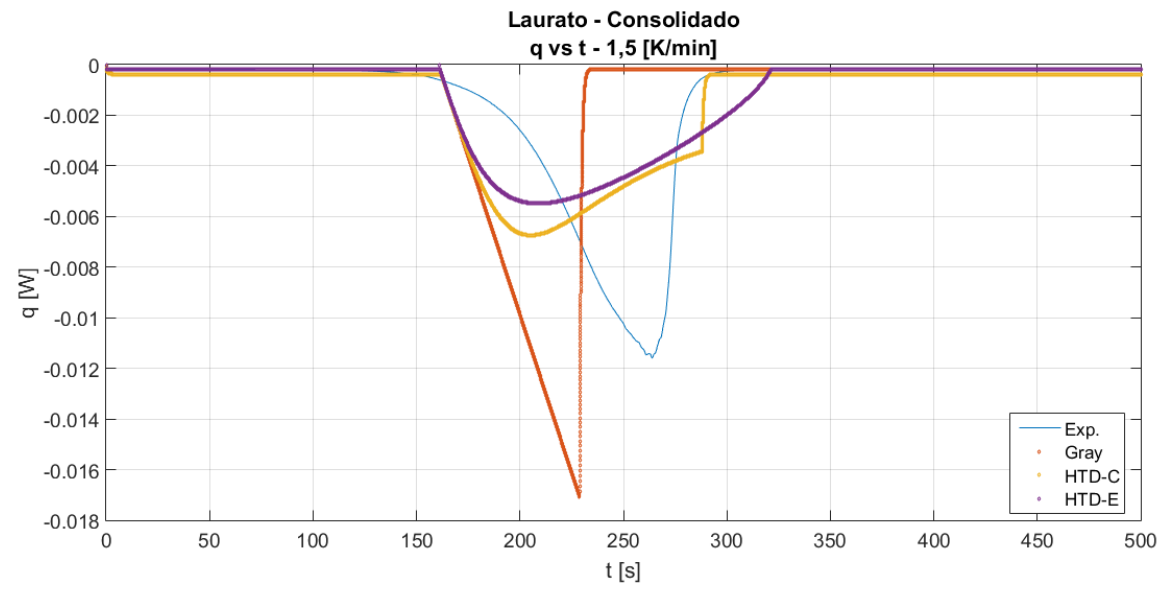

Figura 30 - Termograma simulado para os 3 modelos com o valor de $R=100 \frac{K}{W}$ para a substancia laurato de etila

É importante notar que o próprio parâmetro $\mathrm{R}$ tem influencias da geometria adotada em seu cálculo e na sua grandeza, ou seja não há necessariamente um valor único para todos os modelos. No entanto o objetivo do ajuste não é o de definir uma geometria e sim uma ordem de grandeza da resistência térmica, dessa forma opta-se por escolher um valor de melhor ajuste

\subsubsection{Miristato de Etila}

A Tabela 17 apresenta os dados termodinâmicos levantados para a substância miristato de etila

Os dados fornecidos para a rotina de simulação são apresentados na Tabela 18 
Tabela 17 - Propriedades termodinâmicas do miristato de etila.Dados da literatura

\begin{tabular}{|c|c|c|c|c|c|c|}
\hline $\begin{array}{c}m \\
{[k g]}\end{array}$ & $\left.\begin{array}{c}\rho \\
{\left[\frac{k g}{m^{3}}\right.}\end{array}\right]$ & $\begin{array}{c}c_{p, s} \\
{\left[\frac{J}{k g K}\right]}\end{array}$ & $\begin{array}{c}c_{p, l} \\
{\left[\frac{J}{k g K}\right]}\end{array}$ & $\begin{array}{c}\lambda \\
{\left[\frac{J}{k g}\right]}\end{array}$ & $\begin{array}{c}k \\
{\left[\frac{W}{m K}\right]}\end{array}$ & $\begin{array}{c}T_{\text {fus }} \\
{[K]}\end{array}$ \\
\hline $3 \times 10^{-6}$ & 862 & 2025 & 2165 & 176076 & 0,15 & 284 \\
\hline
\end{tabular}

Tabela 18 - Dados gerais de entrada do programa de simulação para o miristato de etila

\begin{tabular}{|c|c|c|}
\hline$\rho$ & {$\left[\frac{\mathrm{kg}}{\mathrm{m}^{3}}\right]$} & 862 \\
\hline$m$ & {$[\mathrm{~kg}]$} & $3 \times 10^{-6}$ \\
\hline$k$ & {$\left[\frac{\mathrm{W}}{\mathrm{mK}}\right]$} & 0,15 \\
\hline$c_{p, s}$ & {$\left[\frac{\mathrm{J}}{\mathrm{kgK}}\right]$} & 2025 \\
\hline$c_{p, l}$ & {$\left[\frac{\mathrm{J}}{\mathrm{kgK}}\right]$} & 2165 \\
\hline$\lambda$ & {$\left[\frac{\mathrm{J}}{\mathrm{kg}}\right]$} & 176076 \\
\hline$T_{\text {fus }}$ & {$[K]$} & 283 \\
\hline$C_{r}$ & {$\left[\frac{\mathrm{J}}{\mathrm{K}}\right]$} & $6 \times 10^{-3}$ \\
\hline$T_{\text {inicial }}$ & {$[\mathrm{K}]$} & 280 \\
\hline$T_{\text {final }}$ & {$[\mathrm{K}]$} & 289 \\
\hline$S_{r}$ & {$\left[\frac{\mathrm{K}}{\mathrm{min}}\right]$} & 1,5 \\
\hline$h$ & {$[\mathrm{~s}]$} & 0,01 \\
\hline$f$ & {$\left[\frac{\mathrm{kg}}{\mathrm{kg}}\right]$} & 0,999 \\
\hline
\end{tabular}

O resultado dessas simulações pode ser visto na Figura 31, Figura 32 e Figura 33 


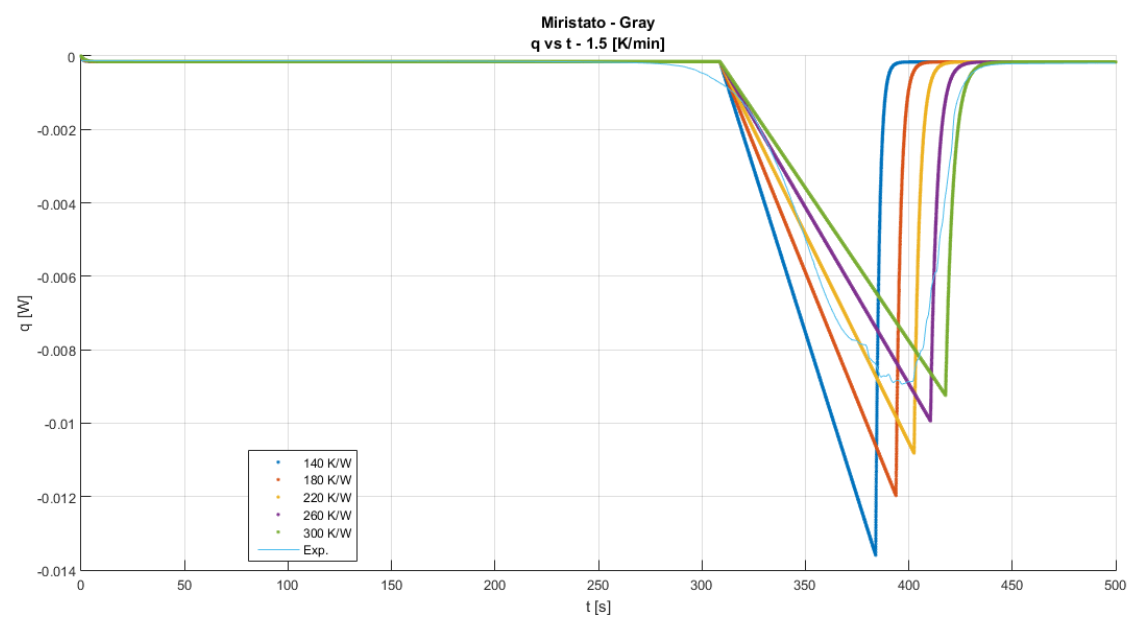

Figura 31 - Termograma simulado para o ajuste de dados para miristato de etila. Modelo de Gray. Abscissa em $t$. Valores de $\mathrm{R}$ variando entre $140 \frac{K}{W}$ e $300 \frac{K}{W}$ segundo legenda. Em azul claro e linha continua a curva experimental

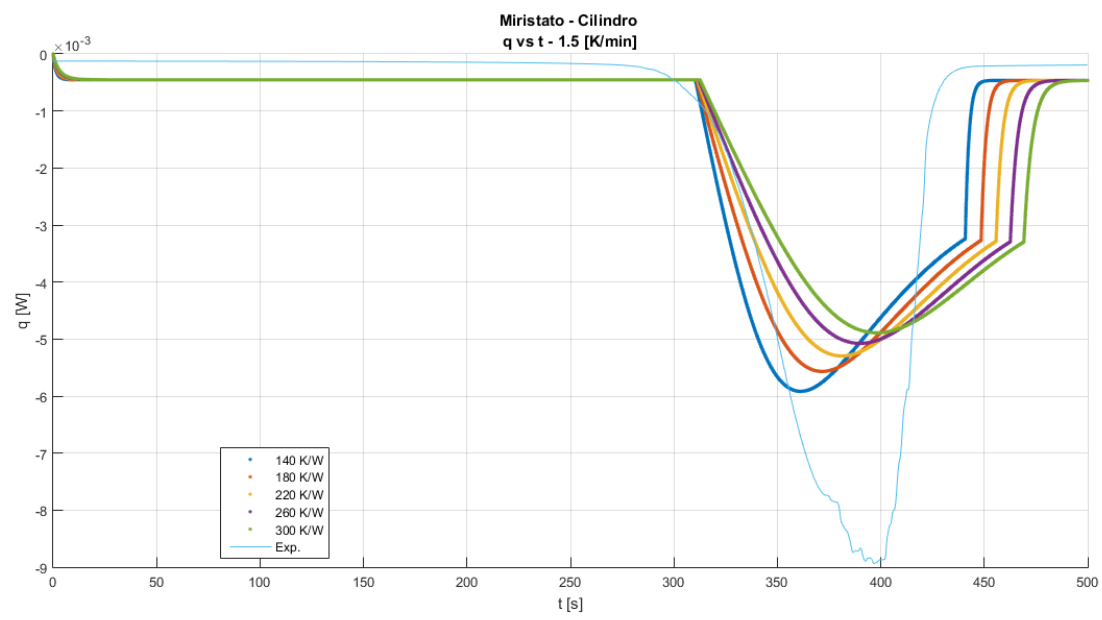

Figura 32 - Termograma simulado para o ajuste de dados para miristato de etila. Modelo HTD - Cilindro. Abscissa em $t$. Valores de $\mathrm{R}$ variando entre $140 \frac{K}{W}$ e $300 \frac{K}{W}$ segundo legenda. Em azul claro e linha continua a curva experimental 


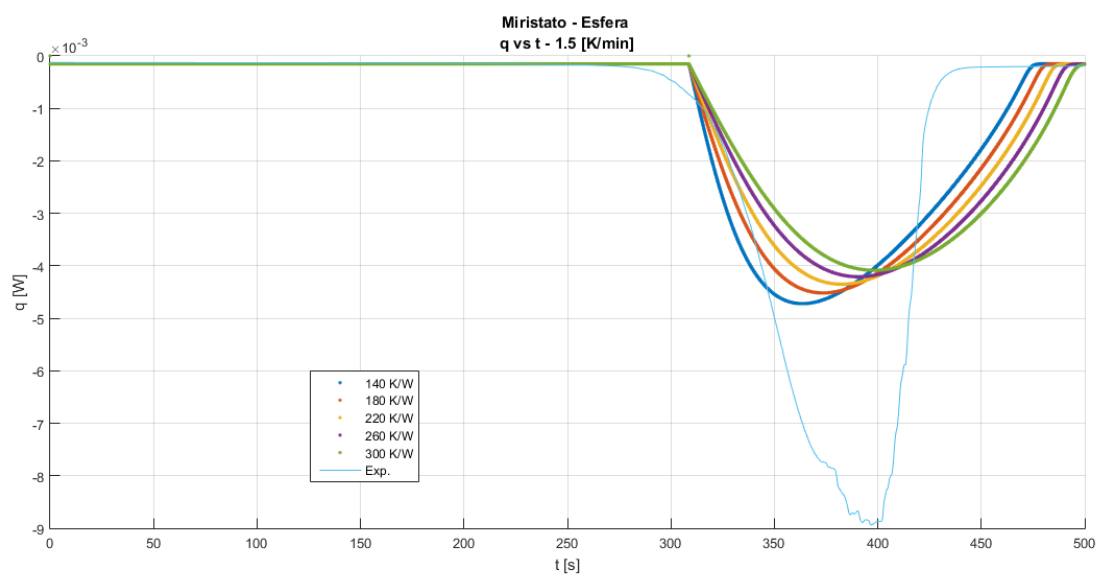

Figura 33 - Termograma simulado para o ajuste de dados para miristato de etila. Modelo HTD - Esfera Abscissa em $t$. Valores de R variando entre 140 $\frac{K}{W}$ e $300 \frac{K}{W}$ segundo legenda. Em azul claro e linha continua a curva experimental

As tabelas Tabela 19, Tabela 20 e Tabela 21 mostram os valores calculados para as três variáveis de ajuste,para os 3 diferentes modelos.

Tabela 19 - Dados comparativos para o ajuste do parâmetro R para o miristato de etila. Modelo de Gray. A última linha apresenta os parâmetros medidos para os dados experimentais disponíveis

\begin{tabular}{|c|c|c|c|}
\hline $\mathrm{R}\left[\frac{K}{W}\right]$ & $\mathrm{A}[J]$ & $p_{\max }[W]$ & $l[s]$ \\
\hline 140 & $-0,6063$ & $-0,0136$ & 75,27 \\
\hline 180 & $-0,6062$ & $-0,0120$ & 85,09 \\
\hline 220 & $-0,6061$ & $-0,0108$ & 93,82 \\
\hline 260 & $-0,6061$ & $-0,0099$ & 101,75 \\
\hline 300 & $-0,6060$ & $-0,0092$ & 109,00 \\
\hline exp. & $-0,6869$ & $-0,0089$ & 68,00 \\
\hline
\end{tabular}


Tabela 20 - Dados comparativos para o ajuste do parâmetro R para o miristato de etila. Modelo HTD- Cilindro. A última linha apresenta os parâmetros medidos para os dados experimentais disponíveis

\begin{tabular}{|c|c|c|c|}
\hline $\mathrm{R}\left[\frac{K}{W}\right]$ & $\mathrm{A}[J]$ & $p_{\max }[W]$ & $l[s]$ \\
\hline 140 & $-0,7438$ & $-0,0059$ & 130,42 \\
\hline 180 & $-0,7434$ & $-0,0056$ & 136,75 \\
\hline 220 & $-0,7432$ & $-0,0054$ & 142,76 \\
\hline 260 & $-0,7429$ & $-0,0051$ & 148,46 \\
\hline 300 & $-0,7427$ & $-0,0050$ & 153,91 \\
\hline exp. & $-0,6869$ & $-0,0089$ & 68,00 \\
\hline
\end{tabular}

Tabela 21 - Dados comparativos para o ajuste do parâmetro R para o miristato de etila. Modelo HTD - Esfera. A última linha apresenta os parâmetros medidos para os dados experimentais disponíveis

\begin{tabular}{|c|c|c|c|}
\hline $\mathrm{R}\left[\frac{K}{W}\right]$ & $\mathrm{A}[J]$ & $p_{\max }[W]$ & $l[s]$ \\
\hline 140 & $-0,5696$ & $-0,0047$ & 169,21 \\
\hline 180 & $-0,5688$ & $-0,0045$ & 174,07 \\
\hline 220 & $-0,5681$ & $-0,0044$ & 178,95 \\
\hline 260 & $-0,5676$ & $-0,0043$ & 183,77 \\
\hline 300 & $-0,5672$ & $-0,0041$ & 188,530 \\
\hline exp. & $-0,6869$ & $-0,0089$ & 68,00 \\
\hline
\end{tabular}

Para o modelo de Gray observa-se uma subestimação da área do pico e uma maior diferença entre o valor máximo atingido.

O modelo cilindrico superestima todos os parametros de ajuste apresnetando maior concordancia para os valores mais baixos de $\mathrm{R}$, o que pode também ser observado no caso esférico.

Um valor consolidade de $R=140 \frac{K}{W}$ é escolhido como melhor ajuste. A Figura 34 apresenta os 3 modelos com este valor de $\mathrm{R}$ comparados aos dados experimentais. 


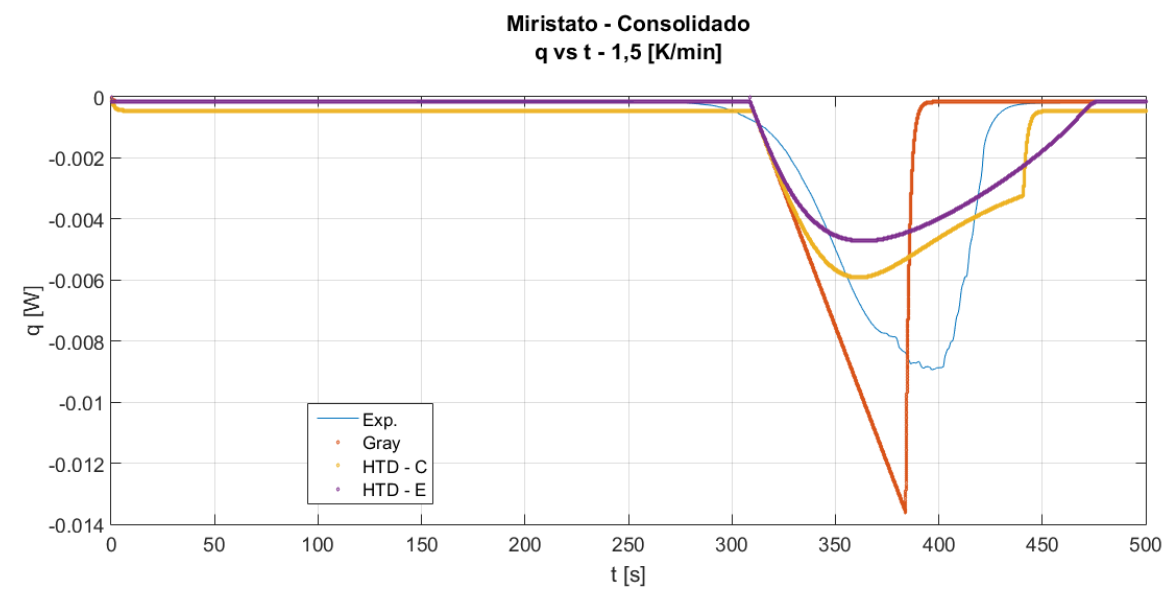

Figura 34 - Termograma simulado para os 3 modelos com o valor de $R=140 \frac{K}{W}$ para a substancia miristato de etila

\subsubsection{Oleato de Etila}

Primeiramente são apresentados os dados termodinâmicos levantados e os dados utilizados para a simulação com a substancia oleato de etila na Tabela 22 e Tabela 23 respectivamente

Tabela 22 - Propriedades termodinâmicas do oleato de etila. dados da literatura.

\begin{tabular}{|c|c|c|c|c|c|c|}
\hline $\begin{array}{c}m \\
{[k g]}\end{array}$ & $\left.\begin{array}{c}\rho \\
{\left[\frac{k g}{m^{3}}\right.}\end{array}\right]$ & $\left.\begin{array}{c}c_{p, s} \\
{\left[\frac{J}{k g K}\right]}\end{array}\right]$ & $\begin{array}{c}c_{p, l} \\
{\left[\frac{J}{k g K}\right]}\end{array}$ & $\begin{array}{c}\lambda \\
{\left[\frac{J}{k g}\right]}\end{array}$ & $\begin{array}{c}k \\
{\left[\frac{W}{m K}\right]}\end{array}$ & $\begin{array}{c}T_{f u s} \\
{[K]}\end{array}$ \\
\hline $5 \times 10^{-6}$ & 890 & 1800 & 1469 & 159510 & 0,15 & 241 \\
\hline
\end{tabular}


Tabela 23 - Dados gerais de entrada do programa de simulação para o oleato de etila

\begin{tabular}{|c|c|c|}
\hline$\rho$ & {$\left[\frac{\mathrm{kg}}{\mathrm{m}^{3}}\right]$} & 890 \\
\hline$m$ & {$[\mathrm{~kg}]$} & $5 \times 10^{-6}$ \\
\hline$k$ & {$\left[\frac{\mathrm{W}}{\mathrm{mK}}\right]$} & 0,15 \\
\hline$c_{p, s}$ & {$\left[\frac{\mathrm{J}}{\mathrm{kgK}}\right]$} & 1800 \\
\hline$c_{p, l}$ & {$\left[\frac{\mathrm{J}}{\mathrm{kgK}}\right]$} & 1469 \\
\hline$\lambda$ & {$\left[\frac{\mathrm{J}}{\mathrm{kg}}\right]$} & 159510 \\
\hline$T_{\text {fus }}$ & {$[K]$} & 250 \\
\hline$C_{r}$ & {$\left[\frac{\mathrm{J}}{\mathrm{K}}\right]$} & $4,5 \times 10^{-4}$ \\
\hline$T_{\text {inicial }}$ & {$[K]$} & 248 \\
\hline$T_{\text {final }}$ & {$[K]$} & 256 \\
\hline$S_{r}$ & {$\left[\frac{K}{\mathrm{~min}}\right]$} & 1,5 \\
\hline$h$ & {$[\mathrm{~s}]$} & 0,01 \\
\hline$f$ & {$\left[\frac{\mathrm{kg}}{\mathrm{kg}}\right]$} & 0,99 \\
\hline
\end{tabular}

É necessário notar uma diferença fundamental na simulação desta substancia. Enquanto nos caso anteriores não houve grande diferença entre os dados levantados e os utilizados na simulação para o oleato de etila pode-se perceber uma grande diferença na temperatura de fusão, sendo a temperatura necessária para alinhar o início do pico de fusão $9 \mathrm{~K}$ maior do que a encontrada na literatura, dessa forma o valor $T_{\text {fus }}$ também foi tratado como um valor ajustável neste caso, sendo modificado para que o onset dos picos concordassem.

Os resultados dessas simulações podem ser visto na Figura 35, Figura 36 e Figura 37 


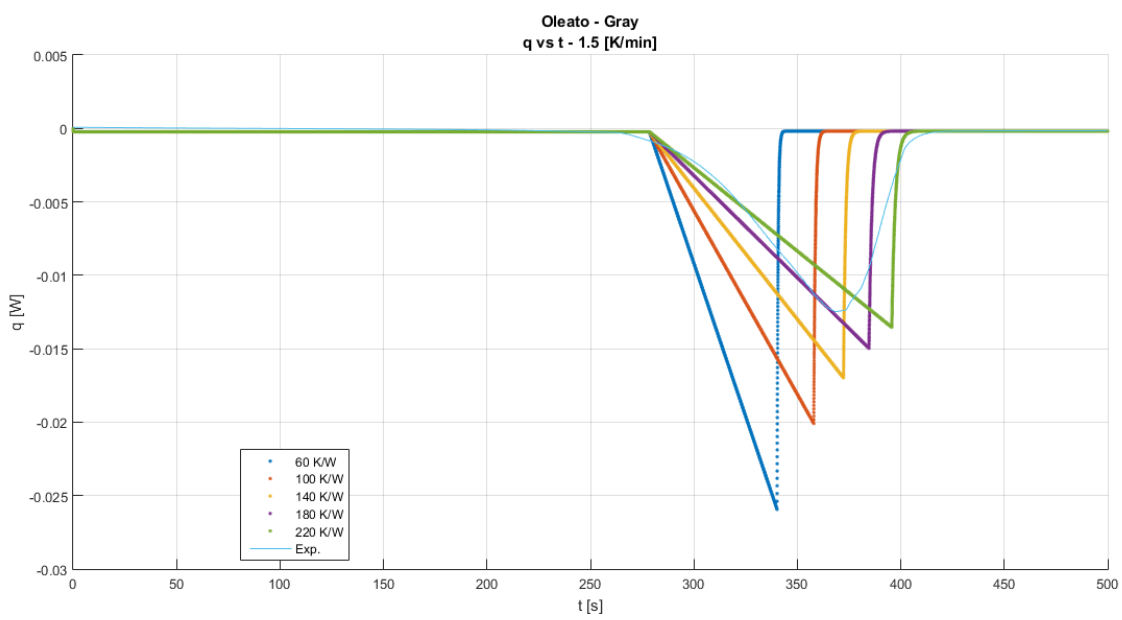

Figura 35 - Termograma simulado para o ajuste de dados para oleato de etila. Modelo de Gray. Abscissa em $t$. Valores de $\mathrm{R}$ variando entre $60 \frac{K}{W}$ e $220 \frac{K}{W}$ segundo legenda. Em azul claro e linha continua a curva experimental

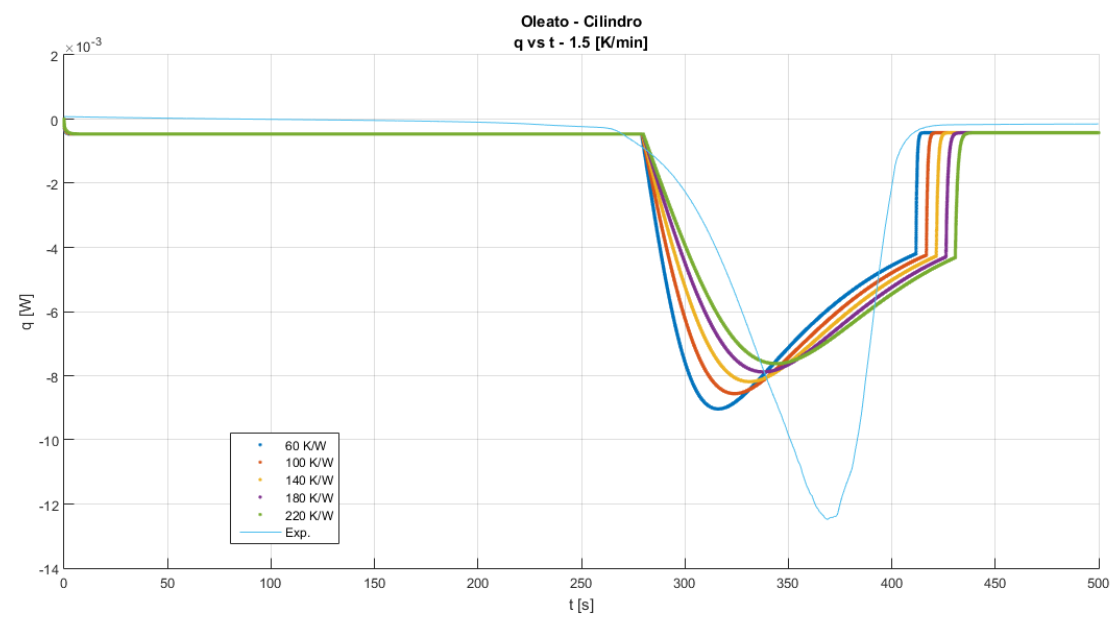

Figura 36 - Termograma simulado para o ajuste de dados para oleato de etila. Modelo de HTD - Cilindro. Abscissa em $t$. Valores de $\mathrm{R}$ variando entre $60 \frac{K}{W}$ e $220 \frac{K}{W}$ segundo legenda. Em azul claro e linha continua a curva experimental 


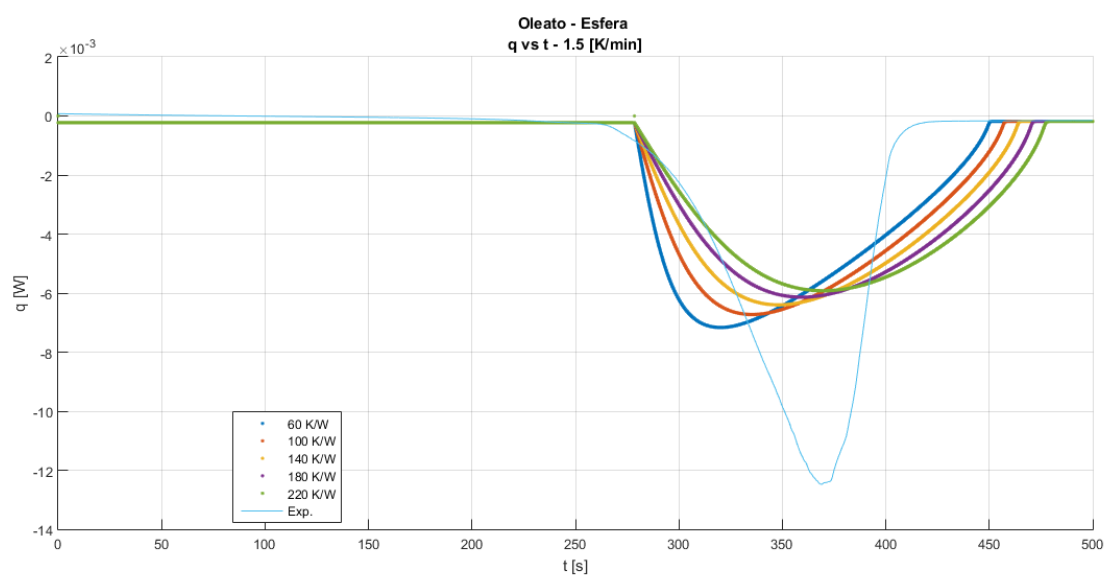

Figura 37 - Termograma simulado para o ajuste de dados para oleato de etila. Modelo de HTD - Esfera. Abscissa em $t$. Valores de $\mathrm{R}$ variando entre $60 \frac{K}{W}$ e $220 \frac{K}{W}$ segundo legenda. Em azul claro e linha continua a curva experimental

As tabelas Tabela 24, Tabela 25 e Tabela 26 mostram os valores calculados para as três variáveis de ajuste, para cada um dos 3 modelos.

Tabela 24 - Dados comparativos para o ajuste do parâmetro R para o oleato de etila. Modelo de Gray. A última linha apresenta os parâmetros medidos para os dados experimentais disponíveis

\begin{tabular}{|c|c|c|c|}
\hline $\mathrm{R}\left[\frac{K}{W}\right]$ & $\mathrm{A}[J]$ & $p_{\max }[W]$ & $l[s]$ \\
\hline 60 & $-0,9121$ & $-0,0259$ & 61,69 \\
\hline 100 & $-0,9122$ & $-0,0201$ & 79,43 \\
\hline 140 & $-0,9121$ & $-0,0170$ & 93,77 \\
\hline 180 & $-0,9120$ & $-0,0150$ & 106,12 \\
\hline 220 & $-0,9120$ & $-0,0135$ & 117,12 \\
\hline exp. & $-0,8469$ & $-0,0125$ & 139,40 \\
\hline
\end{tabular}


Tabela 25 - Dados comparativos para o ajuste do parâmetro R para o oleato de etila. Modelo HTD - Cilindro. A última linha apresenta os parâmetros medidos para os dados experimentais disponíveis

\begin{tabular}{|c|c|c|c|}
\hline $\mathrm{R}\left[\frac{K}{W}\right]$ & $\mathrm{A}[J]$ & $p_{\max }[W]$ & $l[s]$ \\
\hline 60 & $-1,0152$ & $-0,0090$ & 132,58 \\
\hline 100 & $-1,0149$ & $-0,0082$ & 142,03 \\
\hline 140 & $-1,0147$ & $-0,0076$ & 150,82 \\
\hline 180 & $-1,0144$ & $-0,0072$ & 159,05 \\
\hline 220 & $-1,0143$ & $-0,00690$ & 166,83 \\
\hline exp. & $-0,8469$ & $-0,0125$ & 139,40 \\
\hline
\end{tabular}

Tabela 26 - Dados comparativos para o ajuste do parâmetro R para o oleato de etila. Modelo HTD - Esfera. A última linha apresenta os parâmetros medidos para os dados experimentais disponíveis

\begin{tabular}{|c|c|c|c|}
\hline $\mathrm{R}\left[\frac{K}{W}\right]$ & $\mathrm{A}[J]$ & $p_{\max }[W]$ & $l[s]$ \\
\hline 60 & $-0,8851$ & $-0,0072$ & 172,25 \\
\hline 100 & $-0,8840$ & $-0,0067$ & 179,41 \\
\hline 140 & $-0,8831$ & $-0,0064$ & 186,31 \\
\hline 180 & $-0,8823$ & $-0,0061$ & 192,98 \\
\hline 220 & $-0,8817$ & $-0,0059$ & 199,45 \\
\hline exp. & $-0,8469$ & $-0,0125$ & 139,40 \\
\hline
\end{tabular}

O oleato de etila apresenta um comportamento diferente dos dois compostos anteriores, enquanto aqueles mostravam certa concordancia entre os 3 modelos estudados , para o oleato de etila o modelo de Gray apresenta um ajuste melhor para valores grandes de $\mathrm{R}$ enqquanto os dois modelos HTD tem seu melhor ajuste nos valores menores de R. Dessa forma o valor intermediario de $R=140 \frac{K}{W}$ é tomado como melhor ajuste. A Figura 38 apresenta os 3 modelos com este valor de $\mathrm{R}$ comparados aos dados experimentais. 


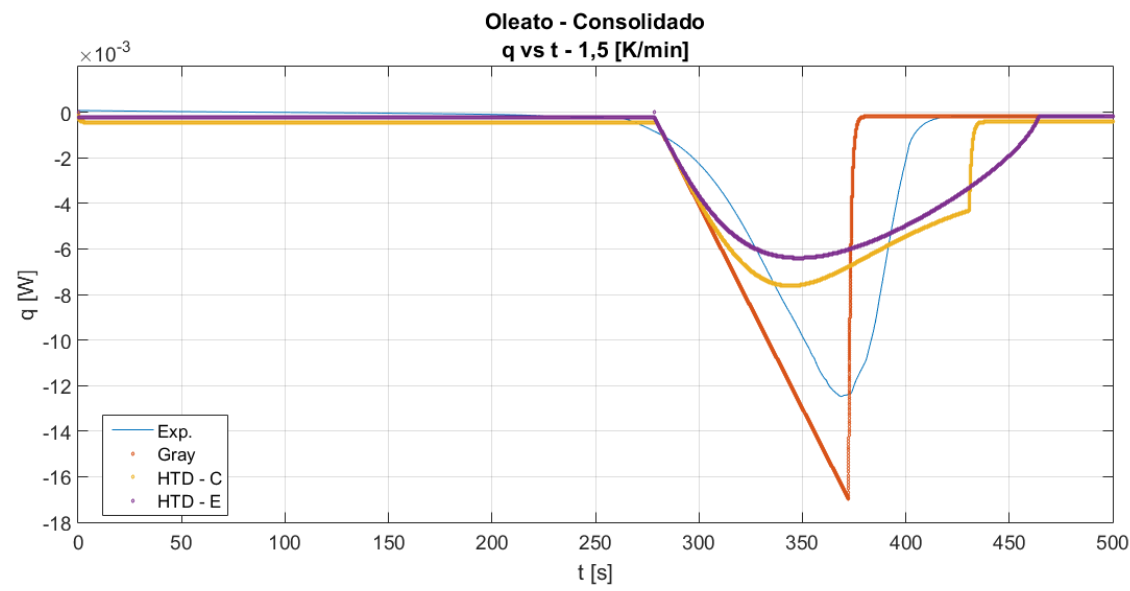

Figura 38 - Termograma simulado para os 3 modelos com o valor de $R=140 \frac{K}{W}$ para a substancia oleato de etila

\subsubsection{Palmitato de Etila}

Os dados termodinâmicos e utilizados para as simulações envolvendo a substância palmitato de etila são apresnetados na Tabela 27 e Tabela 28

Tabela 27 - Propriedades termodinâmicas do palmitato de etila. Dados da literatura.

\begin{tabular}{|c|c|c|c|c|c|c|}
\hline $\begin{array}{c}m \\
{[k g]}\end{array}$ & $\begin{array}{c}\rho \\
{\left[\frac{\mathrm{kg}}{\mathrm{m}^{3}}\right]}\end{array}$ & $\left.\begin{array}{c}c_{p, s} \\
{\left[\frac{\mathrm{J}}{\mathrm{kgK}}\right]}\end{array}\right]$ & $\begin{array}{c}c_{p, l} \\
{\left[\frac{J}{k g K}\right]}\end{array}$ & $\begin{array}{c}\lambda \\
{\left[\frac{J}{k g}\right]}\end{array}$ & $\begin{array}{c}k \\
{\left[\frac{W}{m K}\right]}\end{array}$ & $\begin{array}{c}T_{f u s} \\
{[K]}\end{array}$ \\
\hline $2,7 \times 10^{-6}$ & 857 & 1441 & 3400 & 190419 & 0,15 & 297 \\
\hline
\end{tabular}


Tabela 28 - Dados gerais de entrada do programa de simulação para o palmitato de etila

\begin{tabular}{|c|c|c|}
\hline$\rho$ & {$\left[\frac{\mathrm{kg}}{\mathrm{m}^{3}}\right]$} & 857 \\
\hline$m$ & {$[\mathrm{~kg}]$} & $2,7 \times 10^{-6}$ \\
\hline$k$ & {$\left[\frac{\mathrm{W}}{\mathrm{mK}}\right]$} & 0,15 \\
\hline$c_{p, s}$ & {$\left[\frac{\mathrm{J}}{\mathrm{kgK}}\right]$} & 1441 \\
\hline$c_{p, l}$ & {$\left[\frac{\mathrm{J}}{\mathrm{kgK}}\right]$} & 3400 \\
\hline$\lambda$ & {$\left[\frac{\mathrm{J}}{\mathrm{kg}}\right]$} & 190419 \\
\hline$T_{\text {fus }}$ & {$[K]$} & 293,5 \\
\hline$C_{r}$ & {$\left[\frac{\mathrm{K}}{K}\right]$} & $4 \times 10^{-3}$ \\
\hline$T_{\text {inicial }}$ & {$[K]$} & 292 \\
\hline$T_{\text {final }}$ & {$[K]$} & 299 \\
\hline$S_{r}$ & {$\left[\frac{K}{\mathrm{~min}}\right]$} & 1,5 \\
\hline$h$ & {$[\mathrm{~s}]$} & 0,01 \\
\hline$f$ & {$\left[\frac{\mathrm{kg}}{\mathrm{kg}}\right]$} & 0,999 \\
\hline
\end{tabular}

Novamente é observado um desvio grande entre a temperatura de fusão reportada e a encontrada nos experimentos, porém o desvio neste caso é no outro sentido, sendo a temperatura observada nos experimentos menor do que àquela da literatura. Novamente $T_{\text {fus }}$ foi tratado como parâmetro ajustado, não seguindo-se o valor encontrado na literatura mas sim o valor que ajusta o início do pico no termograma.

As curvas de ajuste, Figura 39, Figura 40 e Figura 41 assim como as tabelas comparativas dos dados de ajuste, Tabela 29, Tabela 30 e Tabela 31, seguem : 


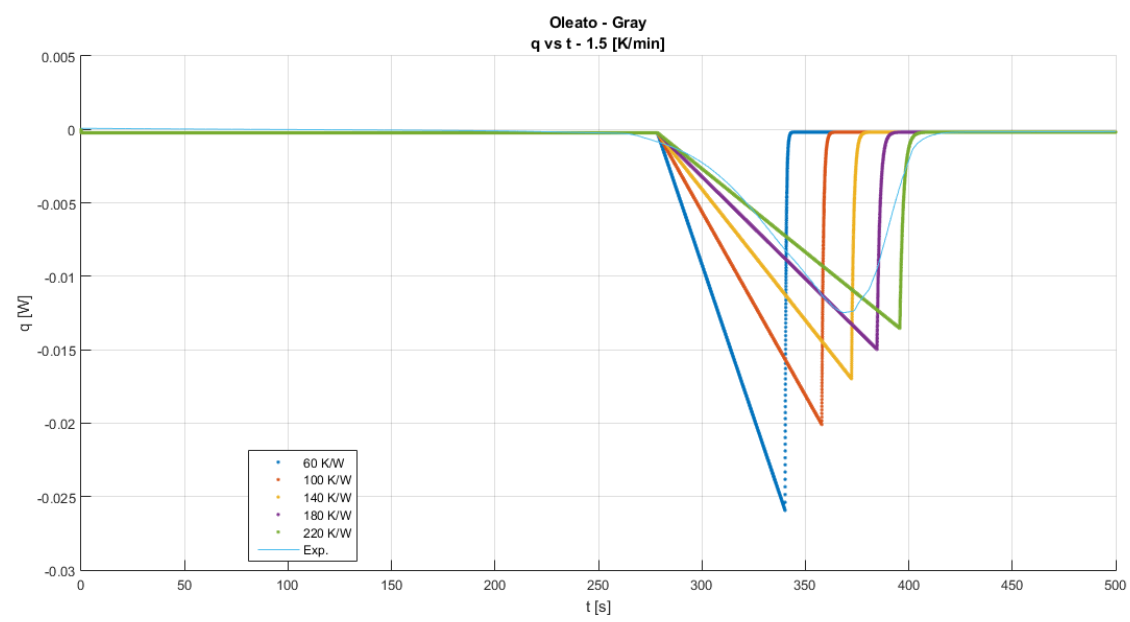

Figura 39 - Termograma simulado para o ajuste de dados para palmitato de etila. Modelo de Gray. Abscissa em t. Valores de $\mathrm{R}$ variando entre $60 \frac{K}{W}$ e $220 \frac{K}{W}$ segundo legenda. Em azul claro e linha continua a curva experimental

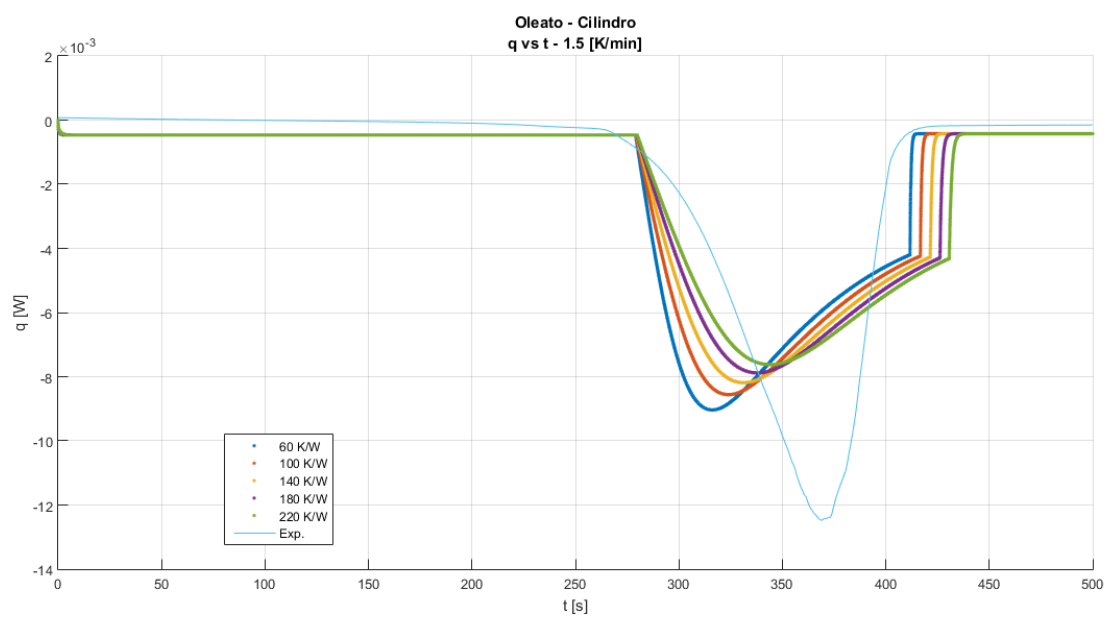

Figura 40 - Termograma simulado para o ajuste de dados para palmitato de etila. Modelo HTD - Cilindro. Abscissa em $t$. Valores de $\mathrm{R}$ variando entre 60 $\frac{K}{W}$ e $220 \frac{K}{W}$ segundo legenda. Em azul claro e linha continua a curva experimental 


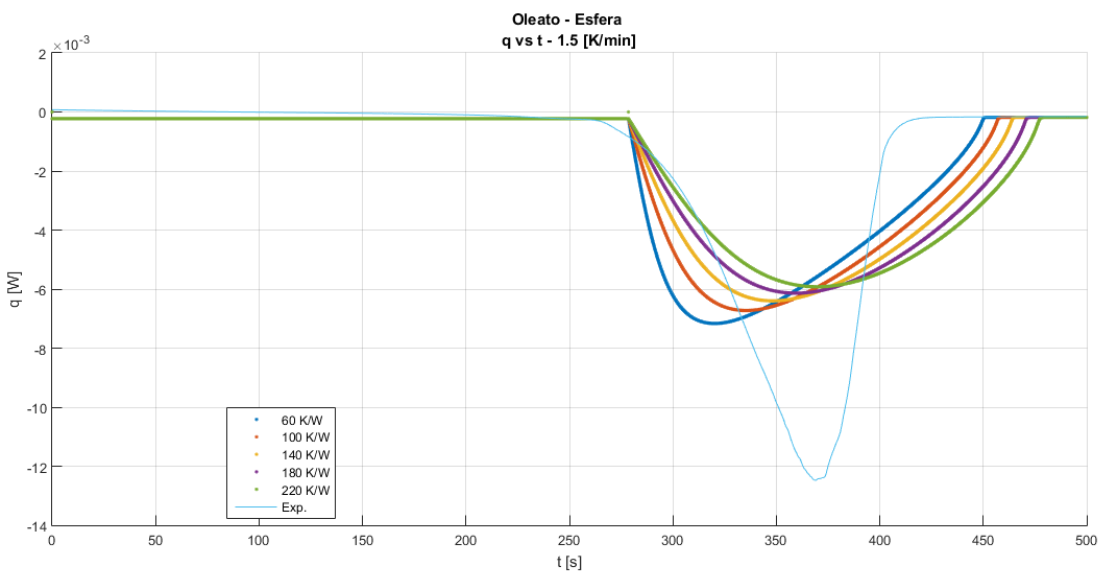

Figura 41 - Termograma simulado para o ajuste de dados para palmitato de etila. Modelo HTD - Esfera. Abscissa em $t$. Valores de $\mathrm{R}$ variando entre 60 $\frac{K}{W}$ e $220 \frac{K}{W}$ segundo legenda. Em azul claro e linha continua a curva experimental

Tabela 29 - Dados comparativos para o ajuste do parâmetro R para o palmitato de etila. Modelo de Gray. A última linha apresenta os parâmetros medidos para os dados experimentais disponíveis

\begin{tabular}{|c|c|c|c|}
\hline $\mathrm{R}\left[\frac{K}{W}\right]$ & $\mathrm{A}[J]$ & $p_{\max }[W]$ & $l[s]$ \\
\hline 60 & $-0,5998$ & $-0,0206$ & 49,32 \\
\hline 100 & $-0,5997$ & $-0,0160$ & 63,49 \\
\hline 140 & $-0,5996$ & $-0,0135$ & 74,95 \\
\hline 180 & $-0,5995$ & $-0,0119$ & 84,82 \\
\hline 220 & $-0,5994$ & $-0,0107$ & 93,61 \\
\hline exp. & $-0,6357$ & $-0,0095$ & 99,00 \\
\hline
\end{tabular}


Tabela 30 - Dados comparativos para o ajuste do parâmetro R para o palmitato de etila. Modelo HTD - Cilindro. A última linha apresenta os parâmetros medidos para os dados experimentais disponíveis

\begin{tabular}{|c|c|c|c|}
\hline $\mathrm{R}\left[\frac{K}{W}\right]$ & $\mathrm{A}[J]$ & $p_{\max }[W]$ & $l[s]$ \\
\hline 60 & $-0,6806$ & $-0,0068$ & 116,62 \\
\hline 100 & $-0,6801$ & $-0,0061$ & 123,75 \\
\hline 140 & $-0,6797$ & $-0,0057$ & 130,46 \\
\hline 180 & $-0,6794$ & $-0,0054$ & 136,80 \\
\hline 220 & $-0,6791$ & $-0,0052$ & 142,81 \\
\hline exp. & $-0,6357$ & $-0,0095$ & 99,00 \\
\hline
\end{tabular}

Tabela 31 - Dados comparativos para o ajuste do parâmetro R para o palmitato de etila. Modelo HTD- Esfera. A última linha apresenta os parâmetros medidos para os dados experimentais disponíveis

\begin{tabular}{|c|c|c|c|}
\hline $\mathrm{R}\left[\frac{K}{W}\right]$ & $\mathrm{A}[J]$ & $p_{\max }[W]$ & $l[s]$ \\
\hline 60 & $-0,5620$ & $-0,0052$ & 158,68 \\
\hline 100 & $-0,5608$ & $-0,0049$ & 163,83 \\
\hline 140 & $-0,5597$ & $-0,0047$ & 168,88 \\
\hline 180 & $-0,5588$ & $-0,0045$ & 173,85 \\
\hline 220 & $-0,5580$ & $-0,0043$ & 178,74 \\
\hline exp. & $-0,6357$ & $-0,0095$ & 99,00 \\
\hline
\end{tabular}

Assim como ocorreu para o oleato de etila o melhor ajustede Gray se da para o maior valor avaliado e os modelos HTD para os menores valores avaliados . Dessa forma, para o palmitato de etila, será considerado $R=140 \frac{K}{W}$.

A Figura 42 apresenta os 3 modelos com este valor de $\mathrm{R}$ comparados aos dados experimentais. 


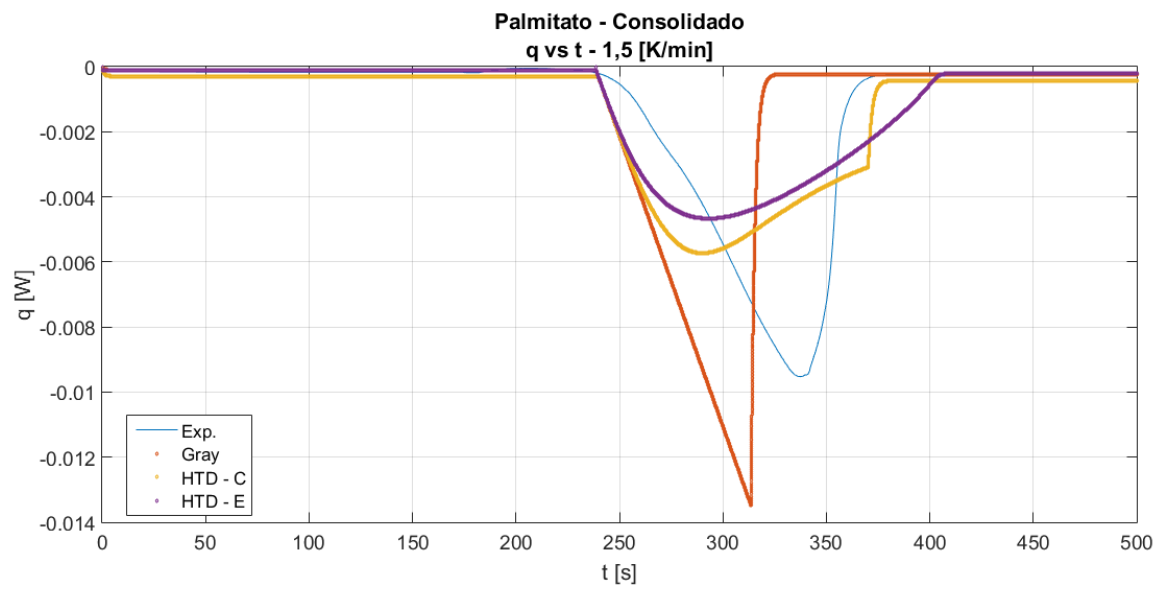

Figura 42 - Termograma simulado para os 3 modelos com o valor de $R=140 \frac{K}{W}$ para a substancia palmitato de etila 



\section{Conclusões}

A implementação da rotina de simulação para o modelo de Gray foi bem sucedida, sendo possível observar os comportamentos previstos pelas equações no gráficos gerados.

A implementação do modelo HTD com geometria cilíndrica obteve êxito , conduto as aproximações do modelo ficam evidentes e foi considerado fundamental o desenvolvimento de um modelo mais rigoroso

Os ajustes foram todos realizados com o modelo HTD esférico pois este foi o modelo desenvolvido com mais rigor teórico. Isso visou diminuir deficiência matemáticos e teóricos do modelo no ajuste dos parâmetros.

O modelo desenvolvido parece ser insuficiente para explicar o processo de fusão, ou prever os dados do termograma.Ele consistentemente subestima o calor necessário e subestima o valor máximo de desvio.Contudo por se tratar de um modelo com diversos parâmetros a serem ajustados e fornecidos ao modelo é possível que estas dificuldades possam ser contornadas. 



\section{Sugestões para trabalhos futuros}

O presente modelo pode ser adaptado para a fusão de espécies que apresentem polimorfismos em sua fase sólida já que o calor pode ser alocado individualmente durante o processo de fusão. è possível a simulação de um composto com geometria conhecida envolvendo diferentes regiões com diferentes valores para o calor de fusão. o objetivo é a simulação de termogramas que apresentam múltiplos picos convolucionados.

Outro caminho possível é o de misturas sólidas em equilíbrio, adicionando ao termo de calor os respectivos calores de mistura que porventura façam parte do equilíbrio 



\section{Bibliografia}

[1] M. D. Robustillo, D. F. Barbosa, A. J. de Almeida Meirelles, P.de A. Pessôa Filho, Fluid Phase Equilibria 361 (2014) 188-199

[2] M. Matsuoka, R. Ozawa, Journal of Crystal Growth 96 (1989) 596-604

[3] S.A. Rocha, R. Guirardello, Fluid Phase Equilibria 281 (2009) 12-21

[4] D.W. Slaughter, M.F. Doherty, Chemical Engineering Science 50 (11) (1995) 1679-1694

[5] U. Domanska, Fluid Phase Equilibria 114 1996. 175

[6] A.R. McGhie, G.J. Sloan, J. Cryst. Growth 32 (1976) 60-67

[7] M. Matsuoka, N. Kanekuni, H. Tanaka, J. Cryst. Growth 73 (1985) $563-570$

[8] Y. Birol Journal of Alloys and Compounds 486 (2009) 173-177

[9] W. Yang, F. Liu, G.C. Yang, Z.F. Xu, J.H. Wang, Z.T. Wang, Thermochimica Acta 527 (2012) 47-51

[10] X.J. Liu I. Ohnuma, R. Kainuma, K. Ishida Journal of Alloys and Compounds 264 (1998) $201-208$

[11] Y. Kong, J.N. Hay Polymer 43 (2002) 3873-3878

[12] M. Iza, S. Woerly, C. Danumah, S. Kaliaguine, M. Bousmina, Polymer 41 (2000) 5885-5893

[13] M. D. Robustillo, D. F. Barbosa, A. J. de Almeida Meirelles, P.de A. Pessôa Filho, Fluid Phase Equilibria 339 (2013) 58-66

[14] M. D. Robustillo, D. F. Barbosa, A. J. de Almeida Meirelles, P.de A. Pessôa Filho, Fluid Phase Equilibria 358 (2013) 272-281

[15], M. C. Costa, M. P. Rolemberg, L. A. D. Boros, M. A. Krähenbühl, M. G. de Oliveira, A. J. A. Meirelles, J. Chem. Eng. Data 2007, 52, 30-36 
[16] Y. Saito, K. Saito, T. Atake, Thermochimica Acta 99 (1986) 299-307

[17] C. C. Huang, Y.P. Chen, Chemeical Engieneering Science 55 (2000) $3175-3185$

[18] S. Sarge, S. Bauerecker, H.K. Cammenga, Termochimica Acta 129 (1988) 309-324

[19] S.W. Chen, C.C. Huang, J. C. Lin, Chemical Engineering Science 50 (1995) 417-431

[20] H. Takiyama, H. Suzuki, H. Uchida, M. Matsuoka, Fluid Phase Equilibria 194-197 (2002) 1107-1117

[21] G.W.H. Höhne, H.K. Cammenga, W. Eysel, E. Gmelin, W. Hemminger, Thermochimica Acta 160 (1990) 1-12

[22] S. M. Sarge, Thermochimica Acta 187 (1991) 323-334

[23] R.G. Gosh, S. Tanaka, A. Toda, Termochimica Acta 500 (2010) 100-105

[24] B.S. Bhatnagar, S. Cardon, M.J. Pikal, R.H. Bogner, Thermochimica Acta 425 (2005) 149-163

[25] A.P. Gray, in: R.S. Porter, J.F. Johnson (Eds.), Analytical Calorimetry, 1968, pp. 209-218.

[26] Itman Filho, Andre;Silva, Rosan;Junior, Dirceu; Oliveira, Pedro. 2015/08/17, COMPARAÇÃO MICROESTRUTURAL DE DOIS AÇOS PARA UTILIZAÇÂO EM MOLDES DE FABRICAÇÃO DE COMPÓSITOS, 10.5151/1516-392X-26871

[27] J. A. P. Coutinho, V. Ruffier-Meray, Fluid Phase Equilibria 148 (1998) $147-160$

[28] https://polymertestinglab.wordpress.com/2018/06/13/differential-scanningcalorimetry/amp/ acessado em 17/02/2021

[29] L. C. B. A. Bessa, M. D. Robustillo, A. J. de A. Meirelles, P. de A. Pessôa Filho, Journal of Thermal Analysis and Calorimetry (2019) 137:2017-2028

[30] Stanley I. Sandler; Chemical, Biochemical, and Engineering Thermodynamics, 5th edition. Hoboken ,NJ : John Wiley \& Sons [2016] 
[31] Frank P. Incropera, David P. DeWitt, Theodore L. Bergman, Adrienne S. Lavine; Fundamentals of Heat and Mass Transfer, 6th Edition, Hoboken ,NJ : John Wiley \& Sons [2006]

[32] Steven C. Chapra; Métodos Numéricos Aplicados com MATLAB®para

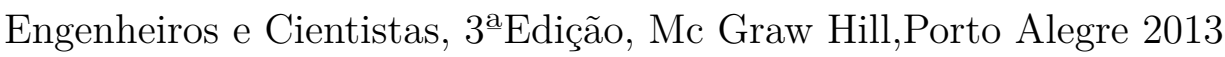

[33] G. Wang,J. Fan,X. Wang,F. Song,Q. Wang, L. Zhang,Fluid Phase Equilibria 473 (2018) 106-111 

Anexos 



\section{ANEXO A - Código MATLABR para geometria esférica}

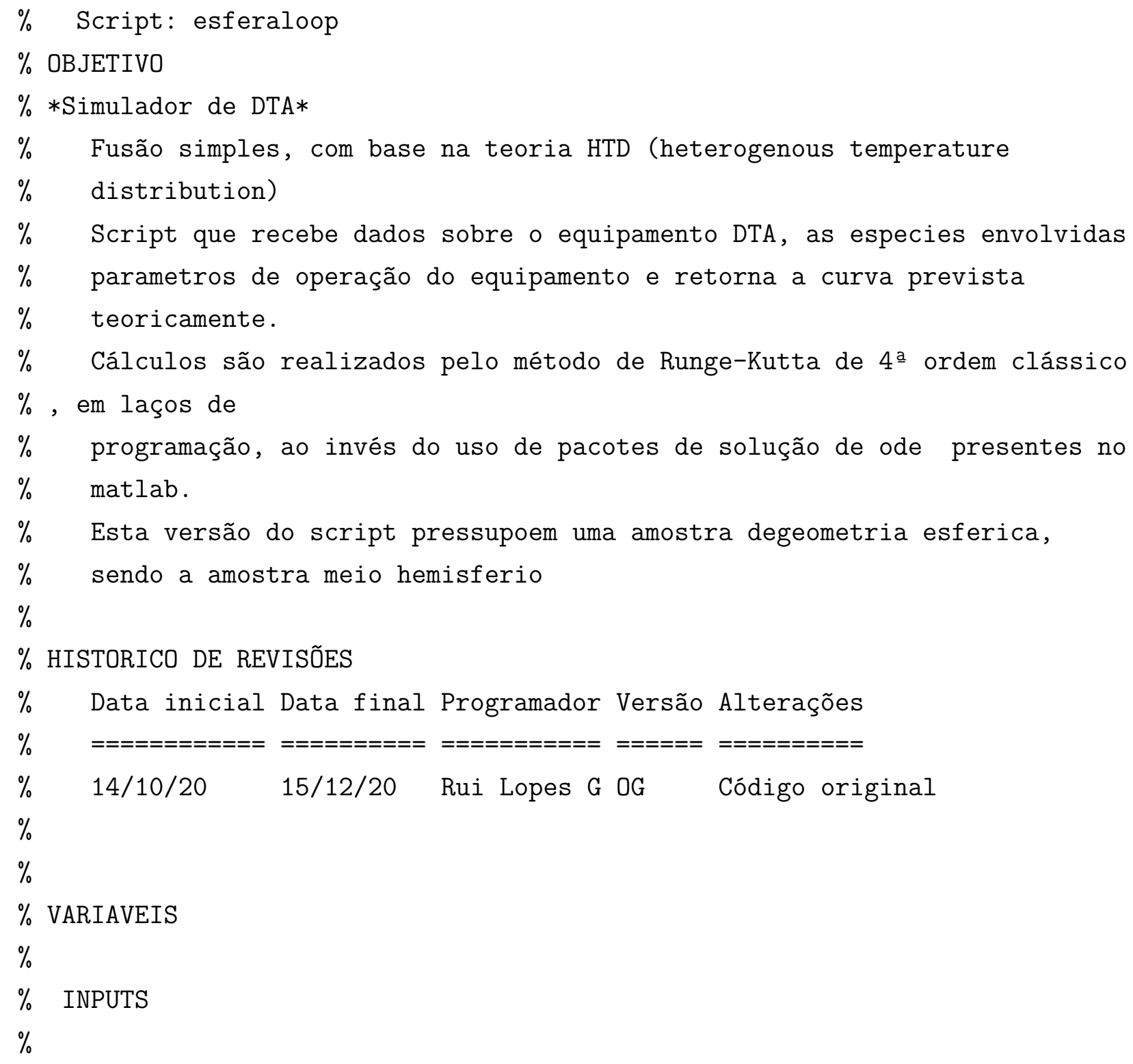


$\%$ rho $\rightarrow$ densidade da amostra; $\mathrm{kg} / \mathrm{m}^{\wedge} 3$

$\% \quad$ m0 $\rightarrow$ massa da amostra; kg

$\%$ r0 $\rightarrow$ raio da amostra; m

$\% \quad$ knd $\rightarrow$ condutividade da amostra; W/ $\mathrm{m} \mathrm{K}$

$\% \quad$ cps $\rightarrow$ calor específico da amostra. (1) sólido. (2) liquido; J/ K kg

$\% \quad \operatorname{lmb} \rightarrow$ calor de fusão da amostra; J/ kg

$\% \quad$ Tfs $\rightarrow$ temperatura de fusão da amostra; $K$

$\%$ RO $\rightarrow$ resistencia a troca termica do cadinho de referencia; K/W

$\% \mathrm{Cr} \rightarrow$ capacidade térmica do cadinho de refrencia; J/K

$\% \quad \mathrm{Ti} \rightarrow$ temperatura de inicio da varredura; $\mathrm{K}$

$\%$ Tf $\rightarrow$ temperatura do fim da varredura; $K$

$\% \mathrm{Sr} \rightarrow$ taxa de aquecimento da varredura; $\mathrm{K} / \mathrm{s}$

$\%$ h $\rightarrow$ tamanho do passo numerico da simulação; ad

$\%$ f $\rightarrow$ porcentagem do raio do solido que é retirado matematicamente

$\%$ para que o caluculo da dericada de rs seja possivel; m/m

$\%$

$\%$

$\% \quad$ OUTPUTS

$\%$

$\%$ t $\rightarrow$ vetor tempo da simulação; s

$\% \quad \operatorname{Tr} \rightarrow$ vetor temperatura da referencia; $\mathrm{K}$

$\% \quad$ Ts $\rightarrow$ vetor temperatura da amostra; $\mathrm{K}$

$\%$ qr $\rightarrow$ taxa de calor da refrencia; $W$

$\%$ qs $\rightarrow$ taxa de calor da amostra; $W$

$\% \quad$ dsc $\rightarrow$ diferença dos taxa de calor da amostra e referencia, sinal simulado;

$\%$ rs $\rightarrow$ raio de sólido da referencia; $m$

$\%$ firs $\rightarrow$ vetor com os acrescimos diferencias do raio da amostra; m/s

$\%$ fits $\rightarrow$ vetor com os acrescimos diferecias da temperatura da amostra; $\mathrm{K} / \mathrm{s}$

$\%$ qsfus $\rightarrow$ vetor da parcela de calor da amostra refrente a fusao ; W

\% qssol $\rightarrow$ vetor da parcela de calor da amostra refrente ao aquecimento

$\%$ do sólido; $W$

$\% \quad$ qsliq $\rightarrow$ vetor da parcela de calor da amostra refrente ao aquecimento $\%$ do liquido ; $W$ 
$\% \quad$ qsref $\rightarrow$ vetor da parcela de calor da amostra refrente ao aquecimento

$\%$ do cadinho de referencia; $W$

$\% \quad$ qssmp $\rightarrow$ vetor da parcela de calor da amostra refrente ao aquecimento

$\%$ da amostra, seja no estado liquido ou sólido; $W$

$\% \quad$ mdsc $\rightarrow$ valor minimo da simulacao; $W$

$\%$ iddsc $\rightarrow$ localização do minimo, endereço de vetor

$\%$

$\%$ PARAMETROS

$\%$

$\% \quad \mathrm{~V} \quad \rightarrow$ Volume da amostra; m^3

$\%$ offset $\rightarrow$ desvio para temperatura da fornalha; $\mathrm{K}$

$\% \quad$ Tio $\rightarrow$ Temperatura inicial da varredra acrescida do offste; $K$

$\% \quad \mathrm{Tp} \rightarrow$ Temparatura da fonte de calor; $\mathrm{K}$

$\%$ phirs $\rightarrow$ acrescimo diferencial do raio da amostra; $\mathrm{m} / \mathrm{s}$

$\%$ phits $\rightarrow$ acrescimo diferencial da temperatura da amostra; $\mathrm{K} / \mathrm{s}$

$\%$

$\%$

$\%$

$\%$

$\% \quad$ AUXILIARES

$\%$

$\% \quad$ sw $\rightarrow$ variavel do switch para modo do tamanho: 1-massa 2-geometria

$\%$ rep $\rightarrow$ auxiliar que mantem o laço principal ativo

$\%$ tvar $\rightarrow$ auxiliar para montar vetor tempo

$\%$

$\%$

$\%$

$\%$

$\%$

$\%$

$\%$

$\%$ 
\%obtenção dos inputs

display ( '***BEM VINDO AO SIMULADOR DE DSC -

MODELO HTD-esferico***');

display ('1- TAMANHO DA AMOSTRA');

rho = input ('Informe a densidade da amostra [Kg/

$\left.\left.\mathrm{m}^{-} 3\right] \backslash \mathrm{n}^{\prime}\right)$;

$\mathrm{sw}=$ input ('Selecione um modo: $\backslash \mathrm{n}$

1- Massa de amostra conhecida \n

2- Geometria da amostra conhecida (n');

switch sw

case 1

m0 = input('Informe a massa da amostra em

$\left.[\mathrm{kg}] \backslash \mathrm{n}^{\prime}\right)$;

$\mathrm{V}=\mathrm{mo} / \mathrm{rho}$;

\%calculo do volume baseado em $\mathrm{m}$ e rho, e

definição de $r 0$ com base em V

$r 0=(3 * V /(p i * 2))^{-}(1 / 3)$;

case 2

r0 = input ('Infore o raio da amostra r0[m]

$\left.\backslash \mathrm{n}^{\prime}\right)$;

$\mathrm{V}=2 / 3 * \mathrm{pi} * \mathrm{r} 0^{\sim} 3$;

$\mathrm{m} 0=\mathrm{rho} * \mathrm{~V}$;

$\%$ calculo de m0 com base na geometria

fornecida e rho

end

display('2- DADOS TÉRMICOS');

knd = input ('Informe a condutividade da amostra

$\left.[\mathrm{W} /(\mathrm{m} * \mathrm{~K})] \backslash \mathrm{n}^{\prime}\right)$; 
$\operatorname{cps}(1)=$ input ('Informe $\circ \mathrm{cp}$ da fase sólida $[\mathrm{J} /$

$\left.(\mathrm{K} * \mathrm{~kg})] \backslash \mathrm{n}^{\prime}\right)$;

$\operatorname{cps}(2)=$ input ('Informe $\circ \mathrm{cp}$ da fase líquida [J/

$\left.(\mathrm{K} * \mathrm{~kg})] \backslash \mathrm{n}^{\prime}\right)$;

lmb = input('Informe o calor de fusão da amostra

$\left.[\mathrm{J} / \mathrm{kg}] \backslash \mathrm{n}^{\prime}\right)$;

Tfs = input('Informe a temperatura de fusão da

amostra $\left.[\mathrm{K}] \backslash \mathrm{n}^{\prime}\right)$;

display (' 3-REFERÊNCIA') ;

R0 = input('Informe a resitência térmica da

referência $\left.[K / W] \backslash n^{\prime}\right)$;

$\mathrm{Cr}=$ input('Informe a capacidade térmoica da

referencia $\left.[\mathrm{J} / \mathrm{K}] \backslash \mathrm{n}^{\prime}\right)$;

display ('4-VARREDURA');

$\mathrm{Ti}=$ input('Informe a temperatura inicial da

varredura $\left.[\mathrm{K}] \backslash \mathrm{n}^{\prime}\right)$;

Tf = input('Informe a temperatura final da

varredura $\left.[\mathrm{K}] \backslash \mathrm{n}^{\prime}\right)$;

$\mathrm{Sr}=\operatorname{input}($ 'Informe $\mathrm{o}$ scan rate $[\mathrm{K} / \mathrm{s}] \backslash \mathrm{n}$ ');

display('5- MÉTODO NUMÉRICO');

$\mathrm{h}$ = input('Informe o tamanho de passo do método

numerico $\left.\backslash \mathrm{n}^{\prime}\right)$;

$f=$ input ('Informe a porcentagem da faisca $\backslash n$ ');

rep $=1$;

while rep $\sim=0$

\%inicialização de variaveis 
\%inicializa o tempo

tvar $=\operatorname{abs}((\mathrm{Tf}-\mathrm{Ti}) / \mathrm{Sr})$;

$\mathrm{t}=0: \mathrm{h}:$ tvar;

$\%$ inicializa as temperaturas d esaida de referencia e amostra

$\operatorname{Tr}=\operatorname{ones}($ length $(t), 1) * \mathrm{Ti}$;

$\mathrm{Ts}=\operatorname{ones}($ length $(t), 1) * \mathrm{~T} i$;

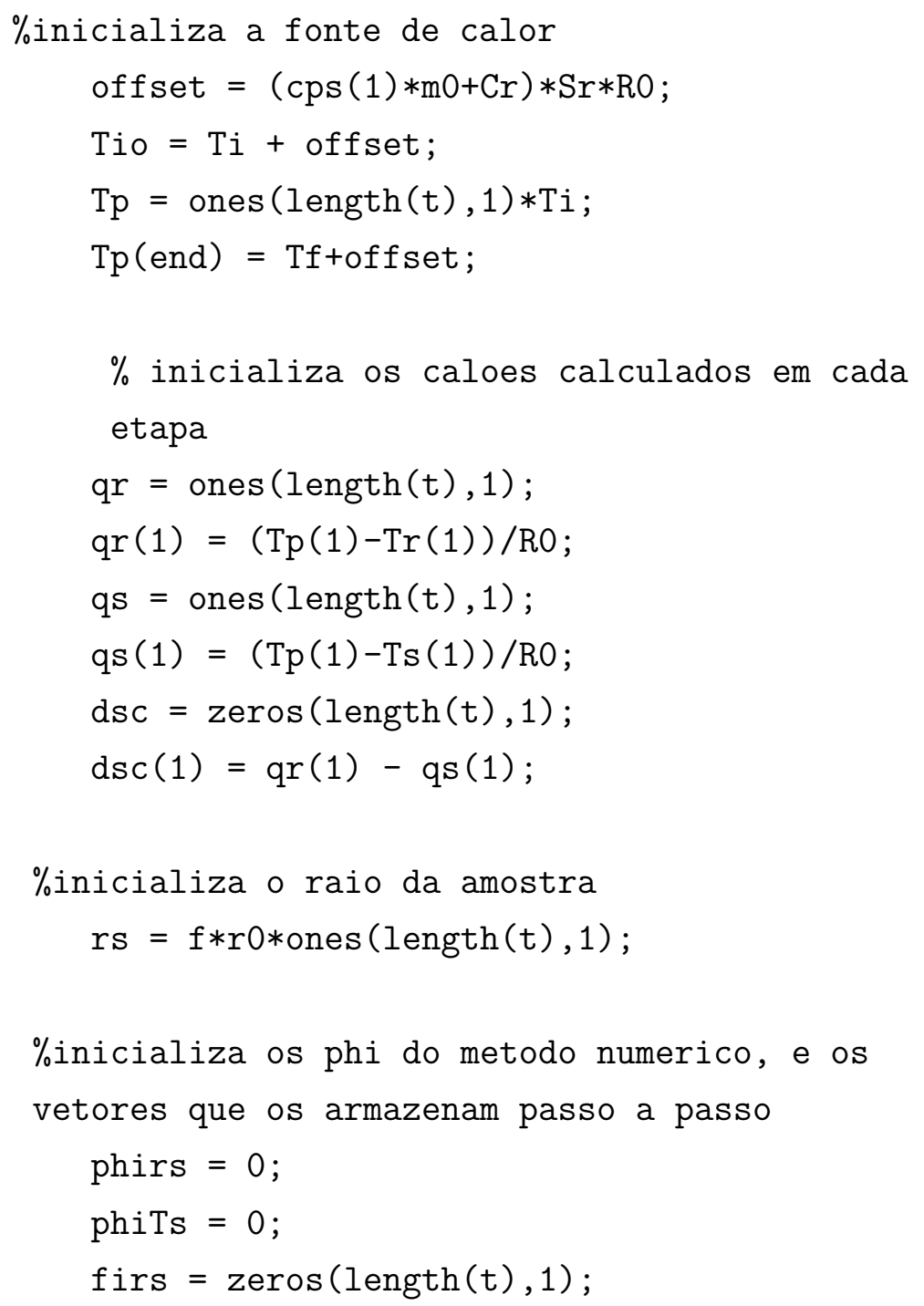


fits $=\operatorname{zeros}($ length $(t), 1) ;$

$\%$ inicializa os vetores para os calores particulares de cada processo

qsfus $=\operatorname{zeros}(\operatorname{length}(t), 1)$;

qssol $=\operatorname{zeros}(\operatorname{length}(t), 1)$;

qsliq $=\operatorname{zeros}($ length $(t), 1)$;

qsref $=\operatorname{zeros}(\operatorname{length}(t), 1)$;

qssmp $=\operatorname{zeros}(\operatorname{length}(t), 1)$;

\%inicializa o marcador para termino da fusão

dhfus $=1 \mathrm{mb} * \mathrm{~m} 0$;

som $=0$;

\%inicializa variaveis auxiliares do processo.

Bandeiras de checagem do processo

flaglamb = 1 ;

flagad $=1$;

fus $=0$;

$\mathrm{sl}=1$;

for $i i=1: 1: \operatorname{length}(t)-1$

$\%$ calcula $\mathrm{Tp} \%$

$\operatorname{Tp}(i i)=\operatorname{Tio}+\operatorname{Sr} * t(i i)$

\%resolução para Tr, simples aplicação do

balanço de energia de AP Grey

$\mathrm{k} 1 \mathrm{Tr}=(\operatorname{Tp}(\mathrm{ii})-\operatorname{Tr}(\mathrm{ii})) /(\mathrm{R} 0 * \mathrm{Cr}) ;$ 


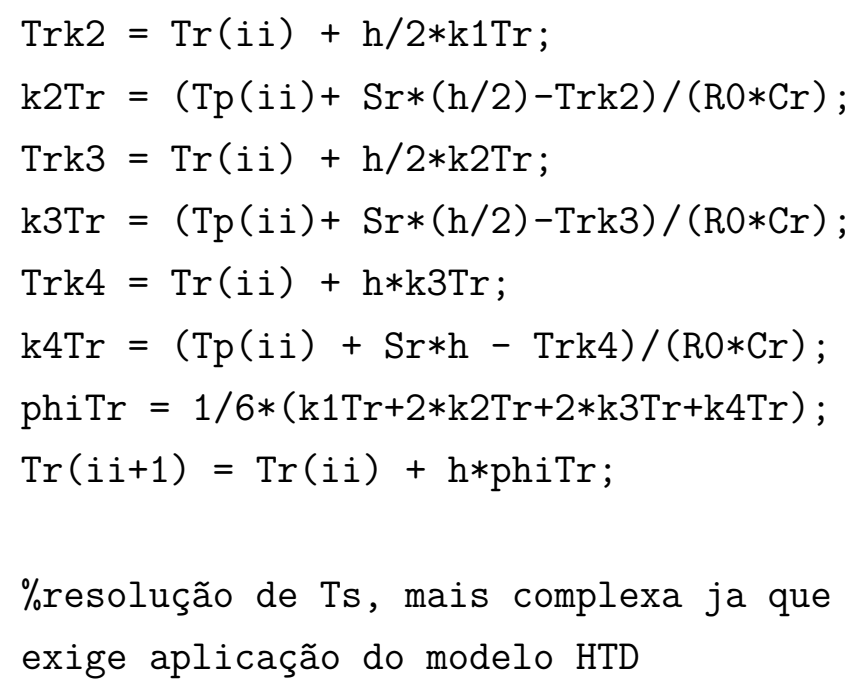

\%caso não haja fusão valem as mesmas equações que $\operatorname{Tr}$

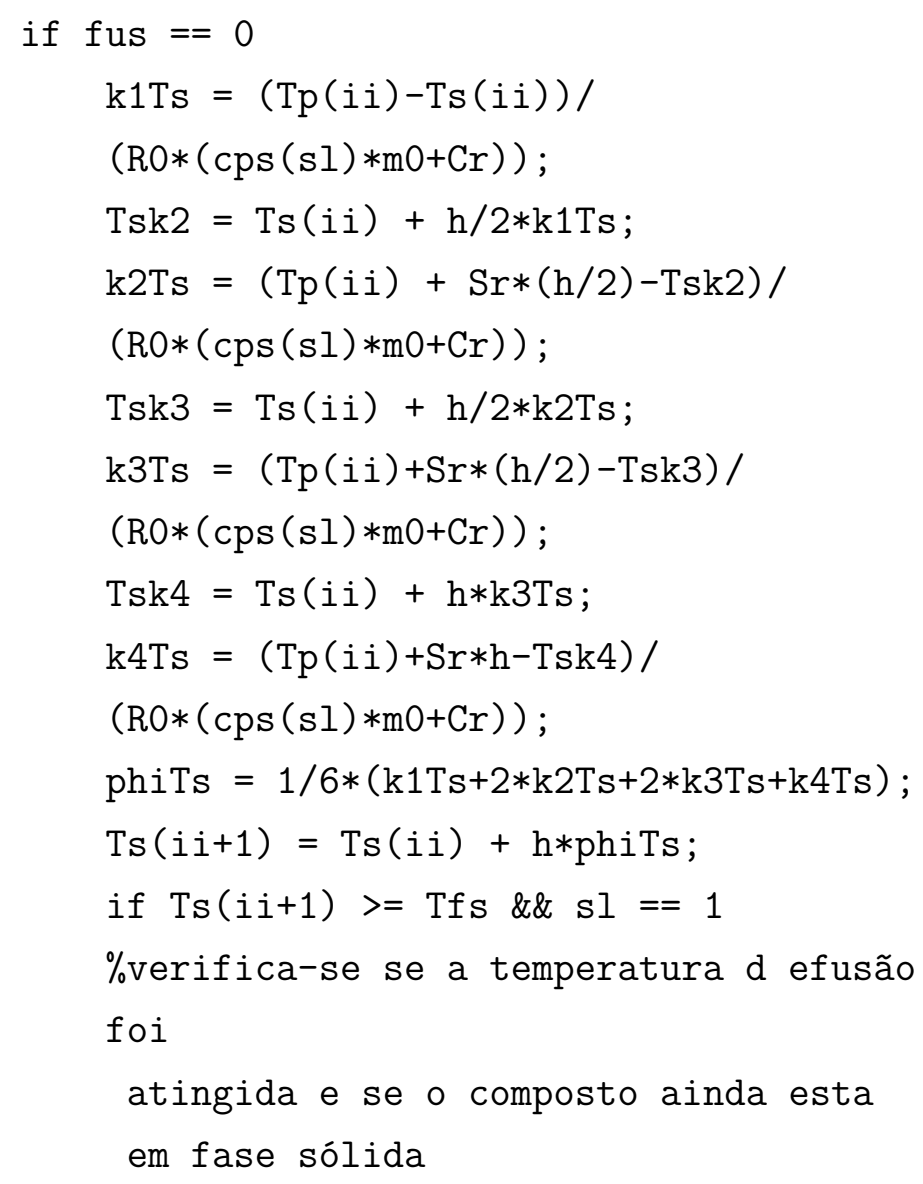




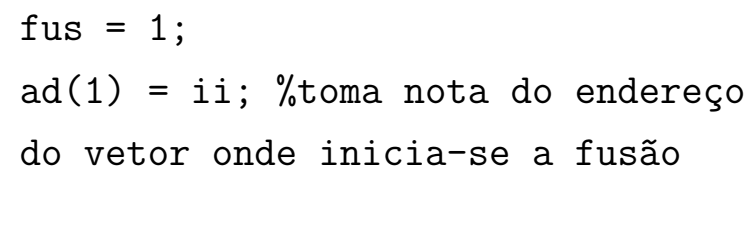

else

\%Aplicação do modelo HTD válido durante a fase 2 (fusão) do processo

\%inicia-se com o cálculo das variaveis auxiliares que dependem de m para depois calcular os ks de RK

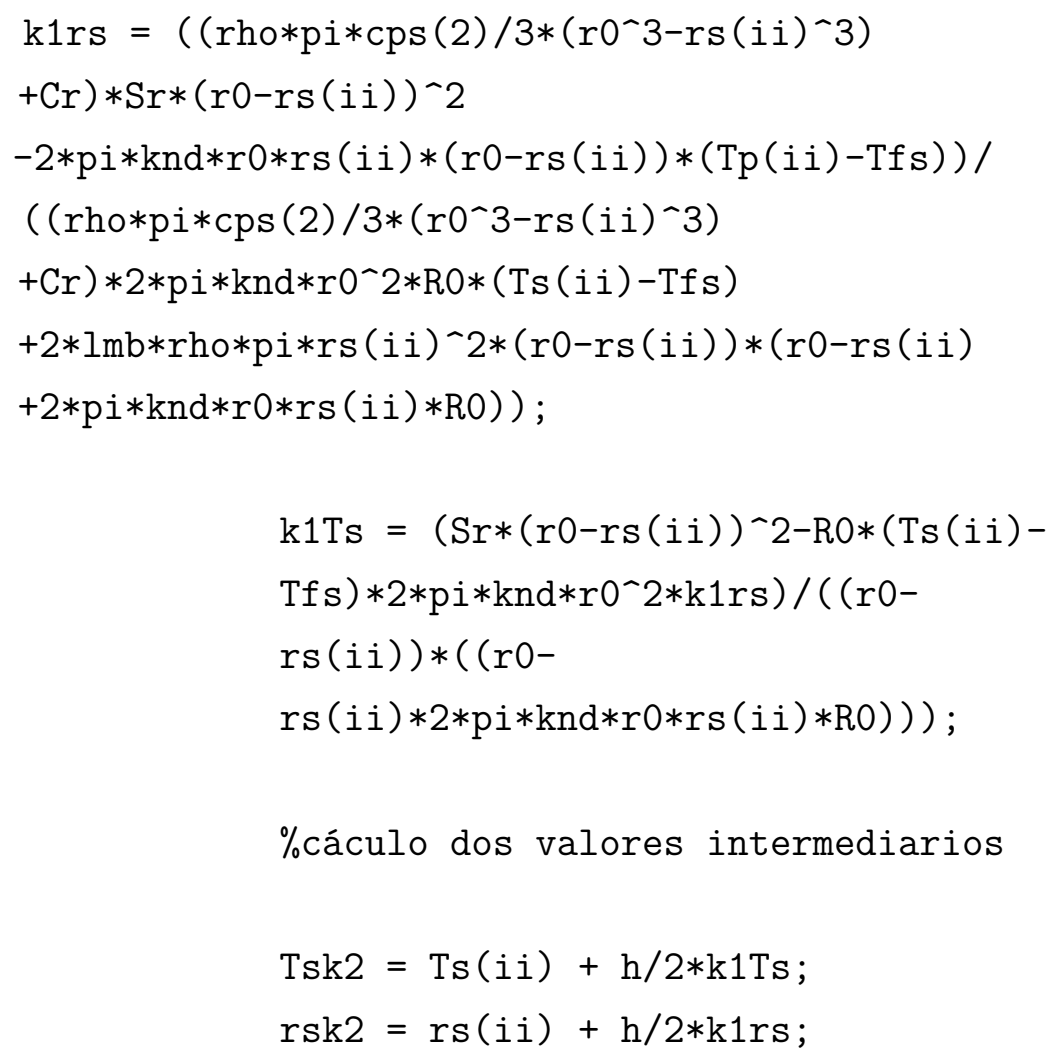




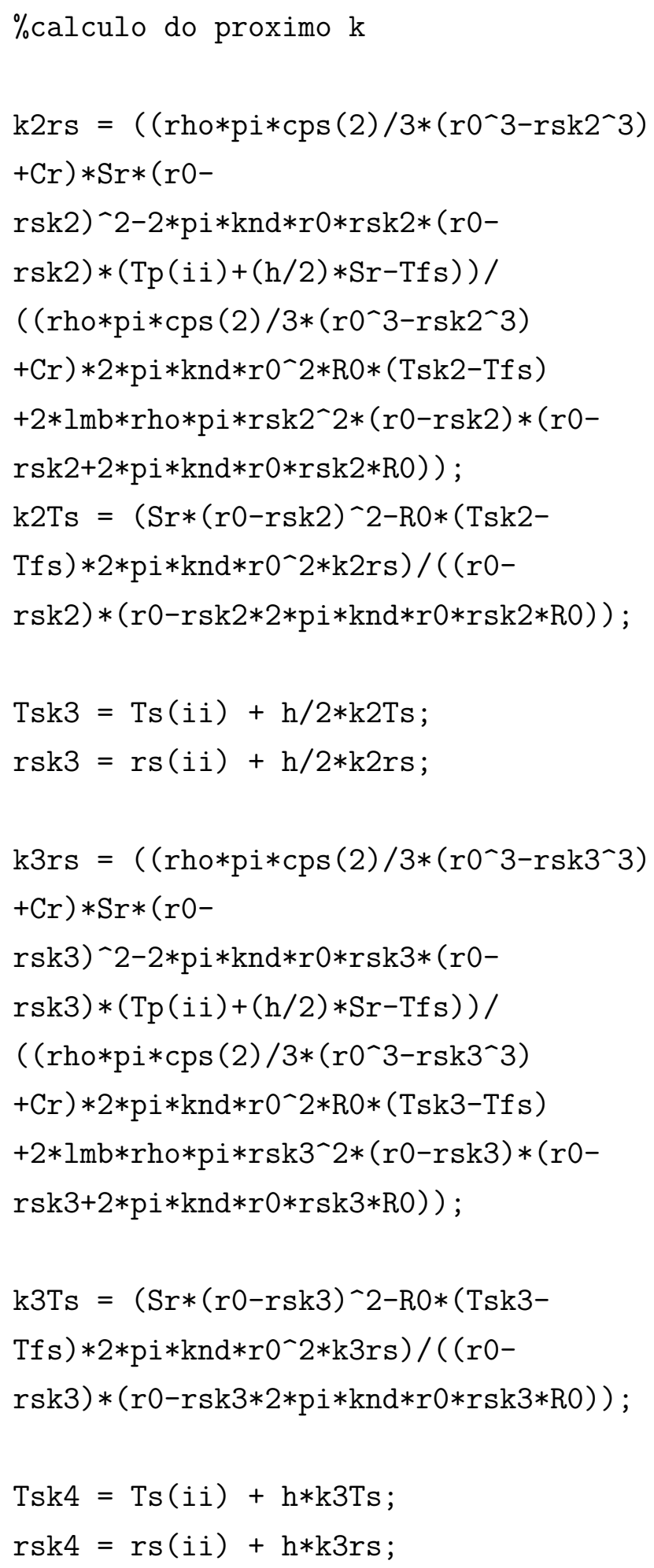


$\mathrm{k} 4 \mathrm{rs}=\left(\left(\mathrm{rho} * \mathrm{pi} * \mathrm{cps}(2) / 3 *\left(\mathrm{r}^{-} 3-\mathrm{rsk} 4^{\wedge} 3\right)\right.\right.$

$+\mathrm{Cr}) * \mathrm{Sr} *(\mathrm{r} 0-$

rsk4) ^2-2*pi*knd*r0*rsk4*(r0-

$\operatorname{rsk} 4) *(\mathrm{Tp}(\mathrm{ii})+\mathrm{Sr} * \mathrm{~h}-\mathrm{Tfs})) /$

( (rho*pi*cps (2)/3*(r0^3-rsk4^3)

$+\mathrm{Cr}) * 2 * \mathrm{pi} * \mathrm{knd} * \mathrm{r} 0 \sim 2 * \mathrm{R} 0 *(\mathrm{Tsk} 4-\mathrm{Tf} \mathrm{s})$

$+2 * 1 \mathrm{mb} * \mathrm{rho} * \mathrm{pi} * \mathrm{rsk} 4{ }^{\sim} 2 *(\mathrm{r} 0-\mathrm{rsk} 4) *(\mathrm{r} 0-$

rsk4+2*pi*knd*r0*rs (ii)*R0));

$\mathrm{k} 4 \mathrm{Ts}=\left(\mathrm{Sr} *(\mathrm{r} 0-\mathrm{rsk} 4)^{\sim} 2-\mathrm{R} 0 *(\mathrm{Tsk} 4-\right.$

Tfs $\left.) * 2 * \mathrm{pi} * \mathrm{knd} * \mathrm{r} 0^{\wedge} 2 * \mathrm{k} 4 \mathrm{rs}\right) /((\mathrm{r} 0-$

rsk 4$) *($ r0-rsk $4 * 2 *$ pi $*$ knd $*$ r $0 * r s k 4 * R 0))$;

phiTs $=1 / 6 *(\mathrm{k} 1 \mathrm{Ts}+2 * \mathrm{k} 2 \mathrm{Ts}+2 * \mathrm{k} 3 \mathrm{Ts}+\mathrm{k} 4 \mathrm{Ts}) ;$

phirs $=1 / 6 *(k 1 r s+2 * k 2 r s+2 * k 3 r s+k 4 r s)$;

$\mathrm{Ts}(i i+1)=\mathrm{Ts}(i i)+\mathrm{h} * \operatorname{phiTs} ;$

$\%$ avanço das duas variveis

independentes após o calculo de seus 4

$\mathrm{k}$ e

respectivo phi

$r s(i i+1)=r s(i i)+h * p h i r s ;$

end

qs $(i i+1)=-2 *$ pi*rho*rs $(i i$

$+1)^{\wedge} 2 * \operatorname{lmb} *((\mathrm{rs}(i \mathrm{i}+1)-\mathrm{rs}(\mathrm{ii})) / \mathrm{h})+$

$\left((2 * \mathrm{pi} * \mathrm{rho} * \operatorname{cps}(2)) / 3 *\left(\mathrm{r}^{-} 3-\mathrm{rs}(\mathrm{i} i+1) \sim 3\right)\right.$

$+\mathrm{Cr}+2 / 3 * r s(i \mathrm{i}+1)-3 * \mathrm{pi} * \operatorname{cps}(1) * \mathrm{rho} *(1-$

fus $)) *((\operatorname{Ts}(i i+1)-T s(i i)) / h)$;

qsfus $(i i+1)=-2 *$ pi*rho*rs $(i i$

$+1)^{\sim} 2 * \operatorname{lmb} *((\operatorname{rs}(i i+1)-r s(i i)) / h)$; 


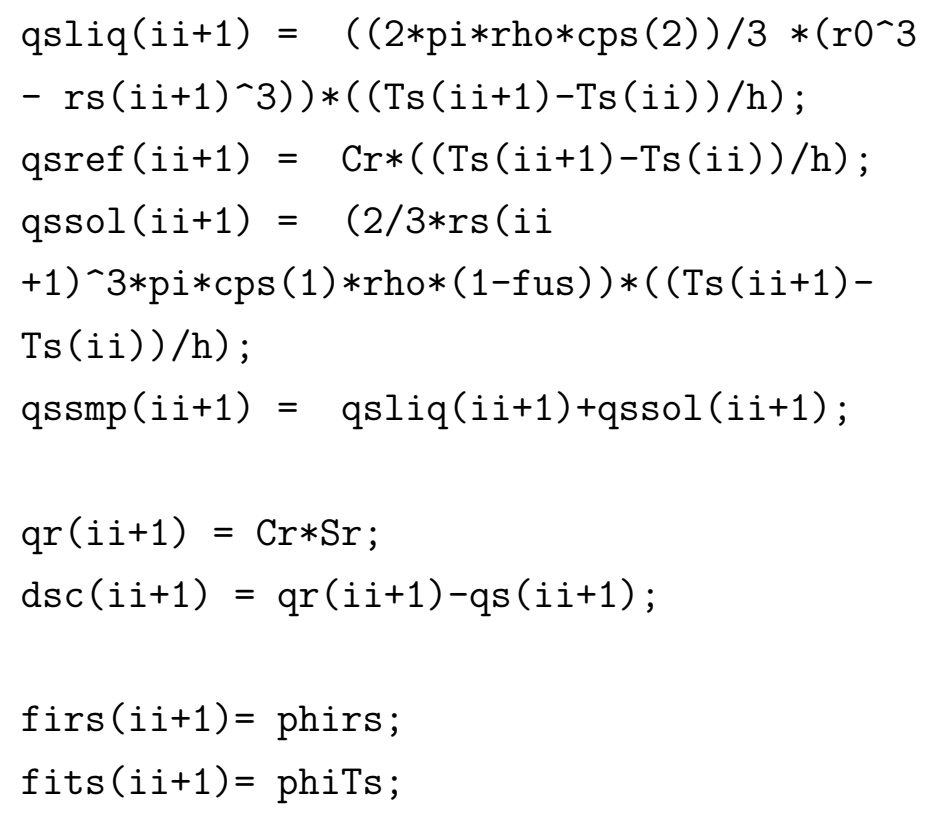




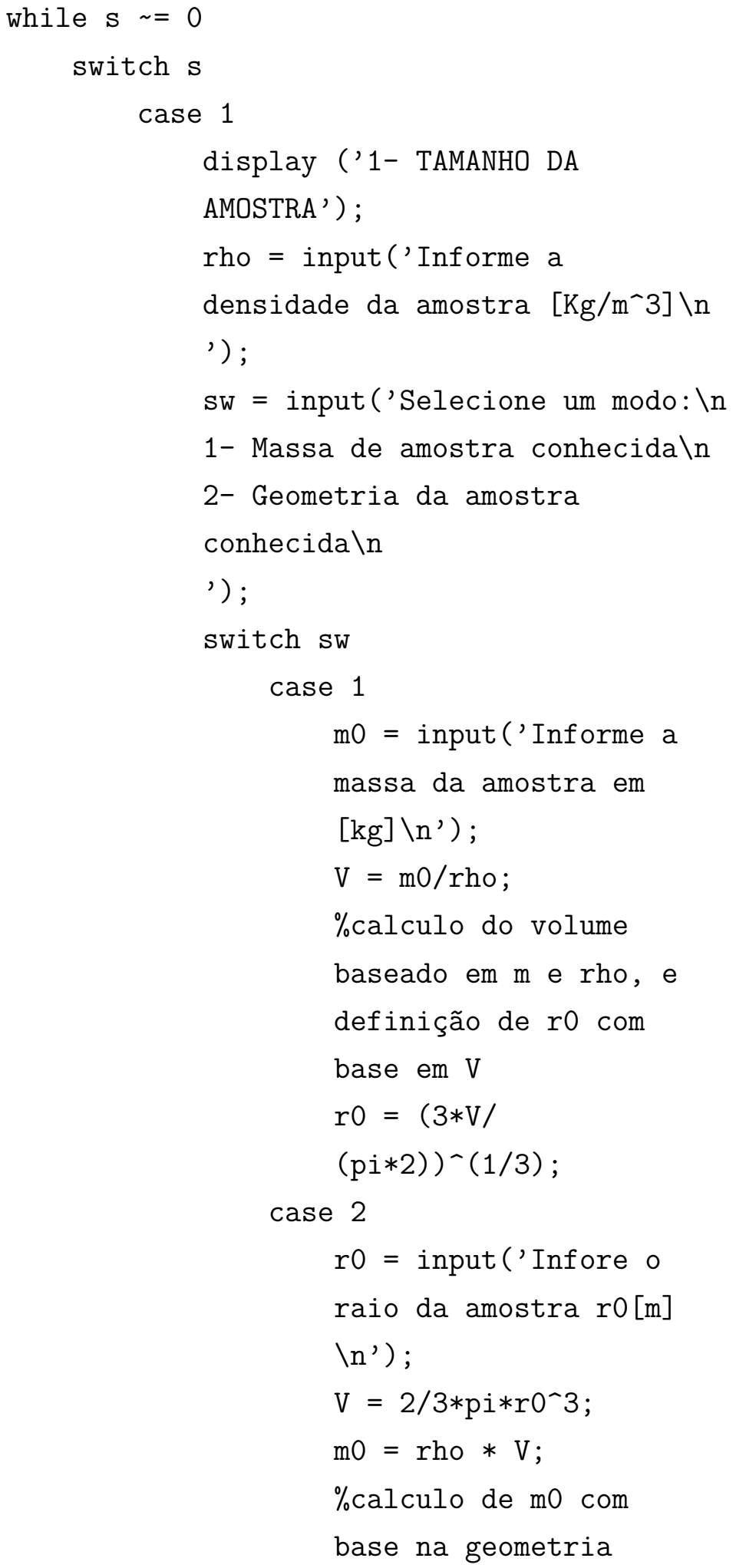


fornecida e rho

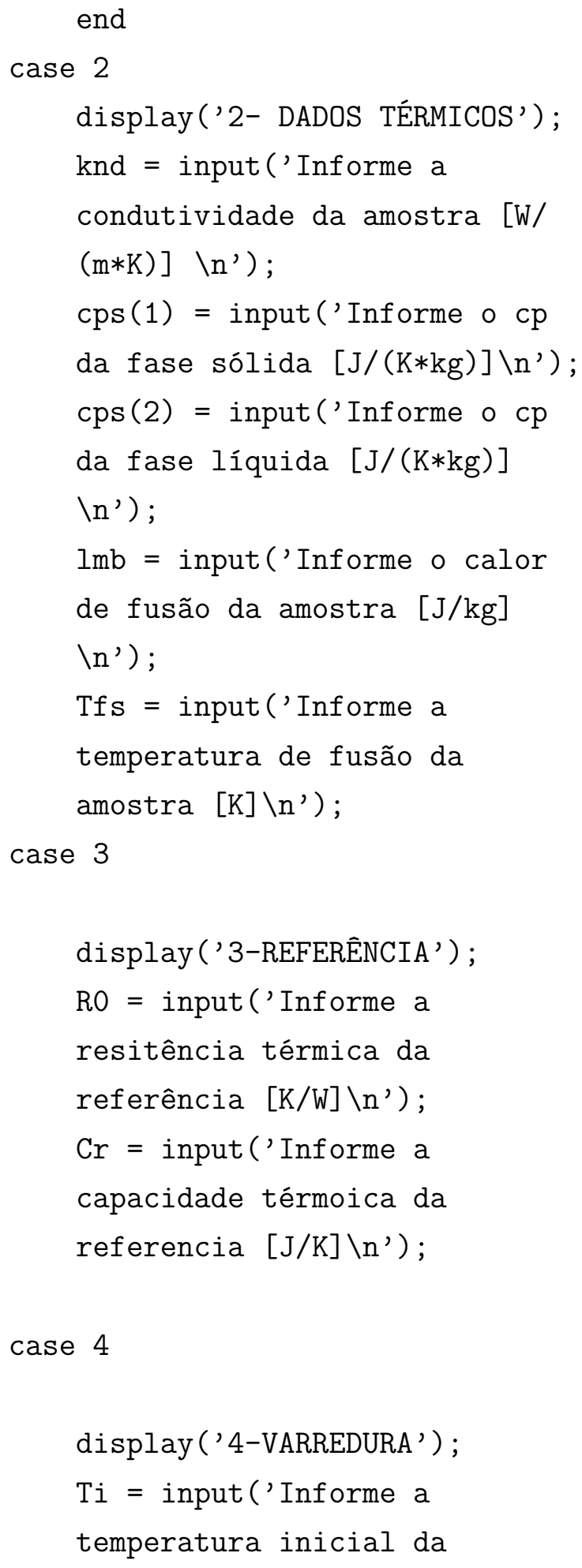




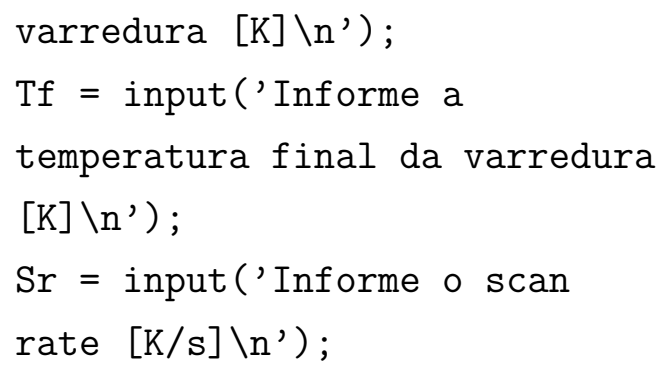

case 5

$$
\begin{aligned}
& \text { display('5- MÉTODO NUMÉRICO'); } \\
& \mathrm{h}=\operatorname{input}(\text { 'Informe o tamanho } \\
& \text { de passo do método numerico } \\
& \backslash \mathrm{n} \text { '); } \\
& \mathrm{f}=\text { input ('Informe a } \\
& \text { porcentagem da faisca } \backslash \mathrm{n} \text { '); }
\end{aligned}
$$

end

$\mathrm{s}=$ input ('Selecione o que deseja

alterar:

\1-TAMANHO DA AMOSTRA \n

2- DADOS TERMICOS $\backslash \mathrm{n}$

3-REFERENCIA \n

4-VARREDURA \n

5-METODO NUMERICO\n

0-FINALIZAR ALTERAÇÔES \n');

end

end

end 



\section{ANEXO B - Exemplo de dados de entrada e saída do programa de simulação para geometria esférica}

Seguem os prompts de comando e dados fornecidos para o programa de simulação.

***BEM VINDO AO SIMULADOR DE DSC - MODELO HTD-esferico***

1- TAMANHO DA AMOSTRA

Informe a densidade da amostra $\left[\mathrm{Kg} / \mathrm{m}^{-3}\right]$

1000

Selecione um modo:

1- Massa de amostra conhecida

2- Geometria da amostra conhecida

1

Informe a massa da amostra em [kg]

$1 e-5$

2- DADOS TÉRMICOS

Informe a condutividade da amostra [W/ $(\mathrm{m} * \mathrm{~K})]$

.6065

Informe o cp da fase sólida [J/(K*kg)]

2054

Informe o cp da fase líquida [J/(K*kg)]

4188

Informe o calor de fusão da amostra [J/kg]

333550

Informe a temperatura de fusão da amostra [K]

273

3-REFERÊNCIA 
ANEXO B. Exemplo de dados de entrada e saída do programa de simulação para geometria 138

esférica

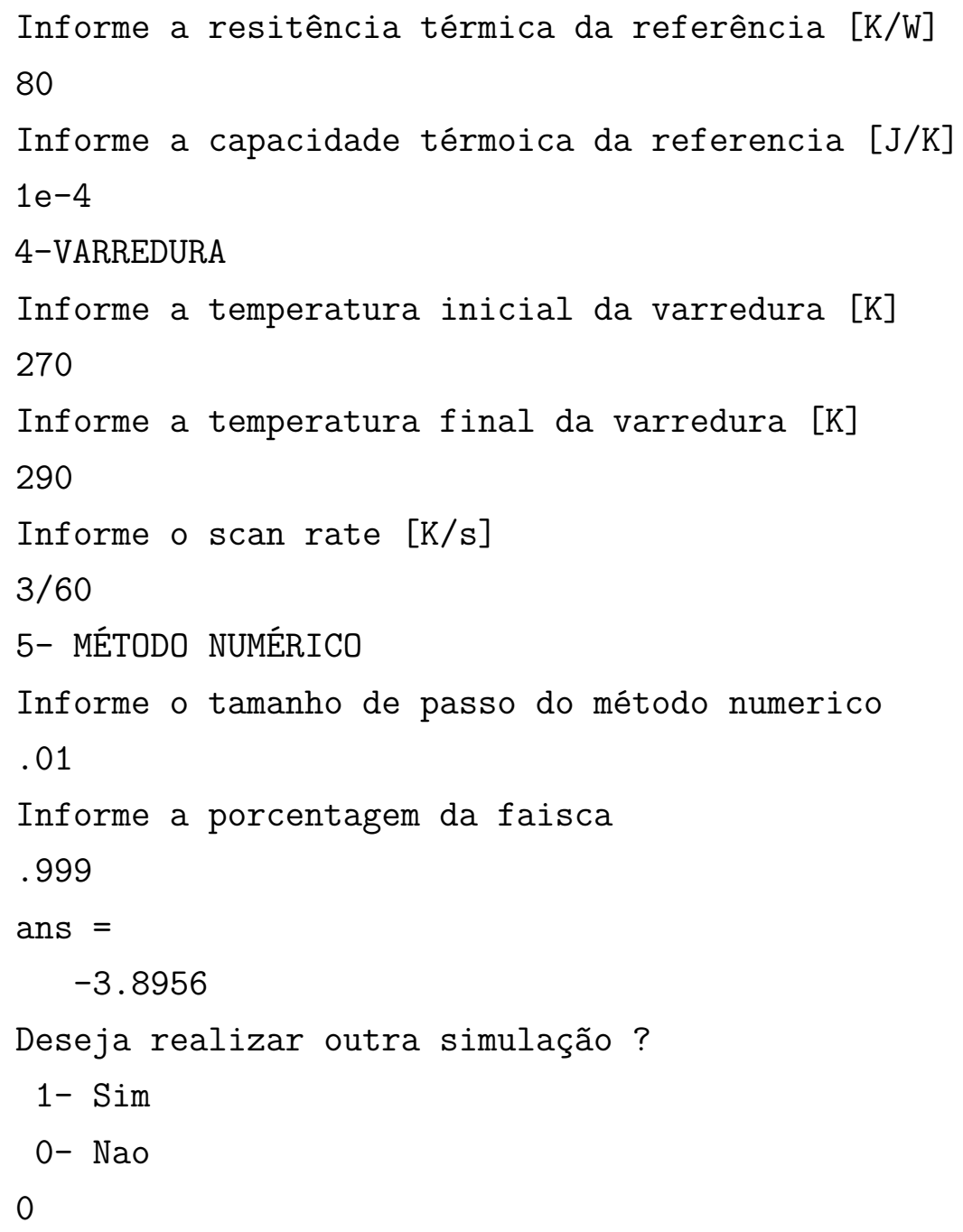

Essa execução da rotina de cálculos resultou no seguinte gráfico , não editado 


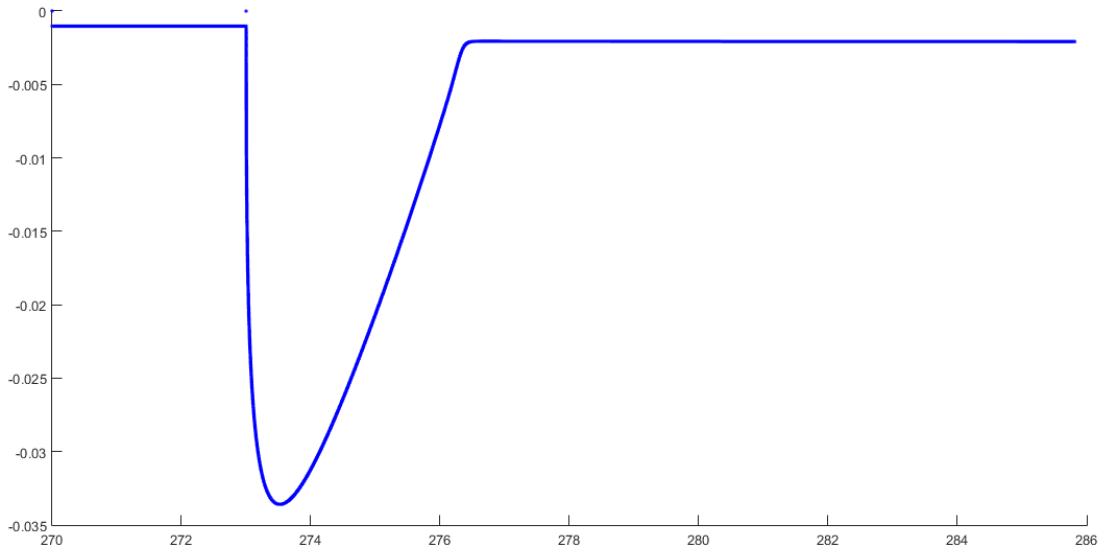

Figura 43 - Gráfico gerado como saída do programa de simulação do modelo HTD esférico. Eixos sem legenda, pois este é o resultado gerado. A Abscissa esta em $T_{s}[K]$ e a ordenada em $q[W]$

o valor indicado por ans é o valor daárea sob o gráfico em $J$. 



\section{ANEXO C - Tabelas completas de ajuste de dados}

Esse Anexo apresenta as janelas de comando do MATLAB® com os dados consolidados do ajuste de curvas com $\mathrm{R}$ variando de 60 a $220 \frac{K}{W}$ em intervalos de 40 $\frac{K}{W}$, exceto o miristto de etila onde essa faixa varia entre 140 e $300 \frac{K}{W}$ com o mesmo incremento . A última linha iniciada por 0 apresenta os dados experimentais. A ordem dos dados apresentados é tal que o primeiro agrupamento se refere a taxa de $0,5 \frac{K}{s}$ (identificado como $\mathrm{xYtDHC}(:,:, 1)$, sendo $\mathrm{x}$ a letra inicial do composto, Y refere-se ao modelo utilizado. G-gray,C- HTD cilindro e E - HTD esfera) e os agrupamentos seguintes nas taxas restantes com acréscimo de $0,5 \frac{K}{a}$

Alguns valores de largura de pico apresentam valor 0 , isso ocorre pois a rotina de cálculo desenvolvida para obter este valor falhou nestes casos, devido ao comportamento das curvas. Esta rotina procura regiões de sem variações grandes antes e após o pico, observa-se principalmente nas curvas experimentais uma grande variação em torno de uma média, ou as vezes desvios do comportamento ideal , que inviabilzam a aplicação da rotina desenvolvida

A sequência de dados apresentados é: valor da resitencia $\mathrm{R}$, em $\frac{K}{W}$; área da curva gerada A, em $J$; o valor mínimo atingido pelo pico min, em $W$ e a largura do pico gerado cmp, definido nesse caso por sua duração em $s$.

De Figura 44 a Figura 46 são apresentados os dados referente ao laurato de etila, de Figura 47 a miristato de a Figura 49 os dados referentes ao miristato de etila, de Figura 50 a Figura 52 os referentes ao oleato de etila e de Figura 53 a Figura 55 os dados referentes ao palmitato de etila. 


\section{MATLAB Command Window}

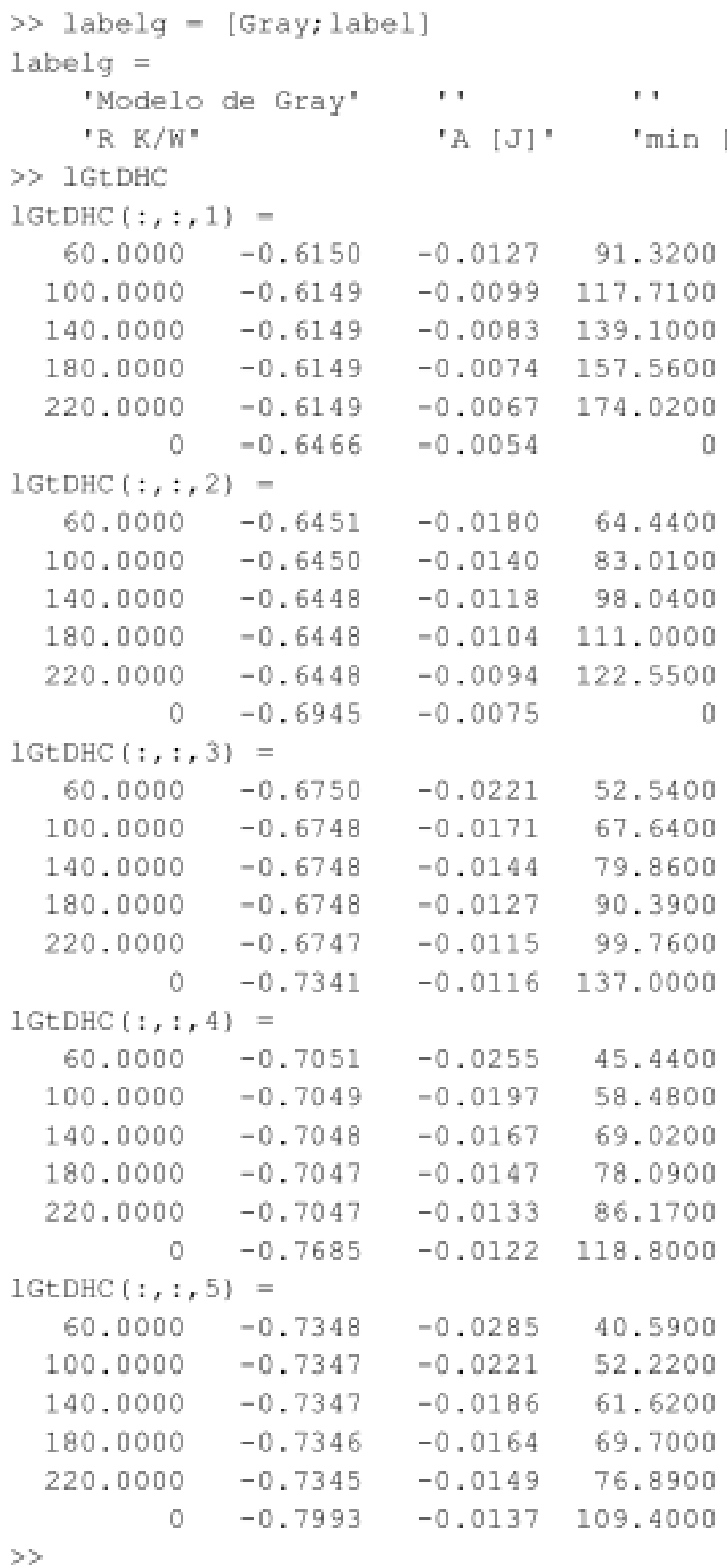

Figura 44 - Tabelas de ajuste de dados para o composto laurato de etila. Modelo de Gray 


\section{MATLAB Command Window}

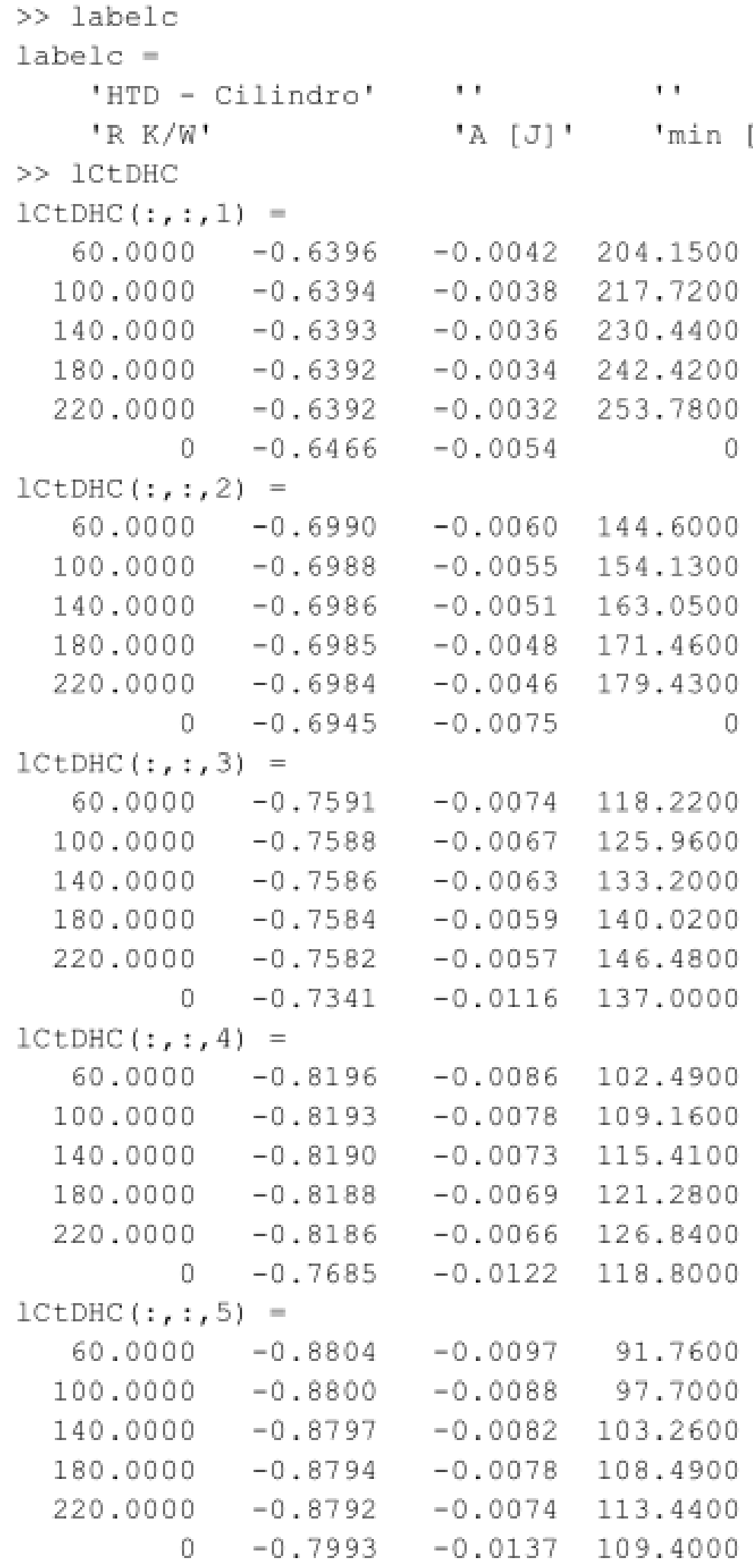

Figura 45 - Tabelas de ajuste de dados para o composto laurato de etila. Modelo HTD cilindro 
MATLAB Command Window

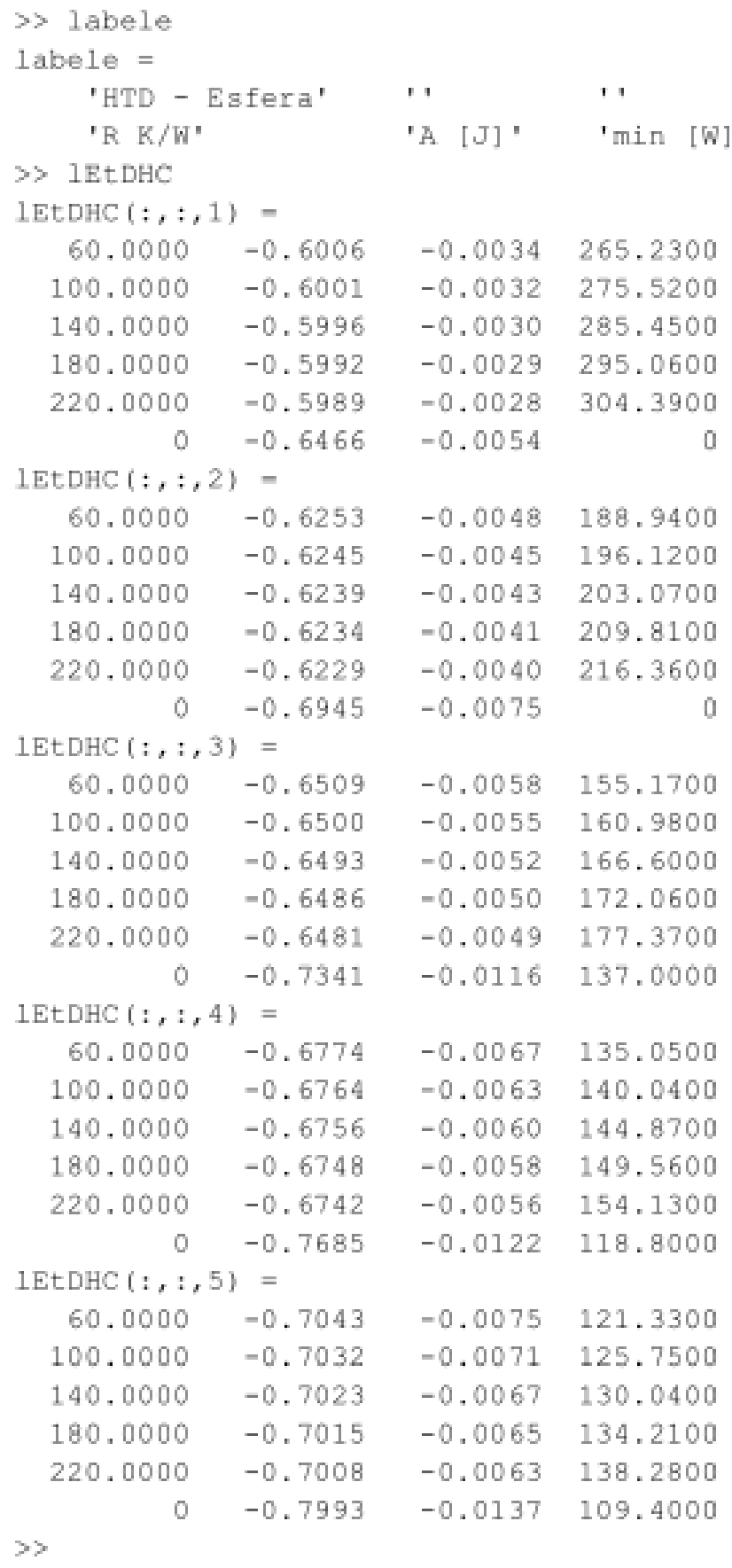

Figura 46 - Tabelas de ajuste de dados para o composto laurato de etila. Modelo HTD esfera 


\section{MATLAB Command Window}

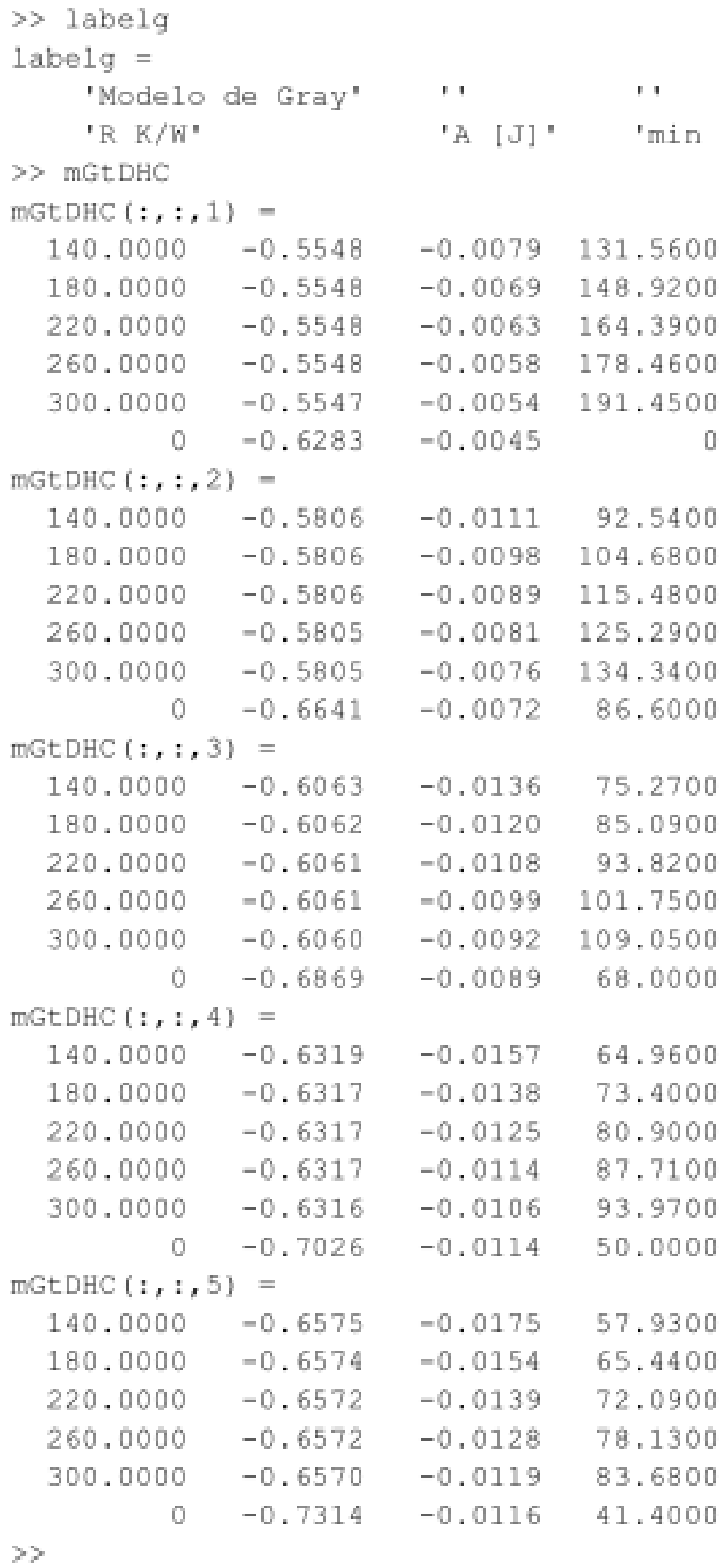

Figura 47 - Tabelas de ajuste de dados para o composto miristato de etila. Modelo de Gray 


\section{MATLAB Command Window}

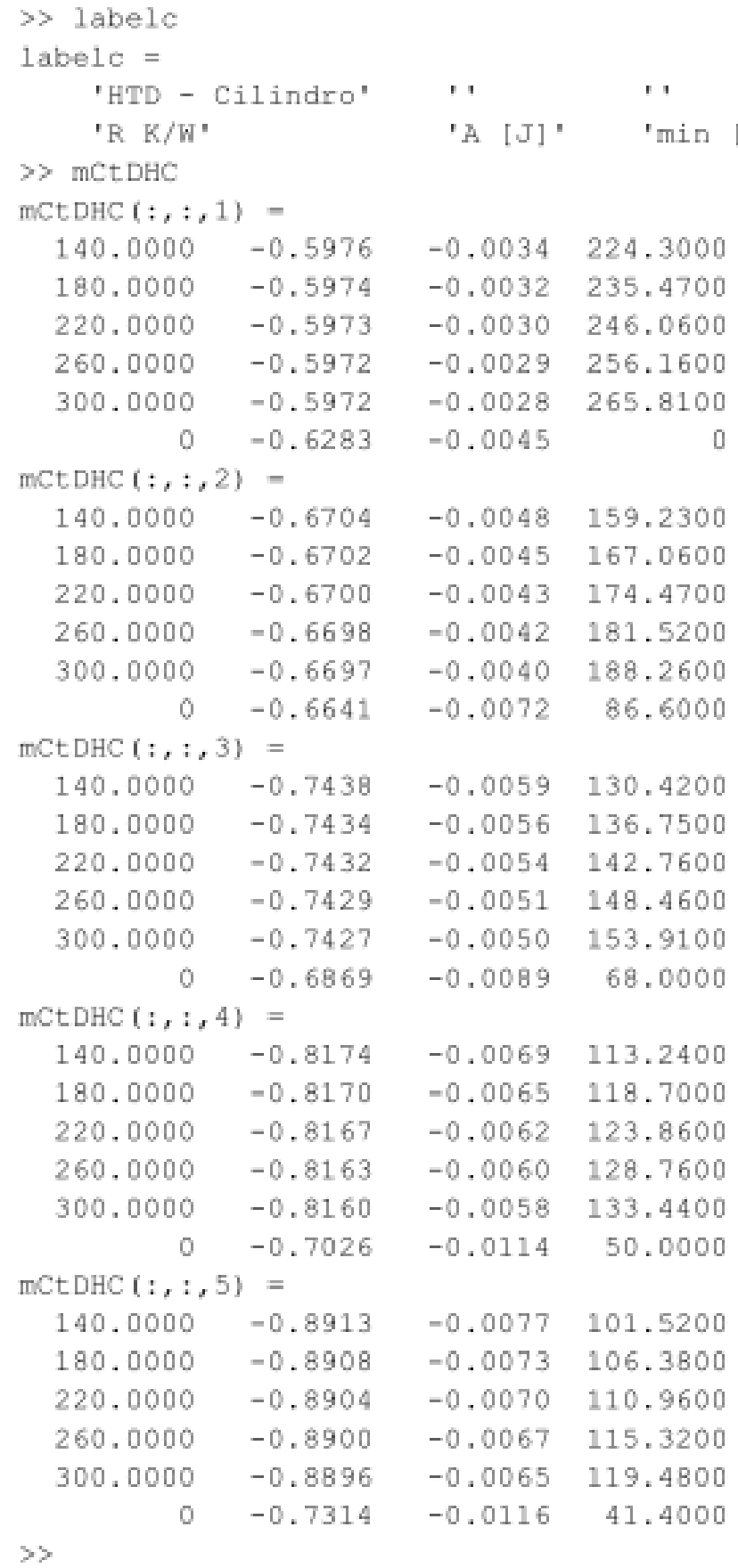

Figura 48 - Tabelas de ajuste de dados para o composto miristato de etila. Modelo HTD cilindro 


\section{MATLAB Command Window}

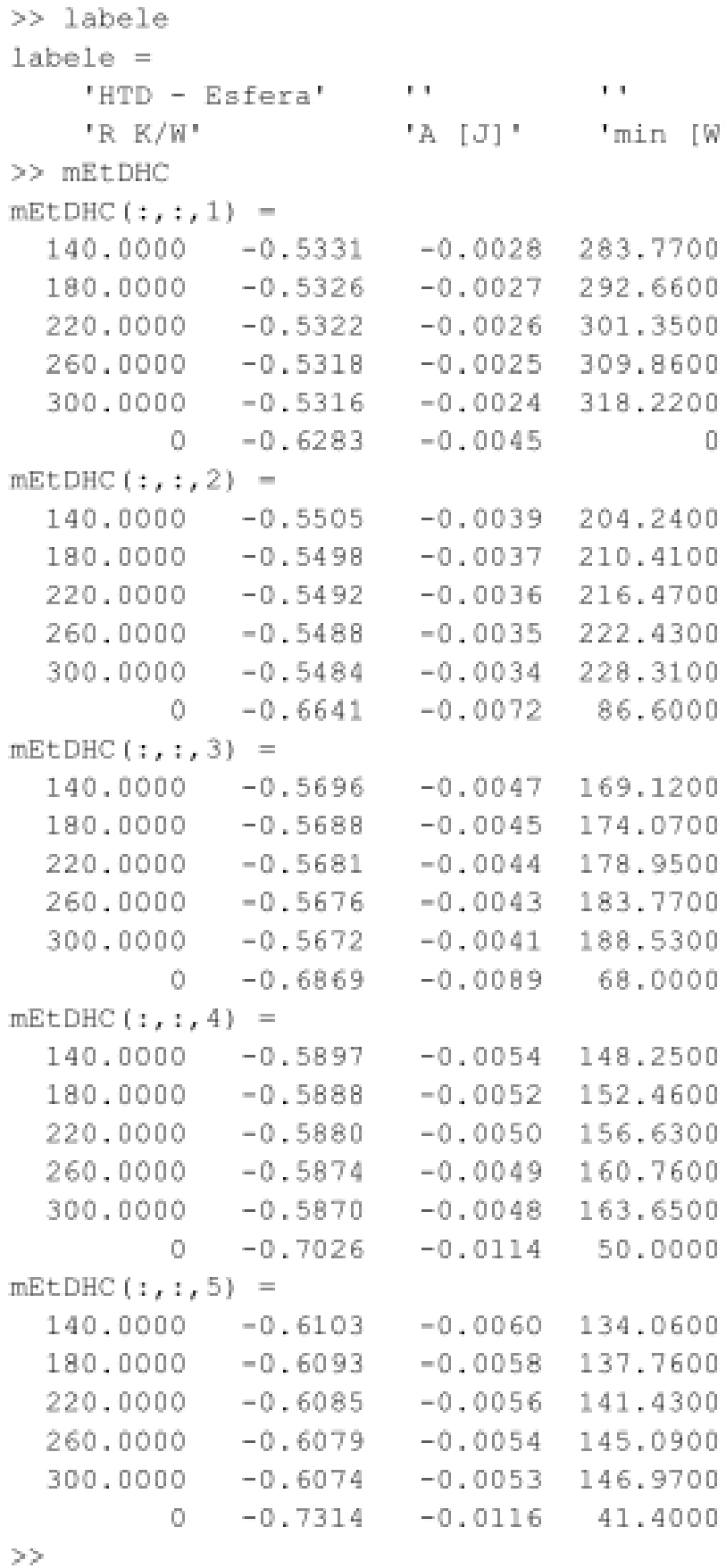

Figura 49 - Tabelas de ajuste de dados para o composto miristato de etila. Modelo HTD esfera 


\section{MATLAB Command Window}

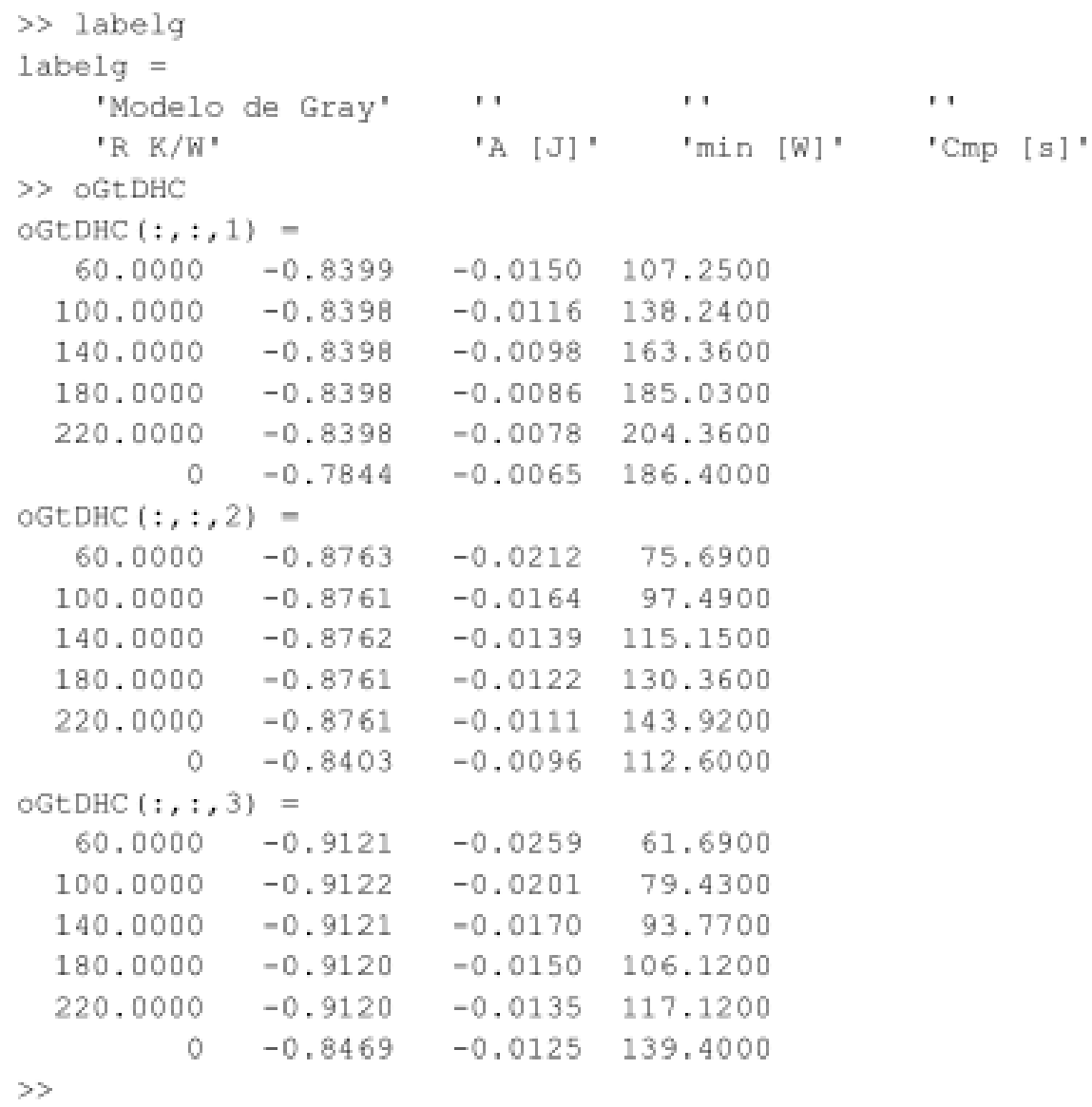

Figura 50 - Tabelas de ajuste de dados para o composto oleato de etila. Modelo de Gray 
MATLAB Command Window

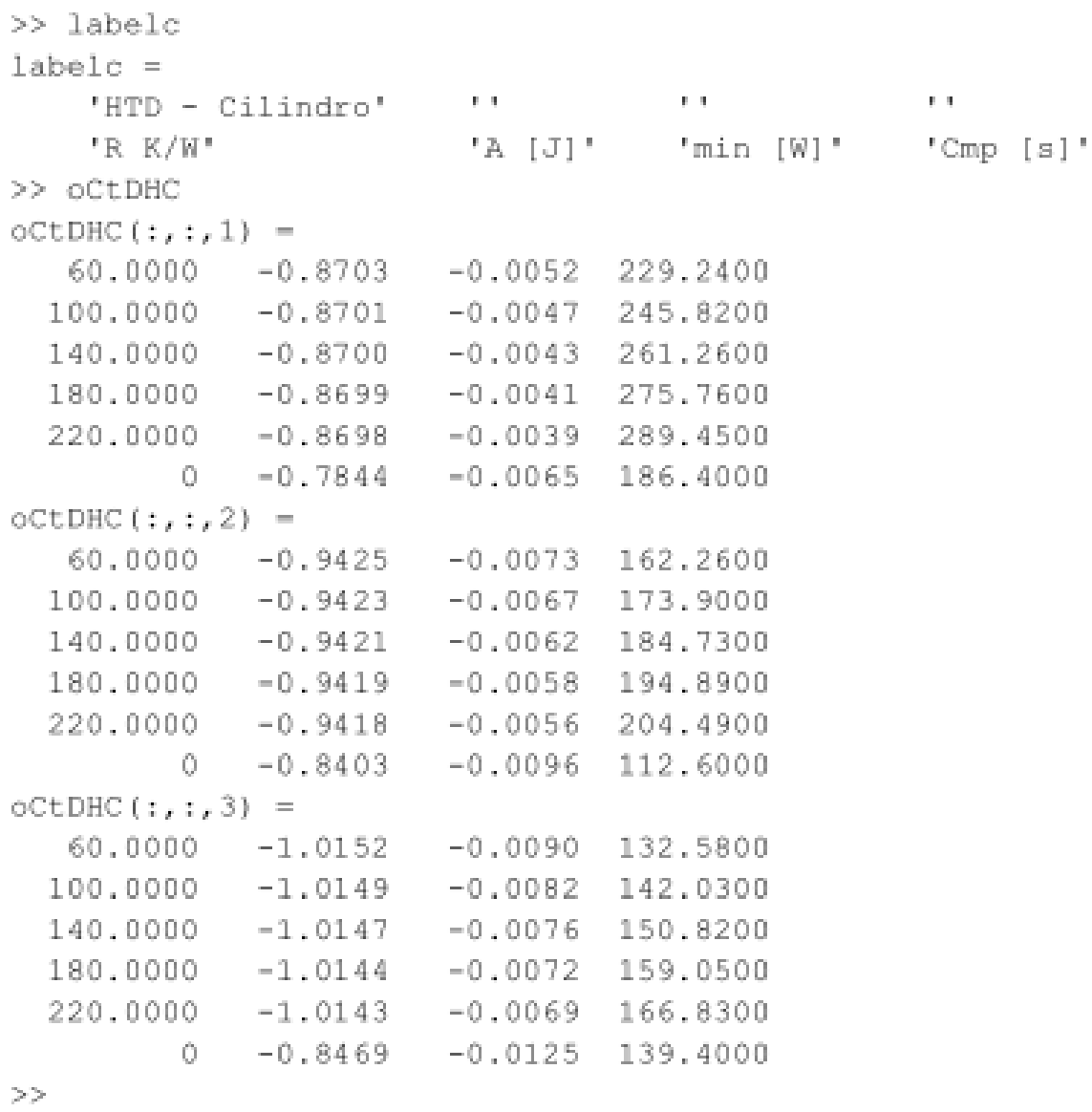

Figura 51 - Tabelas de ajuste de dados para o composto oleato de etila. Modelo HTD cilindro 


\section{MATLAB Command Window}

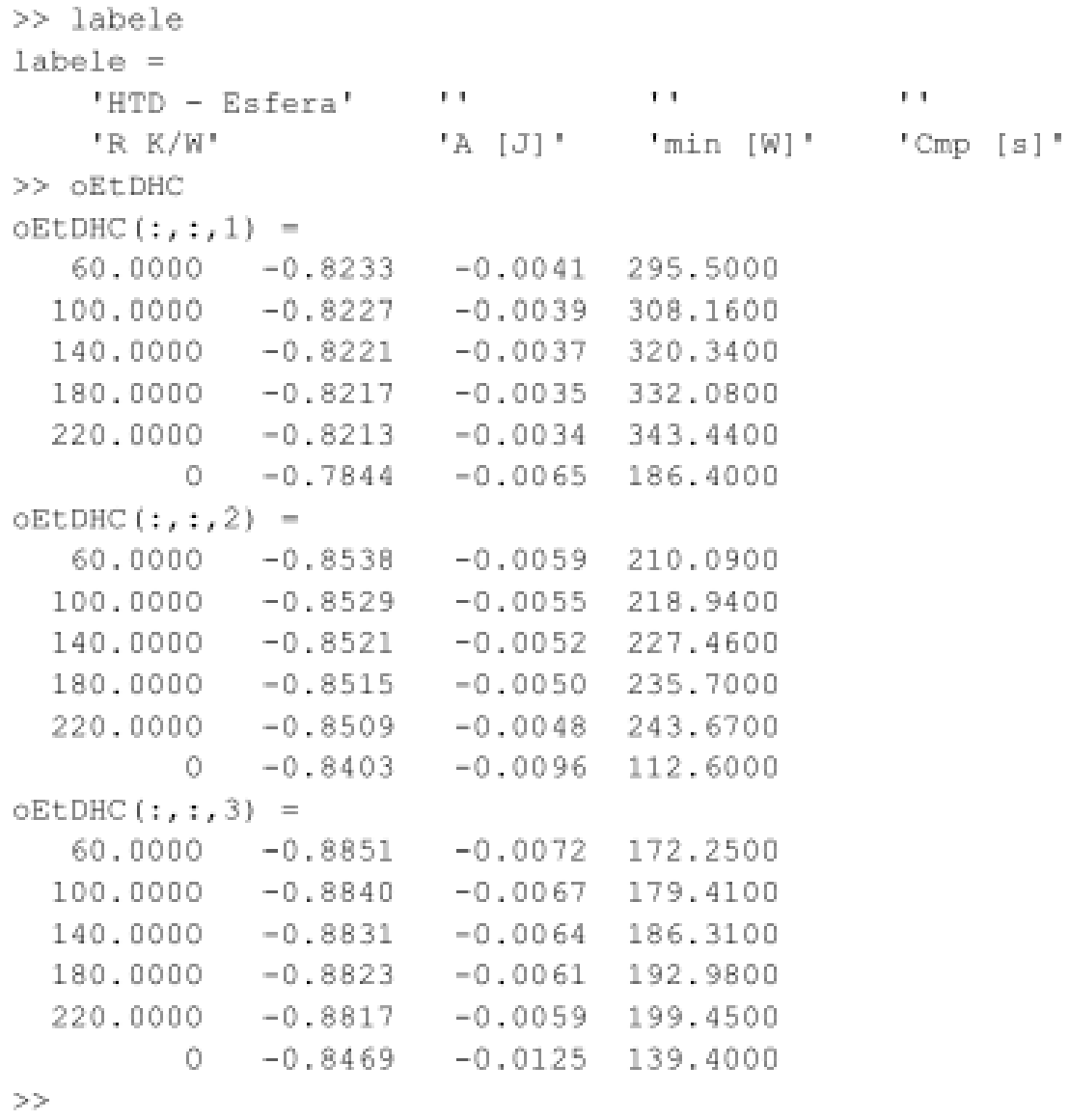

Figura 52 - Tabelas de ajuste de dados para o composto oleato de etila. Modelo HTD esfera 
MATLAB Command Window

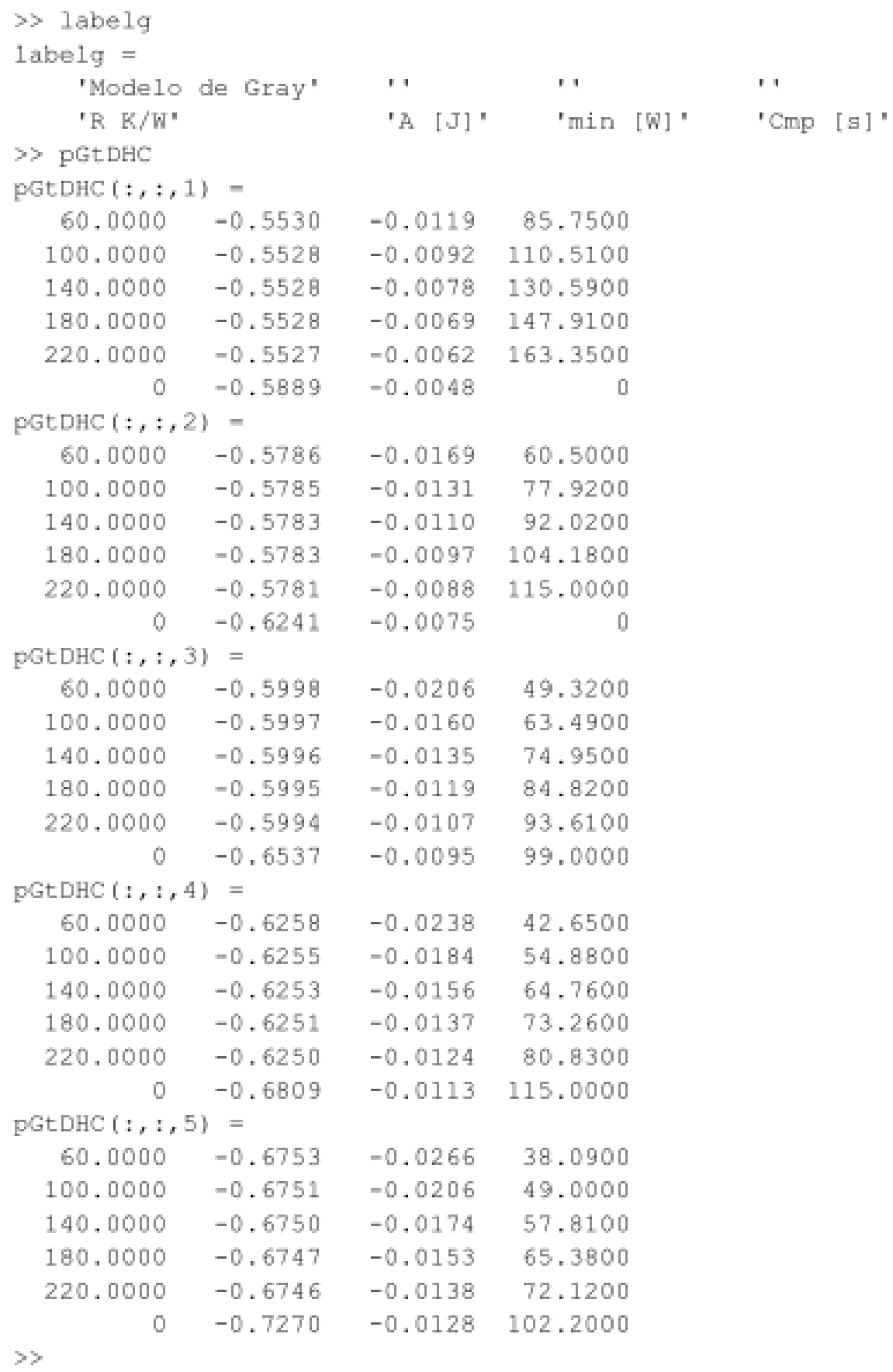

Figura 53 - Tabelas de ajuste de dados para o composto palmitato de etila. Modelo de Gray 


\section{MATLAB Command Window}

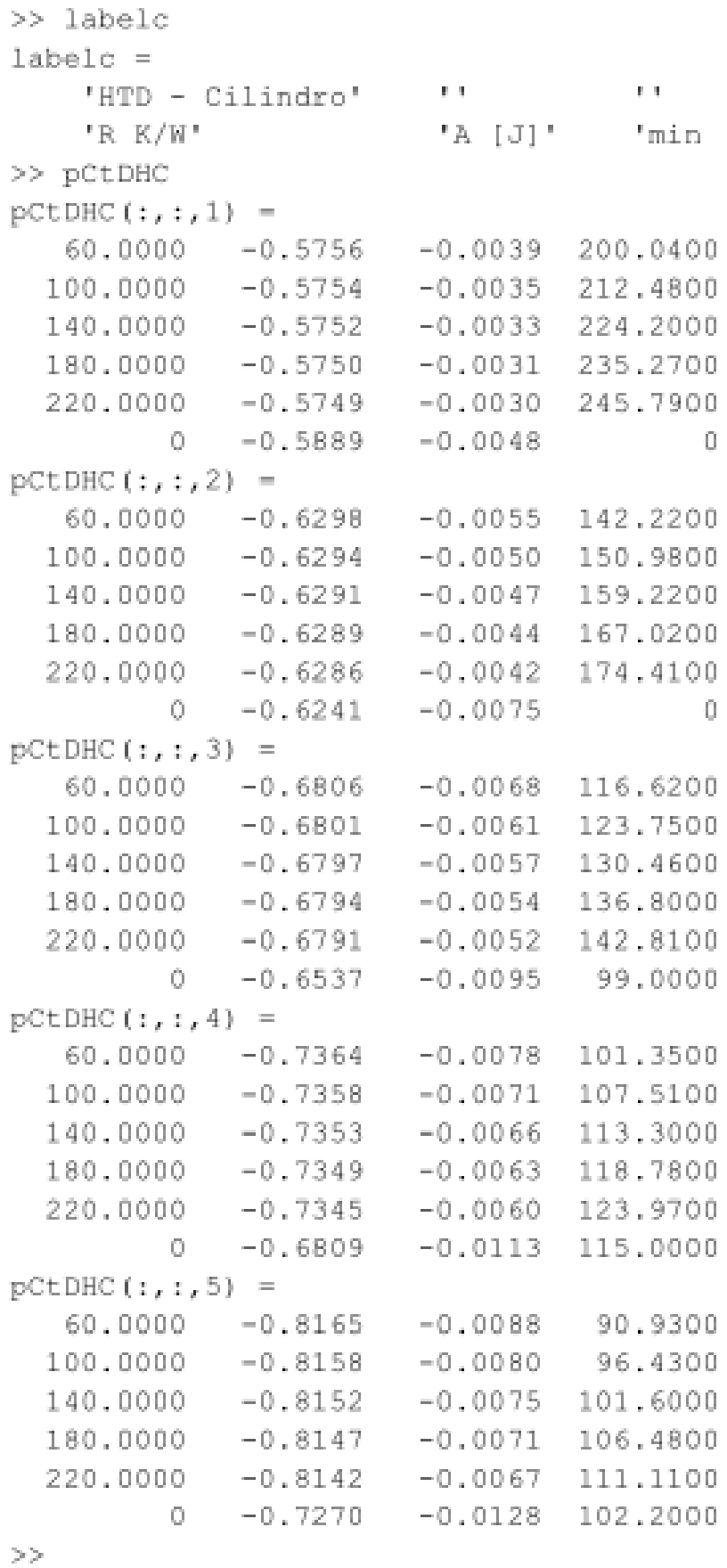

Figura 54 - Tabelas de ajuste de dados para o composto palmitato de etila. Modelo HTD cilindro 


\section{MATLAB Command Window}

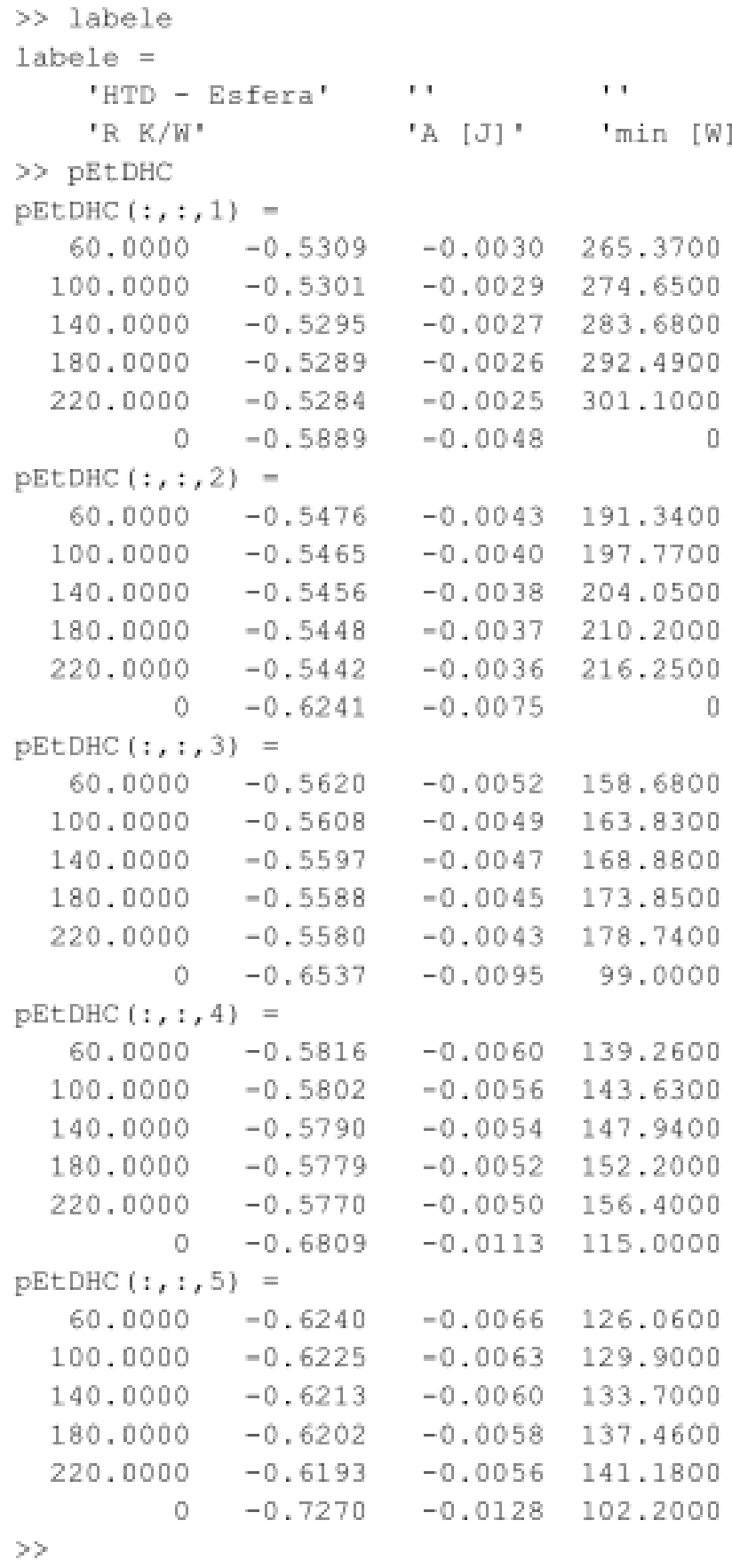

Figura 55 - Tabelas de ajuste de dados para o composto palmitato de etila. Modelo HTD esfera 